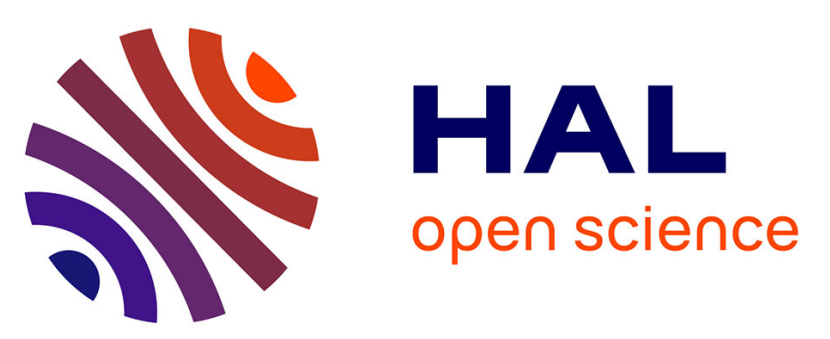

\title{
True price as condition of sustainability: the global coffee crisis (1999-2003) and the Brazilian Amazon as case studies
}

\author{
Xavier Vincent Andrillon
}

\section{- To cite this version:}

Xavier Vincent Andrillon. True price as condition of sustainability: the global coffee crisis (1999-2003) and the Brazilian Amazon as case studies. Economics and Finance. UNIVERSIDADE ESTADUAL DE CAMPINAS (Brésil), 2020. English. NNT : . tel-02910183v2

\section{HAL Id: tel-02910183 \\ https://theses.hal.science/tel-02910183v2}

Submitted on 6 Aug 2020

HAL is a multi-disciplinary open access archive for the deposit and dissemination of scientific research documents, whether they are published or not. The documents may come from teaching and research institutions in France or abroad, or from public or private research centers.
L'archive ouverte pluridisciplinaire HAL, est destinée au dépôt et à la diffusion de documents scientifiques de niveau recherche, publiés ou non, émanant des établissements d'enseignement et de recherche français ou étrangers, des laboratoires publics ou privés. 


\section{UNIVERSIDADE ESTADUAL DE CAMPINAS INSTITUTO DE ECONOMIA}

XAVIER VINCENT ANDRILLON

TRUE PRICE AS CONDITION OF SUSTAINABILITY: THE GLOBAL COFFEE CRISIS (1999-2003) AND THE BRAZILIAN AMAZON AS CASE STUDIES

PREÇO VERDADEIRO COMO CONDIÇÃO PARA A SUSTENTABILIDADE: A CRISE CAFEEIRA GLOBAL (19992003) E A AMAZÔNIA BRASILEIRA COMO ESTUDOS DE CASO 


\section{UNIVERSIDADE ESTADUAL DE CAMPINAS \\ INSTITUTO DE ECONOMIA}

\section{TRUE PRICE AS CONDITION OF SUSTAINABILITY: THE GLOBAL COFFEE CRISIS (1999-2003) AND THE BRAZILIAN AMAZON AS CASE STUDIES}

\section{PREÇO VERDADEIRO COMO CONDIÇÃO PARA A SUSTENTABILIDADE: A CRISE CAFEEIRA GLOBAL (1999- 2003) E A AMAZÔNIA BRASILEIRA COMO ESTUDOS DE CASO}

Prof. Dr. Maurício Aguiar Serra - orientador

Tese de Doutorado apresentada ao Programa de Pós-Graduação em Desenvolvimento Econômico do Instituto de Economia da Universidade Estadual de Campinas para obtenção do título de Doutor em Desenvolvimento Econômico na área de concentração Economia Agrícola e do Meio Ambiente.

ESTE EXEMPLAR CORRESPONDE À VERSÃO FINAL DA TESE DEFENDIDA PELO ALUNO XAVIER VINCENT ANDRILLON E ORIENTADA PELO PROF. DR. MAURÍCIO AGUIAR SERRA. 
Ficha catalográfica

Universidade Estadual de Campinas

Biblioteca do Instituto de Economia

Luana Araujo de Lima - CRB 8/9706

Andrillon, Xavier Vincent, 1982-

An28t True price as condition of sustainability : the global coffee crisis (1999-2003) and the Brazilian Amazon as case studies / Xavier Vincent Andrillon. - Campinas, SP : [s.n.], 2020.

Orientador: Maurício Aguiar Serra.

Tese (doutorado) - Universidade Estadual de Campinas, Instituto de Economia.

1. Amazônia Legal. 2. Contabilidade. 3. Café - Aspectos econômicos 1999-2003. 4. Preço verdadeiro. 5. Sustentabilidade. I. Serra, Maurício Aguiar, 1963-. II. Universidade Estadual de Campinas. Instituto de Economia. III. Título.

Informações para Biblioteca Digital

Título em outro idioma: Preço verdadeiro como condição para a sustentabilidade : a crise cafeeira global (1999-2003) e a Amazônia brasileira como estudos de caso

Palavras-chave em inglês:

Legal Amazon

Accounting

Coffee - Economic aspects - 1999-2003

True price

Sustainability

Área de concentração: Economia Agrícola e do Meio Ambiente

Titulação: Doutor em Desenvolvimento Econômico

Banca examinadora:

Maurício Aguiar Serra [Orientador]

Danilo Araújo Fernandes

Miguel Juan Bacic

Rodrigo Lanna Franco da Silveira

Vitor Bukvar Fernandes

Data de defesa: 17-06-2020

Programa de Pós-Graduação: Desenvolvimento Econômico

Identificação e informações acadêmicas do(a) aluno(a)

- ORCID do autor: https://orcid.org/0000-0002-8945-5321

- Currículo Lattes do autor: http://lattes.cnpq.br/0492183690377786 


\section{UNIVERSIDADE ESTADUAL DE CAMPINAS \\ INSTITUTO DE ECONOMIA}

\section{XAVIER VINCENT ANDRILLON}

TRUE PRICE AS CONDITION OF SUSTAINABILITY: THE GLOBAL COFFEE CRISIS (1999-2003) AND THE BRAZILIAN AMAZON AS CASE STUDIES

\section{PREÇO VERDADEIRO COMO CONDIÇÃO PARA A SUSTENTABILIDADE: A CRISE CAFEEIRA GLOBAL (1999- 2003) E A AMAZÔNIA BRASILEIRA COMO ESTUDOS DE CASO}

Prof. Dr. Maurício Aguiar Serra - orientador

Defendida em 17/06/2020

COMISSÃO JULGADORA

Prof. Dr. Maurício Aguiar Serra - PRESIDENTE

Universidade Estadual de Campinas (UNICAMP)

Prof. Dr. Danilo Araújo Fernandes

Universidade Federal do Paraná (UFPR)

Prof. Dr. Miguel Juan Bacic

Universidade Estadual de Campinas (UNICAMP)

Prof. Dr. Rodrigo Lanna Franco da Silveira

Universidade Estadual de Campinas (UNICAMP)

Dr. Vitor Bukvar Fernandes

Centro de Tecnologia e Informação Renato Archer

A Ata de Defesa, com as respectivas assinaturas

dos membros encontra-se no SIGA/Fluxo de

Dissertação e Tese e na Secretaria do Programa da 


\section{Acknowledgements}

I express gratitude to my former and present research advisors, Prof. Dr. Bastiaan Philip Reydon and Prof. Dr. Maurício Aguiar Serra, for their openness in exploring this topic, many stimuli and steady support. I also thank Dr. Christopher Houghton Budd for sharing his genuine knowledge of Rudolf Steiner's economic works.

I am also grateful to the members of the thesis committee: Prof. Dr. Danilo Araújo Fernandes, Prof. Dr. Miguel Juan Bacic, Prof. Dr. Rodrigo Lanna Franco da Silva and Dr. Vitor Bukvar Fernandes. I very much appreciate their availability for reading this thesis and sharing their insights and comments, which allowed me to widen my views and enrich this study.

I was lucky enough to meet with a variety of rural producers in France, Indonesia, Paraguay, Spain and, mostly, Brazil. I thank them for sharing their experiences, the why and how of their practices, and their words of wisdom. They made me realise how the question of true and untrue prices is a real and vital aspect of their and everyone's livelihood.

Last but not least, I express my deepest thanks to my better half Veridiana and children Élise and Philippe for supporting me. They motivated me throughout this research, even if the immediate result for them was a less present partner and father. 
BUYING AND SELLING

And a merchant said, Speak to us of Buying and Selling.

And he answered and said:

To you the earth yields her fruit, and you shall not want if you but know how to fill your hands.

It is in exchanging the gifts of the earth that you shall find abundance and be satisfied.

Yet unless the exchange be in love and kindly justice, it will but lead some to greed and others to hunger.

When in the market-place you toilers of the sea and fields and vineyards meet the weavers and the potters and the gatherers of spices-

Invoke then the master spirit of the earth, to come into your midst and sanctify the scales and the reckoning that weighs value against value.

And suffer not the barren-handed to take part in your transactions, who would sell their words for your labour.

To such men, you should say:

'Come with us to the field, or go with our brothers to the sea and cast your net;

'For the land and the sea shall be bountiful to you even as to us.'

And if there come the singers and the dancers and the flute-players - buy of their gifts also.

For they too are gatherers of fruit and frankincense, and that which they bring, though fashioned of dreams, is raiment and food for your soul.

And before you leave the market-place, see that no one has gone his way with empty hands.

For the master spirit of the earth shall not sleep peacefully upon the wind till the needs of the least of you are satisfied.

Khalil Gibran, The Prophet. (GIBRAN, 1997, p. 22) 


\section{Resumo}

O presente estudo visa explorar o papel fundamental que a combinação da lógica contábil e do conceito de "preço verdadeiro" - proposto pela primeira vez por Rudolf Steiner (1861-1925) - pode desempenhar para definir, medir e avançar rumo à sustentabilidade. Visto que as abordagens econômicas atuais se mostraram ineficientes para tais propósitos, essa tese fornece um modelo enraizado na teoria contábil que propõe que preços não verdadeiros contribuem para a insustentabilidade, e explica como. Para demonstrar nossa hipótese, foram utilizados dois estudos de caso: agricultores enfrentando preços não verdadeiros durante a crise cafeeira global (1999-2003) e atuando em frentes de desmatamento na Amazônia brasileira. Os resultados obtidos nesse estudo nos levam a afirmar que preços verdadeiros são necessários para o desenvolvimento sustentável - embora provavelmente não seja a única condição - e a fazer recomendações para produtores, consumidores, investidores e formuladores de políticas públicas, no intuito de promover preços verdadeiros e assim fomentar a sustentabilidade.

Palavras-chave: Amazônia brasileira, Contabilidade, Crise cafeeira, Rudolf Steiner, Preço verdadeiro, Sustentabilidade. 


\section{Abstract}

Current approaches to pricing have proved inexplicable and unable to deliver sustainable development. This study explores how the combination of accounting logic and the concept of 'true price' - first proposed by Rudolf Steiner (1861-1925) - can provide a novel, dynamic and comprehensive causal model to understand how prices can contribute to unsustainability. Case studies are used to verify if the purported model is fit for explaining real-world issues, here, farmers facing untrue prices during the global coffee crisis (1999-2003) and on deforestation fronts in the Brazilian Amazon. The analysis of these case studies leads us to framing true prices as a necessary condition of sustainability, although it is probably not the only one. Combining accounting as a gauging tool and true price as a reference point lends both concrete meaning and technical grounding to the notion of sustainability, and guidelines to measure progress toward it. We make recommendations on how producers, consumers, investors, and public policymakers could further true prices and thus support sustainability.

Keywords: Accounting, Brazilian Amazon, Coffee crisis, Rudolf Steiner, Sustainability, True price. 


\section{List of Figures}

Figure 1: Prices are either below or above a 'true price' threshold........39

Figure 2: Interventions of two types can result in price falsification .....40

Figure 3: Representation of a set of accounts.....................................43

Figure 4: Representation of the mirrored relationships between the accounts of a producer and his or her economic partners ........49

Figure 5: Representation of the four compensating strategies on a set of accounts

Figure 6: Representation of the causal model and its four parts .53

Figure 7: Nominal prices received by coffee growers before, during, and after the crisis in major producing countries (in cents USD per pound)

Figure 8: Average nominal prices received by coffee growers before, during, and after the coffee crisis, combining prices in major producing countries (in cents USD per pound)

Figure 9: Average nominal prices to coffee growers; total area harvested, production and yields for major producing countries ................74

Figure 10: Long-term world price index for coffee and cereals dating 18502015, measured relative to real prices in $1900(1900=100) \ldots \ldots .89$

Figure 11: Map of the distribution of deforestation in 2016-17 across municipalities $\left(\mathrm{km}^{2}\right)$

Figure 11: Map of the distribution of farms across municipalities in the 2017 agricultural census (number of farm units). .98

Figure 13: Farms with no access to extension services by group of farm size $(\%)$ 104

Figure 14: Access to credit for different funding purposes by group of farm size (\%) 105

Figure 15: Forms of access to land by group of farm size (\%) ............106

Figure 16: Farmers receiving non-agricultural income by group of farm size (\%). 108

Figure 17: Farms making different types of expenses by group of farm size (\%). 110

Figure 18: Farms hiring workers with no kinship tie by group of farm size (\%) 111

Figure 19: Farms not controlling diseases and/or parasites and not using supplements by group of farm size (\%)

Figure 20: Farms producing charcoal or timber by group of farm size (\%) 
Figure 21: Farms with forests allocated as permanently protected areas and legal reserves, and with pastures in good conditions by group of farm size (\%) 115

Figure 22: Farms adopting good environmental practices by group of farm size (\%) 116

Figure 23: Average prices of different types of land in the Brazilian Amazon in 2015 (BRL/ha). 118

Figure 24: Average annual gross income (USD) and proportion of land use (\%) for major commodities in the Brazilian Amazon 120

Figure 25: Representation of indicators of progress towards true prices 126 


\section{List of Tables}

Table 1: Indicators of sustainability and unsustainability ...................41

Table 2: The General Ledger containing five types of Accounts...........43

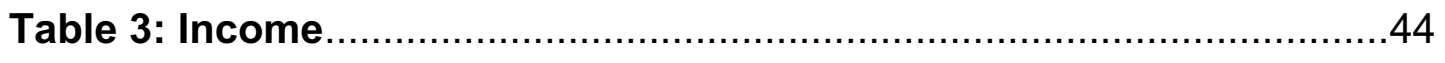

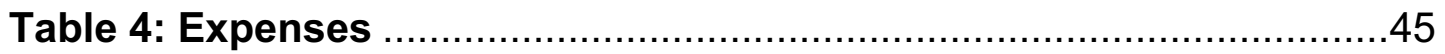

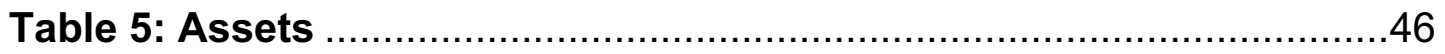

Table 6: Liabilities........................................................................... 4

Table 7: Expected sustainability outcomes of the strategies ...............62

Table 8: Questionnaire for selecting case studies ............................76

Table 9: Search query in English ................................................ 77

Table 10: Number of farms, total area, percentage of total farms and area,

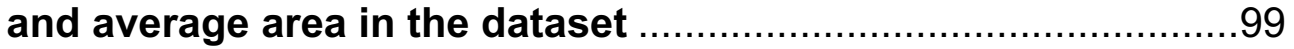

Table 11: IBGE's 2017 agricultural census tables and indicators analysed for the study .................................................................... 100

Table 12: Average farm gross income, costs of production and estimated agricultural net income per group of farm size (BRL) .............102

Table 13: Prices of forest and productive pasture in some States of the Brazilian Amazon (BRL/ha) and variation (\%)

Table 14: Estimated net income from clearing a hectare of forest, establishing a pasture, and selling the land during a period of seven years (BRL). 


\section{Table of Contents}

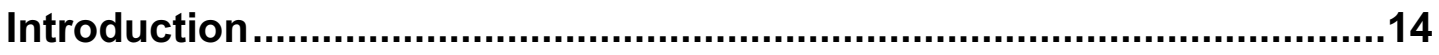

Chapter 1: Literature review ..............................................................19

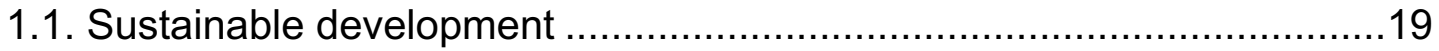

1.2. Neoclassical, environmental, and ecological economics on the relationship

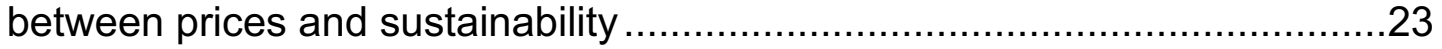

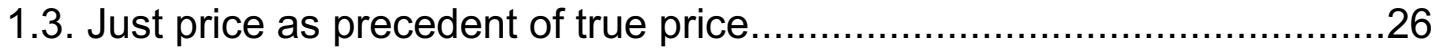

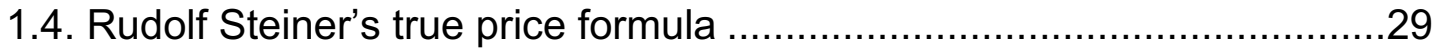

1.5. Falsification and truthening of prices ...................................................

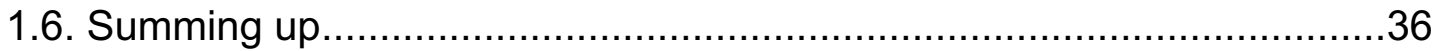

Chapter 2: A causal model linking untrue prices to unsustainability ....38

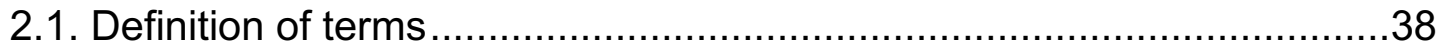

2.2. Conceptual framework ......................................................................

2.3. Overview of the proposed causal model...............................................50

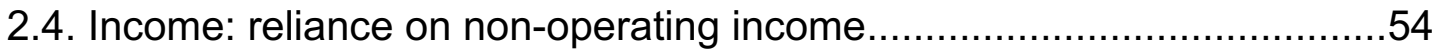

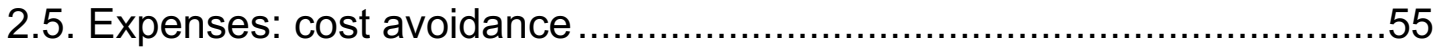

2.6. Assets: depletion and disposal of productive assets ...........................57

2.7. Liabilities: rise in debt and other liabilities...........................................59

2.8. Summary of expected sustainability outcomes of the causal model ......60

2.9. Testing the model with case studies...................................................63

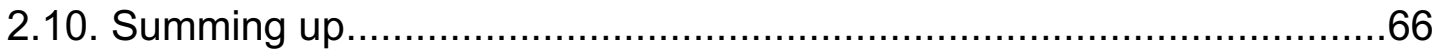

Chapter 3: Case study of the 1999-2003 global coffee crisis ..................69

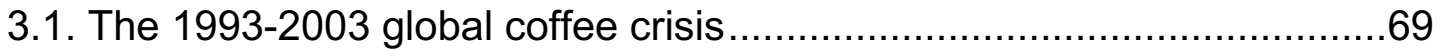

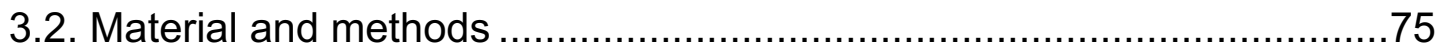

3.3. Analysis of reliance on non-operating income ……............................77

3.4. Analysis of cost avoidance .........................................................

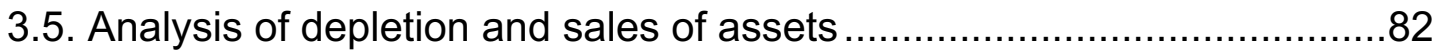

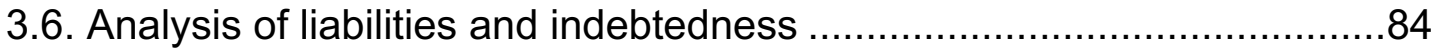

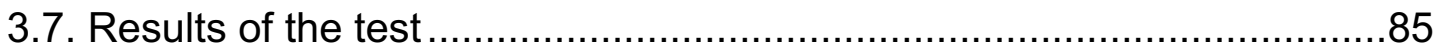

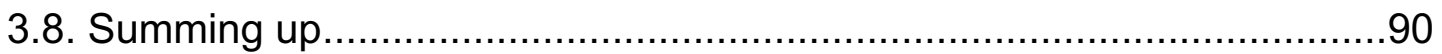

Chapter 4: Case study of farmers in the Brazilian Amazon.......................93

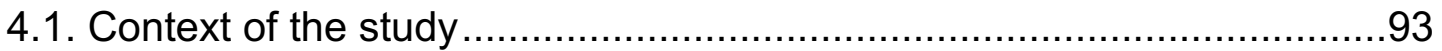

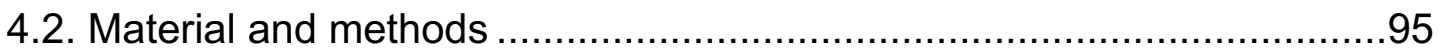


4.3. Estimating the agricultural net income in different groups of farm size 101

4.4. Analysis of reliance on non-operating income ................................107

4.5. Analysis of cost avoidance .....................................................109

4.6. Analysis of depletion and sales of assets ....................................112

4.7. Analysis of raise in liabilities ..........................................................120

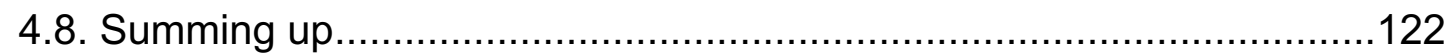

Chapter 5: Conclusions, policy implications and suggestions for future

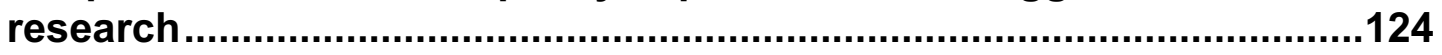

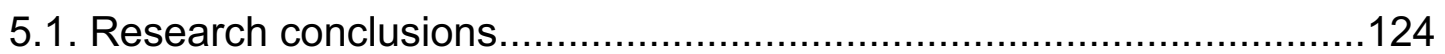

5.2. Policy implications ............................................................... 129

5.3. Suggestions for further research ............................................. 144

Bibliography ......................................................................................149

Glossary of terms used...................................................................160

Index of subjects ..................................................................................161

Appendixes ....................................................................................163 


\section{Introduction}

Sustainability has become a central concern of economic and social policy research. How do we know if the economy and businesses are sustainable or progressing towards sustainability? What should we do to deliver sustainability effectively and efficiently? Conversely, what are the signs or symptoms that would show that the economy or a business is operating unsustainably?

The interest of the author in these questions grew through professional experience with unsustainable farming economics and rural development in different countries, especially in Brazil and the Amazon, along the last fifteen years. Buyers, investors and policymakers asked the author to provide technical assistance to producers so as to solve the social and environmental issues that the latter faced or generated. Businesses and policymakers were often oblivious that how they invested capital, purchased products or implemented policies contributed to create the economic circumstances that made these socio-environmental problems arise in the first place. They lacked clarity and will to address this incoherence, which hindered improvements on the field. They could wield their economic power and agency to make sustainability levels increase, but they did not. Instead, they expected to achieve socioenvironmental progress without changing their own economic behaviours. The author became convinced that isolated work on the social and environmental fronts was akin to the assignment of the Danaids in a Greek myth, condemned to the futile effort of repeatedly carrying water into a perforated barrel. The researcher embarked on this thesis when the sense that this folly needed a cure met with the economic works of Rudolf Steiner (1861-1925). 
Academics have created significant bodies of knowledge on how to measure the three dimensions - economic, social, and environmental - of sustainability. They usually capture these three dimensions in separate ways. This compartmentation poses problems because, in reality, the three dimensions of sustainability interact with each other through complex dynamics. One dimension may both affect and be affected by the other two, and vice versa. What sustainability means from an economic perspective is especially unclear. Economists and businesses need better concepts, which can be translated into more informative and actionable indicators to capture whether the way in which economic agents intervene actually furthers sustainability or not, and provide guidance on how they should correct their courses of action accordingly.

Rudolf Steiner made significant contributions to the field of economics, although his inputs are still little-known. One key input is undoubtedly his concept of "true price" which, he says, is the cornerstone of healthy economic thinking. In 1922, Steiner expresses the concept in the form of a formula:

A true price is forthcoming when a person receives, as counter-value for the product he has made, sufficient to enable him to satisfy the whole of his needs, including of course the needs of his dependants, until he will again have completed a like product. (STEINER, 1993, p. 83)

Producers need to derive enough income from their past production to cover all their legitimate needs until the next production cycle. If they do not, then they may go out of business. The reproduction of production is an obvious prerequisite of economic life. Prices to producers impact the economic pillar of sustainability at the very least. Yet, the sustainable development literature that has burgeoned in recent decades scarcely discusses the effects of prices on sustainability, and even more rarely from the perspective of producers. The mainstream consensus on the relationship between prices and sustainability is consumer- and investor-focused. This mode of thinking typically says that the lowest prices are more affordable to consumers and maximize shareholder value. If they are in the best interest of consumers and investors, then they are also in the best interest of society. As this theory goes, the lowest price paid to producers is therefore the most social price. This thesis explores the alternative idea that producers need to receive true prices to further sustainability. Our research hypothesis is that: untrue prices contribute to unsustainability. We use the term 
'contribute' because we do not claim that sustainability merely requires true prices to arise. Other economic, cultural, technological, or legal factors, among others, may contribute to generate more or less sustainability. In that sense, this thesis does not claim in any way that true price is an economic panacea that will solve by itself the many challenges of sustainability.

This thesis focuses on demonstrating why and how untrue prices contribute to unsustainability, not how true prices contribute to sustainability. Studying the latter would be difficult in practice because we would lack empirical material to do so. Data abounds for the former hypothesis since Humankind mostly has lived and continues living in an economic world where untrue prices pervade. Untrue prices lead to unsustainability in at least one way. They make it impossible to meet all needs. Not meeting this indicator indubitably breaches the Brundtland definition's requirement for development to meet "the needs of the current generation", producers included. We start, however, this study with the supposition that untrue prices may be more pervasive and impact any of the three dimensions of sustainability. If this proposition is right, untrue prices 'contribute' to unsustainability in more ways than it seems at first sight. And so, conversely, true prices are a condition of sustainability for multiple economic, social, and environmental reasons. This study explores how, not whether, untrue prices contribute to unsustainability. Those are two distinct research questions. Simple logic and common sense already answer the whether question. ${ }^{1}$ This study focuses on how we could explain the causal process that occurs. Can we describe a coherent and uninterrupted chain of causes and effects that would link untrue prices to unsustainability?

To succeed, this study therefore needs to address two problems. First, no one has already developed a theoretically plausible and generalisable model that explains how untrue prices contribute to unsustainability. We therefore need to build it. This study combines the true price formula with the logic of accounting to develop a causal explanation or model of how untrue prices force producers to adopt unsustainable practices in one way or another. Second, we need to test this model and reject it if it makes theoretical sense but does not hold up in practice. We thus need to perform

\footnotetext{
${ }^{1}$ To answer this second question, we would need to look at whether $X$ (untrue prices) contributes to causing variations in the values of $Y$ (unsustainability). We could conduct a research experiment comparing the range of values of $Y$ across two sets of producers: a treatment group ( $X$ is present) and a control group ( $\mathrm{X}$ is absent).
} 
empirical tests to check if this causal mechanism is in fact present in real situations where the context indicates that it should. We study two cases to validate the model, a global case (the 1999-2003 crisis of the global coffee market) and a local case (farmers on deforestation fronts of the Brazilian Amazon). These two case studies are complementary tests of both the hypothesis and the purported causal model. The first case is a macro-case that happened across time in a large array of countries. The case is analysed using both qualitative and quantitative data, selected using systematic review methods. The second case is a micro-case where we perform a predominantly quantitative analysis, based on official census data. By comparing and contrasting if and how the causal model helps to explain these two cases, we intend to display its usefulness, versatility, and explanatory power. Both cases also support the process of connecting theory to practice; they show that we can learn about the real world by looking at the concept of true price, and vice versa.

The main contribution of this thesis is that it supplies a novel and logical model or explanation which makes explicit causal connections between prices and sustainability. This model transcends some of the impasses in the literature that we review in the first chapter. It is both theoretically founded by accounting theory and validated by empirical evidence drawn from the two case studies. This model integrates or bridges the concepts of true price and sustainability by applying the universal logic of double-entry bookkeeping. Using the accounting lens allows us to understand why and how the concept of true price brings new meaning to sustainable development and the economic journey that sustainability requires. True price and accounting provide, respectively, a reference point and an instrument to measure where one is in relation to sustainability, and also act remedially. The combined use of true price and accounting makes us think about sustainability in more dynamic, integrative, and practical ways. The accounting foundations and the two case studies indicate that the proposed causal model is generalisable and flexible enough to make sense of many kinds of contexts and situations. The sustainability movement gains an ally in the concept of the true price. Reaching sustainability obviously depends on a considerable number of factors, but we argue that true pricing is one of them. In that sense, the accounting indicators that we propose and discuss in this thesis do not intend to solve the problem of sustainability in its entirety, but rather to illustrate and clarify how the 
complex and dynamic reality of pricing is relevant, in addition to other factors, to sustainability.

Discussing the causes and conditions that lead to true or untrue prices is beyond the scope of this study. We will, however, discuss the topic at two different points. In the literature review (Chapter 1), we introduce how Steiner used the concept of true price to derive concrete policies. We do so because otherwise, we would fail to report an important aspect of Steiner's thinking about true price. He frequently discussed whether economic interventions are healthy depending on whether they result in true or untrue prices. We discuss again how to reach true prices when we draw policy recommendations from the study results in Chapter 5 , which resonate with the policies that Steiner advocated for. This provides another reason for introducing them in the literature review.

In short, the main purpose of this study is to show, both theoretically and empirically, why and how untrue prices generate unsustainability in peculiar manners which accounting can predict. By doing so, it aims to demonstrate why and how true price is a precondition of sustainability and to transform this insight into actionable guidelines.

Given our general aim, this thesis is composed of five different chapters. Chapter 1 reviews the literature. We introduce the concept of true price and show how it fills gaps in economic thought about the relationship between prices and sustainable development. Chapter 2 is theoretical; it focuses on building the causal model based on accounting premises. It describes explicitly the different pathways in which untrue prices can generate unsustainability. Once we have built the model, we need to test if it operates in the real world; this theory-testing is the goal of the two case studies in Chapters 3 and 4 . These chapters help us to test the empirical validity of the model, refine it, and evaluate both its flexibility and explanatory power. Chapter 3 tests the model in the case of farmers facing the 1999-2003 global coffee crisis. Chapter 4 provides another test with the case of farmers on deforestation fronts of the Brazilian Amazon. We end this thesis with Chapter 5, which proposes indicators that capture progress towards true prices and sustainability. We also discuss the policy implications of true price as a condition of sustainability, especially from the perspective of four types of economic agents: producers, consumers, investors and public policymakers. We finish this thesis by suggesting future research avenues. 


\section{Chapter 1: Literature review}

Chapter 1 sets the scene for our research by showing how Rudolf Steiner's concept of true price has the potential to fill in knowledge gaps in terms of how we understand, measure and further sustainable development. We present the concept of sustainable development and show the issues that its current lack of clarity and precise meaning entails. In particular, we know too little about how prices are linked to sustainability. We discuss how the neoclassical, environmental, and ecological economics schools of thought connect prices to sustainable development, and the contributions and limitations of each approach. We then introduce the concept of just price, proposed by Aristotle and Thomas Aquinas, as the antecedent to Rudolf Steiner's concept of true price. Next, we analyse how the notion of true price points to issues that are relevant to the theory and practice of sustainability. We also discuss Steiner's views on how economic interventions can further true prices or have the opposite effect of falsifying ${ }^{2}$ prices.

\subsection{Sustainable development}

What is the benchmark against which to measure whether our economic behaviour amounts to sound, sustainable development? Popular in academic debates, the concept of sustainability ${ }^{3}$ points to the need for healthy relationships between the economy, society, and the environment. In business parlance, sustainability often

\footnotetext{
${ }^{2}$ We use the term employed by Rudolf Steiner in this thesis.

${ }^{3}$ This study uses the terms 'sustainable development' or 'sustainability' interchangeably, although some academics make a distinction. They use 'sustainability' to refer to a long-term goal or ideal and employ 'sustainable development' to refer to the pathways to attain it.
} 
translates into the 'triple bottom line', the triptych of Profit, People, Planet, which points to the need for businesses to commit to society and nature as much as they do to profits (AMINI; BIENSTOCK, 2014; ELKINGTON, 1998; HART; MILSTEIN, 2003). A 2020 Google Scholar query 4 for the keywords "sustainability" and "sustainable development" added up to more than 8 million results. As we will see in this section, academics write more and more about the topic, but academia has yet to provide concrete and scalable solutions to precisely describe what it means and deliver it.

The publication of Our Common Future, often referred to as the 'Brundtland Report', introduced the concept of sustainable development as "economic and social development that meets the needs of the current generation without undermining the ability of future generations to meet their own needs" (UNITED NATIONS, 1987, p. 44 - emphasis ours). Sustainable development means simultaneously developing the economy and society while protecting the environment. These three dimensions are "interdependent and mutually reinforcing" (UNITED NATIONS, 2002, p. 12). The fight against poverty, "in all its forms and dimensions, including extreme poverty, is the greatest sustainability challenge and an indispensable requirement for sustainable development" (UNITED NATIONS, 2015, p. 1).

The Brundtland definition of sustainable development is conceptually and ethically understandable. The problem does not lie in the definition's contestability, but in its vagueness, which hinders implementation. Sustainability is a term that is too broad and not selective enough. This lack of practical meaning makes sustainability more liable "to lose its content and its usefulness" (PISSOURIOS; 2013, p. 425). Researchers, policymakers, and businesses often struggle to understand what sustainability means or entails, let alone how to put it into practice. They do not have clear actionable guidelines telling them how to implement it or indicators with which to measure it. Real-world practitioners cannot pin down how to achieve sustainable development in their specific economic, social, environmental, and operational contexts, which vary greatly from one economy or business to another. When can we say that the economic growth of a business is sustainable? What would be the signals that the use and distribution of natural and social resources is sustainable?

${ }^{4}$ Query by the author on February 2, 2020. 
Sustainability cannot become an effective policy if we do not agree on what it means and entails. Companies, politicians, decision-makers, civil society, and concerned citizens fill the ambiguity of sustainability with their own narratives. They use the same catchall word to defend diverging interests and worldviews, blurring even more what sustainability really means. Businesses and governments often use the term's ambiguity to claim that they defend sustainable development while perpetrating the opposite (JACOBS, 1999). Business as usual has co-opted the term and made empty gestures towards it. The looseness of the term also means that its critics often miss the mark.

Nearly thirty years ago already, Lélé noted that "sustainable development is in real danger of becoming a cliché ... a fashionable phrase that everyone pays homage to, but nobody cares to define" (1991, p. 607). Brooks makes the following recommendations in 1992:

Ideally [sustainability] should be defined so that one could specify a set of measurable criteria such that individuals and groups with widely differing values, political preferences or assumptions about human nature could agree whether the criteria are being met in a concrete development program. In other words, [sustainability] should, as far as possible, take the form of "public knowledge". (BROOKS, 1992, p. 30)

Arguably, Lélé's and Brook's points are still valid today. Businesses continue to ask academics to translate broad definitions of sustainability into precise and actionable guidelines and dynamic analytical tools. The Brundtland definition of sustainability has been around for more than three decades, yet businesses still lack the conceptual and technical means they need to measure where they are and where to go, what to do and what not to do. No consensus exists regarding "the measurement and structural properties of business sustainability . . nor managerial frameworks or practices" (WAGNER, 2015, p. 197).

We should not discard sustainability because of the theoretical and methodological challenges that it brings with it. The problem is not that sustainability is an irrelevant or deceptive concept, but that we still deal with it ambiguously and statically, and analyse its three dimensions separately, without recognising the causal relations and feedback loops that connect them. Instead of rejecting sustainability altogether, we need to provide more grounding to what still remains an abstract and 
elusive aim. We need to identify what processes play a critical role in causing more or less sustainability. We also need to provide more 'substance' to sustainability by linking it more explicitly to well-established principles and practices that economists and businesses are familiar with. As Ranganathan puts it, "without any agreement on the fundamentals of what to measure, by whom, and how, we will all be awash in a sea of confusing, contradictory, incomplete, and incomparable information" (1998, p. 4). Real progress towards sustainability is a complex and multi-layered task; we need dependable methods that every business and individual can apply in their particular circumstances. For practicality, businesses should deal with a limited number of indicators. Furthermore, sustainability indicators must be "supported by a coherent theoretical body, which is reflected in their well-organised structure and leads to their sound practice" (PISSOURIOS; 2013, p. 420).

Critics highlight that the emphasis of a given framework is often mainly on one aspect of sustainability, while the others receive less attention. A particular challenge involves how to understand and promote sustainability through an economic lens. Governments and businesses need to better conform their economic conduct to the social and environmental impacts that they want to have. Antolín-Lopez et al. (2016, p. 11) reviewed nine of the instruments that academics and businesses mostly use to measure their sustainability performance. ${ }^{5}$ Only four out of nine instruments measure or consider the economic aspects of sustainability. These sub-dimensions are: profit generation, efficiency, supplier relations, marketing practices, innovation, risk and crisis management, employee compensation, government relations, and ethics in management. Only three mechanisms mention net income or profit (the original bottom line). None of them explicitly address how prices, paid and received, affect economic sustainability or their inter-linkages with the social and environmental dimensions. Stakeholders do not agree on what economic sustainability means or what should fall within this dimension. Businesses still analyse economic information and sustainability separately, typically reporting on finance and sustainability in two independent reports (ANTOLÍN-LOPEZ et al., 2016, p. 14). Integrating financial information with the measurement of sustainability remains a pending task.

\footnotetext{
${ }^{5}$ These instruments include for instance the United Nations Global Compact, the Global Reporting Initiative, ISO 26000, the Dow Jones Sustainability Index, and B-Corporation.
} 


\subsection{Neoclassical, environmental, and ecological economics on the relationship between prices and sustainability}

What is the connection between economics and sustainability? What kind of role do prices play in a theory of sustainability? The role and correct account of prices, understood as an issue of sustainability, has become a burning issue in economics. Three competing theories have dominated the debate: the neoclassical, environmental, and ecological schools of economics. This section describes these three approaches.

The Brundtland definition highlights the concept of needs. Neoclassical economics focuses on the needs of consumers and shareholders and puts little emphasis on producers. This economic school proposes that, wherever possible, the market should determine what goods and services to produce and at what prices. Buyers should determine prices, depending on their purchasing power and willingness to pay. The role of the market is to bring prices down to the lowest possible levels, through the process of reverse auction. In his notorious book Capitalism and Freedom, Milton Friedman makes a statement that encapsulates how neoclassical economists think businessmen should deal with prices and sustainability:

If businessmen do have a social responsibility other than making maximum profits for stockholders, how are they to know what it is? Can self-selected private individuals decide what the social interest is? Can they decide how great a burden they are justified in placing on themselves or their stockholders to serve that social interest? (FRIEDMAN, 2011, p. 133) ${ }^{6}$

The tacit responsibility that business executives accept is to maximize value for shareholders, who have primacy over other stakeholders. Regardless of the validity of this view, it is what most of these executives learned in school, what they think is expected of them, and the compass they use to steer businesses.

Neoclassical economists understand labour as a cost, which businesses should minimise like any other cost. Producers should be price takers and receive the lowest possible price through their competition on the market. Typically, the argument goes

\footnotetext{
6 Richard Eells, also an American, made the opposite proposition that businesses have a social responsibility to support education, the arts, and the community. See his 1967 book The Corporation and the Arts (1967).
} 
that the lowest possible price is the most social price, and it brings about sustainability because businesses can then reinvest the capital accumulated by minimising costs and maximising profits. These investments provide beneficial effects for the economy; they trickle down to the rest of society in a 'rising tide that lifts all boats'. ${ }^{7}$

Several sub-branches of the theory of the firm ${ }^{8}$ reckon that the role of the company goes beyond maximising shareholder value. However, none of these theories encompasses comprehensively the three dimensions of sustainability or deals with time and inter-generational issues (Lozano et al., 2015). These theories do not clarify sufficiently the role of firms in fostering sustainable development, nor do they systematically address how prices, both paid and received, connect to the issue.

The commitment of neoclassical economics to the lowest price is also relativized by the externality theory. Seminal authors include Coase (1960), Arrow (1969), or Baumol and Oates (1975). Their crucial insight is that prices do not always capture all costs. Sometimes, markets fail and prices are too low because businesses generated 'externalities'. The exact definition varies from one author to another, but the general idea is that externalities arise whenever someone affects other persons, who either are not compensated for the harm done or the advantage obtained (missing market). These externalities create discrepancies between the lowest and most social prices. When companies do not account for their externalities, they over-expand production, pollute and exhaust resources, and pass on these hidden costs to society. Markets must bridge these gaps for the general equilibrium theory to be valid. To redress price imbalances, externality theorists propose to use both public policies and market instruments. On one side, governments can create incentives and disincentives, such as Pigouvian taxes or subsidies applied in proportion to the environmental harm done or benefit given, or command-and-control (punitive laws implemented by appropriate enforcement). On the other side, voluntary markets allow businesses to compensate for their externalities. Businesses can pay other businesses to internalise similar externalities as compensation. If markets internalise externalities, markets get the prices right: the lowest price generates the highest possible levels of sustainability in a

\footnotetext{
${ }^{7}$ An expression attributed to John F Kennedy, who used it in a 1963 speech. This aphorism is often used to express the purported eventual effects of free-market policies.

${ }^{8}$ Lozano et al. (2015) identify up to ten theories of the firm that discuss sustainability. They include for instance the stockholder, aggregate, contractual, stakeholder and resource-based theories.
} 
Pareto-efficient way (MARTÍNEZ-ALIER, 2003; MCAFEE, 2012; MURADIAN et al., 2013).

According to the externality theory, businesses who attempt to be sustainable should proceed with two steps. First, they should estimate the hidden costs and externalities generated through production. They can do it through full-cost accounting (also referred to as true-cost, environmental full-cost, total value, or total impact accounting). Puma, for example, uses "environmental profit and loss accounts" to measure and compensate for their externalities. Second, after externalities were estimated, businesses should internalise these costs. To do so, businesses can use voluntary markets. They can make Payments for Ecosystem Services, or buy products verified by standards and certification schemes (such as Fairtrade or the Forest Stewardship Council) that are presumably more sustainable. Businesses can also offset the impacts they cannot internalise on markets of 'licenses to pollute'. For example, they can compensate for their greenhouse gas emissions or offset loss of biodiversity by investing in markets where carbon stored or species protected by other businesses are priced and exchanged (e.g. cap-and-trade).

Ecological economists criticise the idea that achieving sustainability is only a matter of addressing market failures and internalising externalities. They consider that businesses routinely socialise their costs in the modern economy. Externalities are pervasive because they are generated by the mindset of neoclassical economics. Externality theory does nothing to address the structural root-causes which generate externalities in the first place, especially the cost-minimizing and dividend-maximizing behaviour that neoclassical economics advocates for (SPASH, 2010). Ecological economists propose instead that we need to first sort out the ecological problem of scale, then the social problem of distribution, before we can finally tackle the economic problem of allocation (COSTANZA, 1989, 1996; DALY, 1996). First, the environment puts boundaries on the use of resources by the economy. Physical indicators should therefore precede other indicators and define the scale that the economy cannot exceed. Second, governments need to address the unequal distribution of income and wealth. They can use taxes and social benefits to do so. To end poverty, for instance, governments could create progressive income taxes and redistribute some of the capital accumulated by wealthier people. If scale and distribution are properly resolved - meaning that we have scaled the economy below maximum environmental carrying 
capacity and social mechanisms redistribute wealth and income - and markets or other instruments exist to internalise externalities, then ecological economics embraces the view that the lowest price is the most social price and that markets optimally allocate goods and services (GOODLAND, 2016: 13). Yet, ecological economics insists that pricing is a third-level priority if we are to deliver sustainability. It stresses the need to deal with scale and distribution, as first- and second-order priorities respectively.

What are the "right prices," anyway? Are they the ones that give us the optimal allocation, the optimal distribution, and the optimal scale, all at the same time? That would be lovely, but it runs afoul of logic. ... Is our goal optimal allocation? Fine, then supply equals demand pricing in competitive markets can be our policy equation. We also want just distribution? Fine, but we need a second policy instrument (not prices again). We also want a sustainable scale? Fine, now we need a third policy instrument (not prices yet again). Let us by all means keep prices and markets for solving the allocation problem. (GOODLAND, 2016, p.16)

For ecological economics, price corrections only contribute in part to efficient allocation. Without a defined scale, prices reflect the present availability of each resource regardless of the total resource stock, preventing them from being used to signal the level of ecological sustainability. A different scale would result in a different set of efficient prices for that established scale, just as distribution affects the efficiency of allocation. While the school acknowledges that prices are important to allocate resources sustainably, it focuses primarily on developing public policies that change people's behaviours by policing the economy from the outside. It does not get any further than the externality theory in terms of understanding the causal relation between prices and sustainability.

In short, our literature review indicates that neoclassical, environmental and ecological economics help us to understand certain aspects of sustainability, but fail to grasp the connections between prices and sustainability to their full extent, or to provide holistic pricing solutions to deliver sustainability.

\subsection{Just price as precedent of true price}

Before Rudolf Steiner, Aristotle and Thomas Aquinas discussed how prices affect producers. Their main question about prices was whether they meet the needs of 
producers. This section is not digressive; it is key to reconstruct the historical context preceding Steiner's true price formula, as Steiner himself was well acquainted with these earlier references.

Aristotle (384-322 BC) was the first to propose a reference point to distinguish socially appropriate prices from inappropriate ones. Aristotle conceived of prices as a ratio indicating the health of the balance between the labour involved in the production of goods on each side of any economic exchange.

If there were no exchange there would be no association, and there can be no exchange without equality, and no equality without commensurability. This is why all goods must have their price set on them. (ARISTOTLE, 2009, Book V, Chapter 5)

He postulated that 'just prices' exist for all goods and were 'just' when the values exchanged between parties were equivalent in terms of the amount of labour put by each producer into the goods. For Aristotle, a price is just if it enables the completely mutual exchange of the two parties, that is, equality in terms of exchanged values and liabilities. Paying a just price is the sign that commutative justice has arisen in the exchange (SCREPANTI et al., 2005, pp. 20-21). In Nicomachean Ethics, he affirmed that paying just prices is one of the highest human virtues:

[A]nyone can ... give or spend money; but to do this to the right person, to the right extent, at the right time, with the right motive, and in the right way, that is not for everyone, nor is it easy; wherefore goodness is both rare and laudable and noble. (ARISTOTLE, 2009, Book II, Chapter 9, p. 36)

Aristotle compared producers who do not receive just prices for their produce to the crew of a ship in a tempest who ditches the shipment into the sea to save the vessel and their lives. The crew jettisons the load willingly, but they know this action is ultimately against their interest (ARISTOTLE, 2009, Book III, Chapter 1, p. 201). If we observe the nature of the producer's volition, exchanges under unjust prices are paradoxical. The producer's sale is only voluntary in a limited or superficial sense. Producers who receive unjust prices sell their produce out of economic compulsion or under duress. They proceed with the sale because they would otherwise have to deal with a more catastrophic situation (no income at all); they choose the lesser of two evils. We will revisit this notion of compelled detrimental economic behaviour when we discuss how producers respond to untrue prices in theory and in practice. 
Thomas Aquinas (1225-1274) further developed the notion of just price. For him, the just price was linked to the costs that producers had to pay to support their families. A just price should be enough to maintain the producers' families but not too high to accumulate excessive wealth. The just price is not a precise number and, in practice, the actual price may deviate from it. Correcting these deviations is necessary to ensure commutative justice. Aquinas was also concerned with usury and condemned it as an action that brought up unjust prices (BRADY; GORGA, 2017; KEYS, 2006).

Both Aristotle and Aquinas differentiated exchanges that are economically desirable from those that are not. Aristotle called them natural and unnatural exchanges. The first kind of exchange meets a need, while the second does not and instead "satisfies the greed for gain" (Aquinas, 1947, Vol. 2, Q. 77, Art. 4, pp. 15161517).

Before we turn to Steiner's true price, let us mention that Adam Smith and Karl Marx also thought about the question of needs. Smith acknowledged that producers need enough income to cover the decent necessities of their families "whatever the custom of the country renders it indecent for creditable people, even of the lowest order, to be without" (SMITH, 1776, p. 691). For Marx, too, wages (i.e. the price of labour) should be higher than the low wages that generate a "reserve army of labour" of poor labourers in a capitalist system. Workers should receive more than subsistence wages that merely cover the bare living needs, only to conserve and reproduce their labour power. Capitalists exploit workers by paying them less for their labour than the value that the latter created with it. The part that is not paid puts producers in the same situation of the serf doing his or her corvée in a feudal system. The rate of exploitation depends on how much of the economic value created by the labourer goes unpaid. In Chapter 25 of Capital, Volume I, Marx states that the "absolute general law of capitalist accumulation" is that the more capital grows, the more the prices of wages go down and structural unemployment grows. In this context, workers have to accept any wage; they are not free and independent contractors. The result is a larger poor working class, an immiserated "reserve army" (MARX, 1969, pp. 798-99). As capital accumulates, the income of these workers must worsen; they become increasingly exploited and alienated, and unsustainability exacerbates. 


\subsection{Rudolf Steiner's true price formula}

The connection between sustainability and the economic thinking of Rudolf Steiner (1861-1925) is not obvious on first examination. This section attempts to make these connections clearer by showing how his economic insights are relevant to the topic at hand, especially his discussion of the issue of pricing. Rudolf Steiner was an Austrian writer and philosopher. He has become renowned for his contributions in the fields of education, agriculture, medicine, philosophy, and spirituality. Steiner qua economist is much less known or studied in academic circles, although he discussed economics at length, both in books and lectures. He was also the chairman of Der Kommende Tag from 1920 to 1923, a group of companies who channelled their profits to finance scientific research. The initiative did not outlive the uncontrollable inflation and financial turbulence that plagued post-war Germany, but Steiner did not lose the economic lesson. It is during this time that he shared his economic ideas and the concept of true price $^{9}$, first in the book Towards Social Renewal in 1919 (STEINER, 1999) and then in a cycle of lectures to economics students in 1922 (STEINER, 1993).

A true price is forthcoming when a person receives, as counter-value for the product he has made, sufficient to enable him to satisfy the whole of his needs, including of course the needs of his dependants, until he will again have completed a like product. (STEINER, 1993, p. 83)

Before Steiner introduced the idea, he first stated in a 1906 essay that the social question is less an issue of classes, more one of prices. Whatever other problems we may face, social exploitation happens whenever buyers - whether rich or poor — fail to remunerate producers according to their needs. People are exploiters depending on how much they pay for products, not on how much wealth they own. That said, Steiner indeed knows that the ability to pay prices is a function of one's wealth or income.

The poor worker who has acquired his inferior coat for little money is, in relation to his fellow human beings in this respect, in exactly the same position as the rich man who had a better coat made. Whether I am poor or rich, I exploit if I acquire things for which insufficient payment is made. (STEINER, 2018a, pp. 46-7)

\footnotetext{
${ }^{9}$ Steiner first used the term gerechter Preis ('just', 'fair' or 'equitable' price) on a few occasions. He later switched to the term richtiger Preis ('true', 'real', 'proper', or 'right' price). We choose to use the translation 'true' in this study, in the sense that it is either true or not true that a producer meets his or her needs.
} 
Economics has to start with the moment economic life is set into motion, which is production, while consumption marks its ending point. Steiner recognises the needs of consumers and that prices should not be too high either. But he contends that the consumer's point of view (demand) is limited. In social reality, prices that are affordable to consumers do not necessarily cover the needs of producers. Also, consumers may only press downwards on price because the prices and incomes they get, in their capacity as producers, are untrue.

The true price formula is a descriptive rather than a deductive, inductive, or normative statement. Steiner does not make any judgment of ethical value, since the account contains no indication of what should or should not be. The concept just states that prices either do or do not attend to the needs of producers. The whole point of economic life is to attend to human needs. This is the foremost problem that economists need to solve. We do not need to taint or mix the reality of economic needs with moral questions of justice or fairness. Indeed, the question of how and whose needs are attended to inevitably ends up touching on these issues. Yet Steiner argues that "a sense of concern for the other, however, will not proceed from any moralic acid but from the realisation of the necessities inherent in the economic process itself" (STEINER, 1993, p. 132 - emphasis ours). ${ }^{10}$ Economists should think about needs as an objective, technical issue. Steiner clearly understands the inseparable moral ramifications, but if we direct our attention solely to ethics, we risk missing the fundamental link between one's income and one's ability to meeting needs.

Steiner saw true price as a most basic theorem that has general validity in the economic realm. True price is therefore a key starting point to set thinking into motion. True price begins life as a simple conceptual schema. It only becomes useful when it becomes more precise, when we fill out the variables that give rise to prices.

Although abstract, this formula is nonetheless exhaustive. In setting up a formula it is always necessary that it should contain all the concrete details. I do believe, for the domain of economics, this formula is no less exhaustive than, say, the Theorem of Pythagoras is for all right-angled triangles. But the point is-just as we have to introduce into the Theorem of Pythagoras the varying proportions of the

\footnotetext{
${ }^{10}$ Steiner adds: "Think of people ... who go about preaching that if human beings will only become selfless ... the economic life will become good. Such judgements are really of no more worth than this one: if my mother-in-law had four wheels and a steering wheel in front, she would be a bus! Truly the premise and the conclusion stand in no better connection than this, except that I have expressed it rather more radically" (STEINER, 1993, p. 132).
} 
sides, so shall we have to introduce many, very many more variables into this formula. Economic Science is precisely an understanding of how the whole economic process can be included in this formula. (STEINER, 199, p. 83)

The formula is axiomatic: it applies to all producers. Not only producers of material goods but also service providers, educators, researchers, medics, or artists. Steiner also considers that employees are producers of goods or services, even if appearances disguise them as mere wage earners.

In essence, a true price means that the producer generates sufficient income to meet needs, while an untrue price entails lack of income to attend to necessities. True prices cover all the producers' needs, including those of their dependants. The first image that might come to mind could be that of households, where the dependants are the producers' families. From an economic perspective, though, more entities depend on producers. Producers interact with other economic agents such as their employees, suppliers, investors, tax-collecting governments, and possibly a broader range of stakeholders. "We must not confuse the issue by thinking in the narrow sense of household economics" (STEINER, 1993, p. 62).

Steiner expressed the formula in a future-oriented way on purpose. Producers use the income they derive from sales to pay for future, not past, production. When buyers receive products and pay for them, producers have already covered or financed the costs involved in producing the specific products they delivered. What counts is the future, rather than the past. What matters is whether the prices that producers receive will allow them to cover all their needs during the next production cycle. If the price does not cover these future costs, the process is not reproducible and therefore not sustainable.

This is an absolutely essential feature of the formula. If we were to demand a counter-value, literally, for the product that has been finished . . . it might well happen that he would receive a value which would only satisfy his needs for, say, five-sixths of the time it will take to finish the new product. . . . Where past processes are thus used to set future ones in motion, it inevitably happens in some cases that the values are considerably shifted. Indeed, they are constantly shifting. (STEINER, 1993, pp. 83-4)

The concept of 'needs' is central to the formula. Steiner did not discuss in detail the notion of needs, nor did he specify or define them. He thought that we should 
assess needs on a case-by-case basis, as he knew that they vary from one business or person to another. If needs are singular, the same price can be true for one business and untrue for another producing an equivalent product. Needs should, however, be 'legitimate'. Needs include basic necessities but go beyond them. For instance, Steiner understood the ability to fulfil one's legitimate aspirations as a need. ${ }^{11}$ One could argue that his idea of true price is naive and impractical. Producers could misuse the concept, claim that their needs include luxury or unnecessary items and request excessive prices. For Steiner, economic efficiency implies optimal and economical rather than immoderate and costly behaviours:

Man thinks little about how he stands in social contexts and how responsible he is for what he does. If we take things seriously, we must feel responsible for what we do. One helps one's fellowmen best when he becomes undemanding. Someone with a few needs helps his fellowmen more than if he were a philanthropist. For example, one who does not write unnecessary letters, saves that some people might have to climb many stairs. It is a great mistake to believe that having many requirements helps people by providing them with more work. Giving people work does not increase in the least what they need. (STEINER, 1998, pp. 196-7)

Steiner did not busy his mind thinking about how we could fix prices to make them true. He rather sees price-fixing as an illusory and counter-productive approach. Prices reflect the original conditions and circumstances that led to their generation. They are the culmination of the economic process that leads to an exchange. We can only change the conditions that underlie prices. Steiner used the metaphor of thermometer readings ${ }^{12}$ to point to the fact that we can use prices to observe the health of the economy, but that fixing prices does not solve economic problems.

It only begins to have a real meaning when we regard prices and values much as we regard the positions of the mercury - as indicators, pointing to something else. (STEINER, 1993, p. 52)

We must observe prices as we observe the degrees of the thermometer, and then look for the underlying conditions. . . . If we feel cold in a room, we do not go to the thermometer and try by some mysterious method to lengthen the column of mercury. We leave the thermometer alone and stoke the fire. We get at the problem

${ }^{11}$ This view arguably echoes into Amartya Sen's capability approach to social justice (see SEN, 2010).

12 In Value, Price and Profit, Marx also makes the analogy between prices and thermometer readings: "What are high wages and what are low wages? ... If a man was to lecture on the thermometer, and commenced by declaiming on high and low degrees, he would impart no knowledge whatever. He must first tell me how the freezing-point is found out, and how the boiling-point, and how these standard points are settled by natural laws, not by the fancy of the sellers or makers of thermometers." (2006, p. 33) 
from quite a different angle; and so, it must be in economics too. (STEINER, 1993, p. 59)

A price is the economic equivalent of the thermometer's mercury. The movement of a thermometer or barometer ${ }^{13}$ depends on the temperature or pressure, not vice versa. Similarly, an asymmetric relation of cause-and-effect ties the underlying economic conditions to prices. Just as the temperature can get hotter or colder depending on how far it is above or below zero, we can classify prices depending on their position regarding the threshold above which prices are true. If the reading of the thermometer is below zero, it means that water freezes and rain becomes snow. If the barometer reading is below 990 millibars and going down slowly, it indicates that rain is coming. Now if the barometer is going down significantly and quickly, a storm is coming. Fixing prices is akin to lighting a match to raise the mercury hoping the room will get warmer. We do not change the weather by moving the mercury in the thermometer's column. Economic actors, including governments, should not attempt to manipulate prices artificially because this would be absurd behaviour. They should instead focus their efforts on changing the economic conditions that give rise to the prices that need to change. We can use another metaphor: an economist fixing prices that are going awry is akin to a doctor trying to adjust the cardiograph warning that the patient is under cardiac arrest.

As noted earlier, Steiner recognises the necessity for prices to be not only true to producers, but also affordable to consumers. A key task of the economy is to constantly adjust price levels, so they satisfy both conditions. It is incorrect to assume that paying true prices to producers would be against the interest of consumers. Consumers are also, in most cases, producers themselves, or their dependants. Their purchasing power normally depends on how much income they generate as producers. Consumers may find prices unaffordable, not because they are too high, but because the prices they receive as producers are untrue.

Steiner did not take issue with the question of profit. Profits, when they result from businesses who pay and receive true prices, serve as a metric which shows that some societal need is being met. He does not negate the possibility of and need for profit,

\footnotetext{
${ }^{13}$ Steiner also uses the metaphor of the barometer, with its underlying reference to pressure (1993, Lecture 8).
} 
but points to the fact that profits need not be maximised, nor should they be the primary or only reason to engage in productive activities.

[T] here must be something in the economy that can serve to indicate whether there is a need for a manufactured article. In the modern form of economics, the only indicator of this need is the fact that the article yields profits. . . An article that yields no profits must not be produced because it will upset the price balance of articles in actual circulation. Profits may represent what they will in ethical terms; in conventional economic terms, they represent an indicator for the need to produce an article. (STEINER, 1985, paragraph 5)

\subsection{Falsification and truthening of prices}

Rudolf Steiner remarked that even a single economic agent can intervene in a way that falsifies prices. He takes the example of a manufacturer who, for some reason, gets rid of his inventory of goods well below production costs. The goods are of the same kind and grade as the goods produced by similar manufacturers. For Steiner, by dumping his inventories on the market, the manufacturer falsifies prices for himself and other producers.

That does not mean that the commodities decrease in value; it only means that the true price is not paid. In ways like this, prices are constantly being falsified in the actual economic process. ... There is, nevertheless, a true price. The commodities sold by the man in the above example are worth just as much as the same commodities produced by someone else. (STEINER, 1993, p. 95)

Several types of interventions can falsify prices. The list includes, for example, some types of capital gains coming from speculation on the mortgage, currency, and real estate markets. Those are different forms of 'damming capital', as Steiner puts it. This capital is not used to put human abilities to production so as to attend to the needs of other human beings. Instead, capital becomes dammed in assets and increases the costs that producers have to pay to access the resources that production involves. Interventions falsify prices if they give rise to fictitious values that only adversely affect production, making it dearer.

Economically speaking, it makes no essential difference whether, for example, I issue money that has no foundation in reality but represents a mere increase in the amount of paper money, or whether I assign capital value to the land. In both cases I am creating fictitious values. By inflating the currency, I increase the prices of things numerically; but in the reality of the economic process, I affect absolutely nothing except a redistribution, which may do immense harm to individuals. In the 
same manner ... capitalizing of land does harm to those who are involved in the economic process. (STEINER, 1993, pp. 77-8)

For example, high land prices mean higher costs of rent and interest for producers. Rent or capital gains from these speculated assets have falsifying effects on prices. They reduce the viability of production and harm the economy. Capitalising producers with "real credit", in the form of a collateralized asset, such as mortgages, has the effect of increasing the apparent value of assets and therefore debt, rent, and interest. When investors stock capital into land or financial markets and the values of these assets rise, they place more and more costs onto producers relative to their capacity to generate income. If rent and interest become disconnected from the reality of production, the growth of ground rent and mortgage interest rates is against the interests of producers. Producers who pay lower rents and interest rates "will be less hampered in their use of the capital they have borrowed" (STEINER, 1993, p. 84). The rates of return on land and capital must be proportionate to real productivity. For Steiner, this means that we need to provide personal or unsecured credit rather than real or secured credit (collateralized debt), even and especially to producers who work upon land. Real credit tends to "congest" capital in the asset asked as collateral, often land and real estate (STEINER, 1993, p. 76).

For Steiner, we should not look at production costs in the absolute. To truthen ${ }^{14}$ prices, we can finance the means of production that producers need to improve productivity and reduce costs.

[S]peaking of costs of production, it can be desirable for the attainment of a healthy price not to think how the price will come out if costs of production are looked upon as something absolute, but on the contrary, to think how the costs of production for a given article might have to be reduced so that it has a healthy price when it comes into the market. In other words, you need to have concepts that really begin at the beginning. (STEINER, 1993, p. 167)

Productivity can reach excessive levels and create unhealthy competition that ultimately falsifies prices. Economic actors can truthen prices by constantly improving how they involve labour, land, and capital in the production and distribution processes.

\footnotetext{
${ }^{14}$ The expression 'truthen' appears to be a neologism, as it is not listed in most dictionaries. We use it to avoid less elegant expressions and condensate the idea of acting in a way that renders prices truer. Wiktionary defines 'truthen' as 'to make true; to cause to adhere to the truth; to prove, validate, or support the veracity of'.
} 
True price does not mean in any way that overall price levels would be higher. It would be a sign that we are optimally allocating labour, land, and capital. Perhaps it is today's untrue prices that businesses and individuals everywhere feel to be high. Excessive production occurs especially when producers stop asking themselves how many goods and services consumers need and start producing depending on the financial expectations of the market. This excessive production, dictated by financial expectations rather than real needs, strongly falsifies prices.

Things are now produced for the market regardless of the amount required . . . [A]II that is produced is piled up in warehouses and governed by the money market, and then the producers wait to see how many are bought. This tendency will grow greater and greater until it destroys itself. (STEINER, 1914, Lecture 6)

\subsection{Summing up}

Current approaches to sustainable pricing have proved inadequate to the task at hand. Externality theory adopted an incomplete definition of sustainable pricing (the lowest price, where externalities have been internalised in the cost structure). In contrast, ecological economics has focused on delivering sustainability by defining and policing various ecological limits (sustainable scale) and social mechanisms of redistribution (fair distribution). To then ensure the efficient allocation of resources, it mirrors environmental economics and mostly focuses on internalising externalities through the free play of market forces (e.g. pricing carbon and ecosystem services).

We purposely used the somewhat dated references in the section on sustainable development to make the point that the problem is long-standing, still relevant, and unheeded. More than ever, economists and businesses need to apprehend their distance from and progress towards sustainability. They need to understand where they are and where to go by monitoring a comprehensive yet manageable list of indicators, that works in their specific economic contexts. Our review of Rudolf Steiner's concept of true price suggests that it is a good candidate for such a shortlist.

Steiner has only provided an abstract concept to start with. Obviously, he could not have framed true price from the point of view of sustainability since the latter notion arose six decades after his death. We need to update the term, to frame and translate it into the current theory and practice of sustainability. We need a clear conceptual 
framework and model to understand why and how true pricing matters for sustainability.

True price directly links up with the question of attending to needs and the related issues of deprivation and poverty. Untrue prices, so low that producers cannot meet their needs, are evidently unsustainable. Yet, the causal model that we develop in the next chapter unravels the deleterious impacts of untrue prices on unsustainability, far beyond non-attendance to needs. This causal model places true prices as the economic cornerstone of sustainable development. 


\section{Chapter 2: A causal model linking untrue prices to unsustainability}

The literature review established that the concept of true price fills in knowledge gaps regarding sustainability. Yet, we still lack a clear framework to understand how true or untrue prices could specifically further or hinder sustainability. Chapter 2 aims to develop this framework in the form of a causal model linking untrue prices as a trigger condition to unsustainability as an outcome.

After setting the scene for our causal explanation by introducing our logical framework (the nature and logic of accounting), we introduce the causal model linking untrue prices to unsustainability. The details of this model are then further explored. Our discussion generates clear expectations regarding what kind of empirical evidence should appear if the model really exists. Clarifying these expectations makes the model testable. Once the model is built, we need to test it, especially in terms of its internal and external validity as well as its explanatory power. We finish this chapter by explaining why and how we will test the model by studying two independent cases in Chapters 3 and 4.

\subsection{Definition of terms}

Before we build the causal model, we need to clarify a few terms that we will use along this study. We define our concepts using set-theory. In other words, we link our terms to clear qualitative thresholds, which allow us to differentiate cases into sets of mutually exclusive categories. This study will use three pairs of terms. 
Our first pair of concepts are true and untrue price. By inference, 'true prices' means there are 'untrue prices'. We have the theoretical sets of true prices and untrue or not-true prices. A qualitative threshold separates these sets of prices. Above this threshold, prices are true, and below it they are untrue. We represent how prices relate to this threshold in Figure 1. Price $a$ in the figure is a true price because it is above the threshold, while prices $b$ and $c$ are below it and therefore untrue. Price $c$ is further away from the threshold than price $b$. It is 'more untrue' than price $b$.

Figure 1: Prices are either below or above a 'true price' threshold

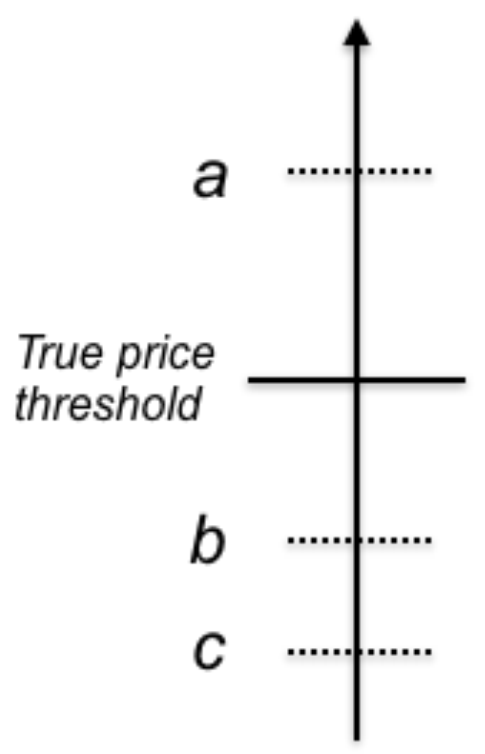

Source: Author.

Furthermore, interventions can be categorised depending on their effect on the relative 'truthiness' of prices. We can say that any human intervention that brings prices to a position that is closer to or above the true price threshold does truthen prices. If an intervention brings a price from position $a$, to position $b$, or position $c$, then we can say that this intervention 'falsified' prices, or contributed to the 'falsification' of prices.

Figure 2 shows that prices can be falsified in at least two ways: through a decrease in prices received or through the raise of the true price threshold, for example through a drop in productivity. 
Figure 2: Interventions of two types can result in price falsification

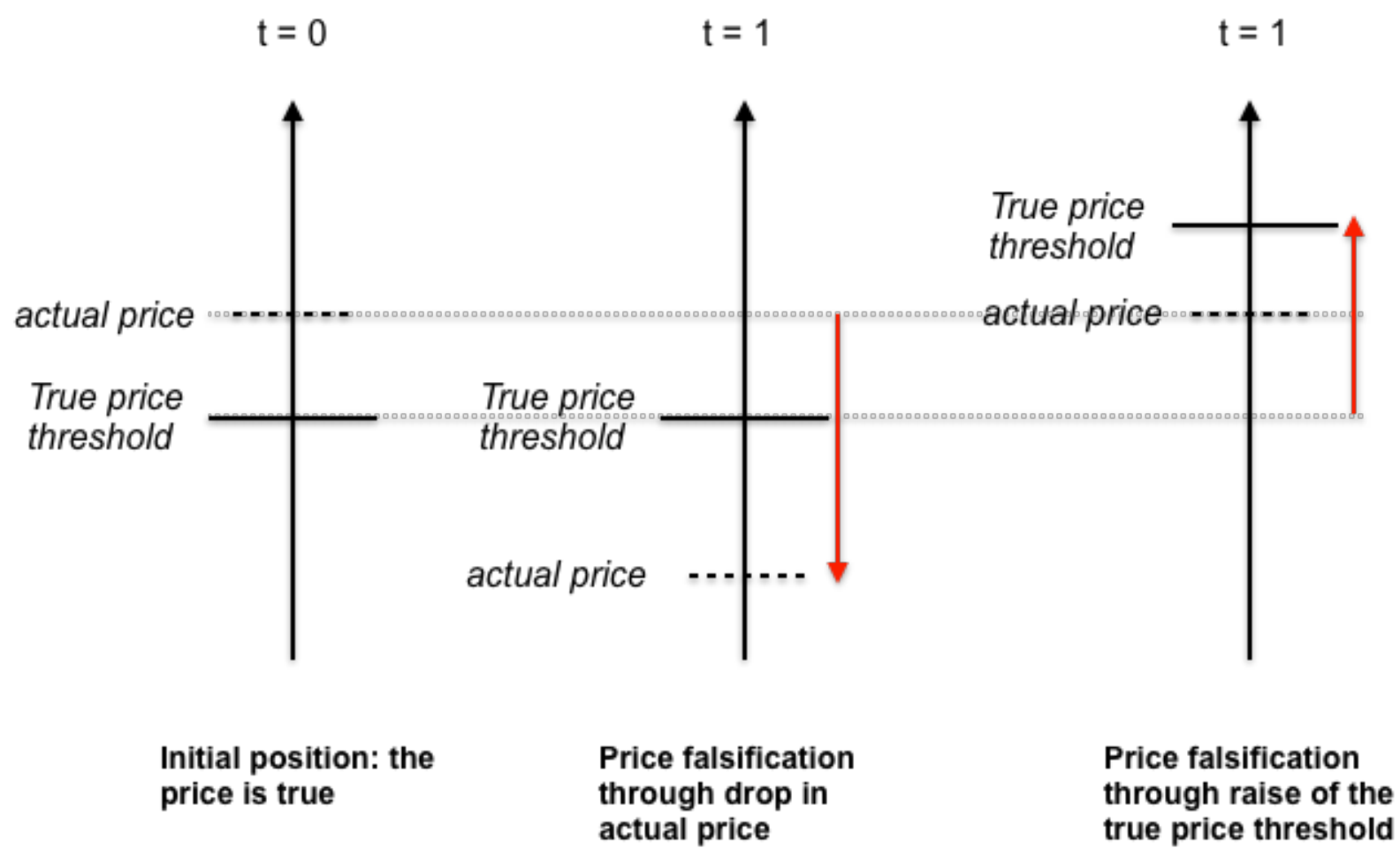

Source: Author.

Finally, we also need to distinguish sustainable economies or businesses from unsustainable ones. As we argued in Section 1.1 of the literature review, the meaning of sustainability is still a moot point. We therefore do not pretend to offer an exhaustive list of sustainability indicators here. Since our research will involve case studies of agricultural producers, we developed a list of indicators that discriminate sustainability from unsustainability in this specific context. Farmers may affect at least eight different indicators of sustainability, listed in Table 1 on the next page. Their behaviour is sustainable if it improves the values of these indicators and unsustainable if it worsens these values. 
Table 1: Indicators of sustainability and unsustainability

\begin{tabular}{ll}
\hline Vector & $\begin{array}{l}\text { Sustainability increases if there are positive changes (and } \\
\text { decreases if changes are negative) in terms of ... }\end{array}$ \\
& Optimal profitability, income, or productivity; \\
& Attending to legitimate needs; \\
Locio- & Dabour conditions and respect for human and community rights; \\
economic & Healthy debt levels; \\
& $\begin{array}{l}\text { Situation of disadvantaged groups: women, children, poor people, or other } \\
\text { kinds of vulnerable social groups; }\end{array}$ \\
\hline Environmental & $\begin{array}{l}\text { Types of land use, land conversion and habitat loss; } \\
\text { Environmental stock and condition of private and communal natural resources }\end{array}$ \\
& (including forests, biodiversity, soil, water, and air quality). \\
\hline
\end{tabular}

Source: Author.

\subsection{Conceptual framework}

We draw from literature on causal mechanisms to develop the model. We need to build a model that clearly expresses why our explanatory target, unsustainability $(\mathrm{Y})$, depends upon another independent variable $(X)$, the relative untruthiness of prices (GLENNAN, 2017, p. 16).

We can symbolise the causal process or mechanism that we want to elucidate as ' $X \rightarrow Y$ ', the process being the arrow between $X$ and $Y$. This study needs to clarify how this arrow transmits causal forces from $X$ to $Y$, to make more explicit the "process whereby causal forces are transmitted through a series of interlocking parts of a mechanism to produce an outcome" (BEACH; PEDERSEN, 2012, p. 4).

We first need to conceptualise this causal process. According to Kaplan, a robust model, one that accurately describes how a cause contributes to a phenomenon, should meet certain conditions.

A model of a target phenomenon explains that phenomenon to the extent that (a) the variables in the model correspond to identifiable components, activities, and organizational features of the target mechanism that produces, maintains, or 
underlies the phenomenon, and (b) the (perhaps mathematical) dependencies posited among these (perhaps mathematical) variables in the model correspond to causal relations among the components of the target mechanism. (KAPLAN, 2011, p. 347)

We should consider only characteristics that are causally relevant to our explanatory target. We need in particular to:

i. specify the initial condition that triggers the causal mechanism;

ii. identify the entities that play a relevant part in this mechanism and the activities they engage in;

iii. disaggregate the causal mechanism into a set of plausible and clearly defined parts or components. We need to explain how actors choose specific actions when prices are untrue, and why these actions are relevant;

iv. explain how these actions produce unsustainable outcomes (either individually or collectively, through dynamic interactions).

We then need to operationalise the mechanism, that is, make it testable through comparison with empirical evidence. We must clearly explain how each part of the mechanism contributes to $Y$ either individually or by interacting with the other parts. Our predictions should be as clear and specific as possible to be verifiable in the empirical world. What observable evidence would each part leave? Empirical tests using case studies will either confirm or refute these predictions, and allow us to update our confidence in the existence and validity of the model $(\mathrm{BEACH} ; \mathrm{PEDERSEN}, 2016$, p. 188).

The conceptual framework of our model is based on accounting. At its simplest, accounting, or double entry bookkeeping, contains five accounts: Assets, Debt, Equity, Expense, and Income. These accounts together constitute the General Ledger. The balance sheet combines assets, debt, and equity, while the income statement combines expenses and income. Net profit or loss is the sum of income less expenses. It is a summation account that is derived from the Expense and Income accounts on the General Ledger. Table 2 on the next page shows that accounts are either Active or Passive. 
Table 2: The General Ledger containing five types of Accounts

\begin{tabular}{ccc}
\hline & Active & Passive \\
\hline Balance sheet & Assets & Liabilities (Debt and Equity) \\
\hline Income statement & Expense & Income
\end{tabular}

Source: Adapted by the author from the International Financial Reporting Standards (LEVY et al, 2018).

The balance sheet is a permanent (or real) set of accounts, while the income statement is a temporary (or nominal) set of accounts that businesses set to zero periodically. At the end of each accounting period (conventionally on December 31 of each calendar year), businesses close their entries. They zero all the entries in the Income and Expense accounts and transfer the result of the accounting period (a net loss or profit) to the Equity (or Own Capital) account on the liabilities side of the balance sheet. On the assets side, the business increases its cash reserves if there is a profit and decreases them if there is a loss. Figure 3 below pictures a set of accounts and the process of closing the entries that applies to any sort of economic entity (including for-profit and non-profit businesses, as well as governments).

Figure 3: Representation of a set of accounts

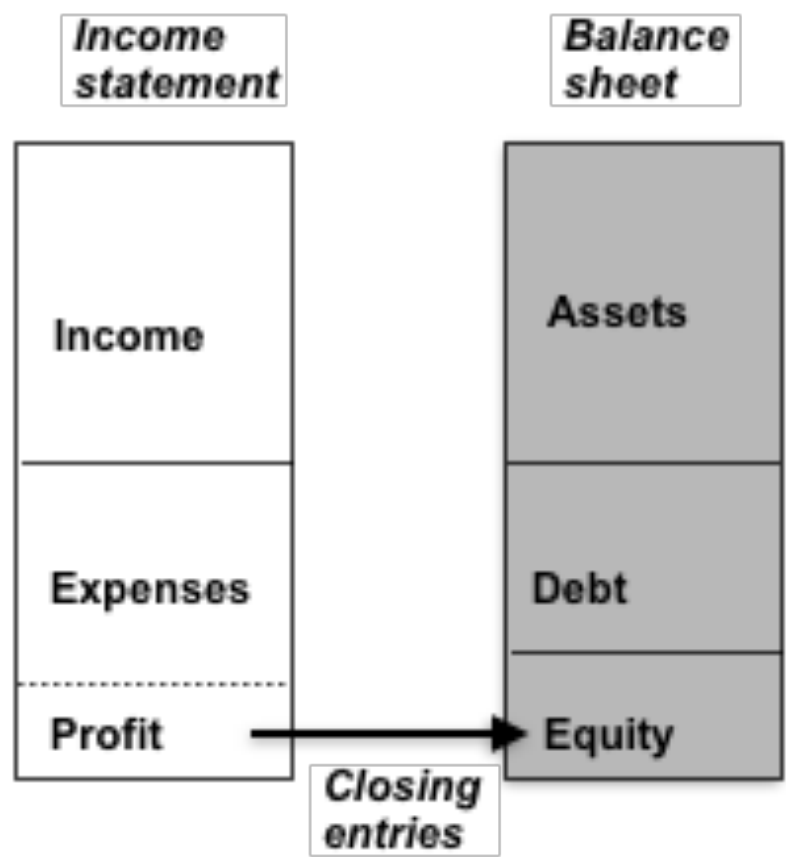

Source: adapted by the author from Houghton Budd (2011, p. 212). 
Note that profit is not a ledger account, hence why we separated it from Expenses with a dotted line, while debt and equity, which are both ledger accounts, are separated by a solid line. Profit is actually a subtotal (income minus expenses). We represent it however to visualise the identity of the income statement (or income and expenditure statement), which must balance.

The income statement identity specifies that:

\section{Income $\equiv^{15}$ Expenses + Profit}

The income statement exposes the trading revenues and expenses that producers receive or incur during an accounting period. It is important to note that some movements in assets or liabilities affect but do not pass through the income and expenditure accounts. For example, if a business makes capital gains from the sale of a productive asset, it can debit accumulated depreciation and credit the purchase price of the asset, removing it from the balance sheet. The capital gain appears on the income statement only afterwards.

Income may result from operating revenues (such as sales), asset improvements, subsidies, or increases in equity resulting from a reduction in liabilities, among other possibilities. Revenues appear in various forms in the accounts of businesses, as represented in Table 3 below.

Table 3: Income

Income

Operating revenue (goods and services)

Non-operating revenue (leases, rents, interest income, dividends, gains from sales of assets, asset write-downs)

Other revenue (gifts, legacies, subsidies, miscellaneous)

Total income

Source: Adapted by the author from the International Financial Reporting Standards (LEVY et al, 2018).

\footnotetext{
15 Mathematicians and accountants use the triple-bar symbol $\equiv$ to represent a relation of identity. If $a \equiv$ $b$ then $a$ and $b$ are logical equivalent counterparts. The meaning of $\equiv$ is more general than the equation $a=b$, which only denotes that the value on the left is equal to the value on the right.
} 
Businesses incur many different types of expenses, represented in Table 4 below. We can also distinguish fixed (or overhead) costs - such as labour, depreciation, and household costs - from direct (or variable) costs. Since variable costs depend on the level of production, producers can adjust them more swiftly.

\section{Table 4: Expenses}

\section{Expenses}

Cost of sales (goods and services)

Operating expense (operation, administration, marketing)

Depreciation (loss on asset impairment)

Remuneration of workers (salaries, social insurance, etc.)

Property (leases, rents, etc.)

Capital (repayment of interest and principal of loans)

Taxes

Total expenses

Source: Adapted by the author from the International Financial Reporting Standards (LEVY et al, 2018).

When businesses close their entries, the result of trading during the accounting period shows up as a net profit or a net loss which is then transferred to the balance sheet, to the Equity, or Own Capital account.

The identity of the balance sheet specifies that:

\section{Assets $\equiv$ Liabilities $\equiv$ Debt + Equity}

This identity states that the balance sheet must always balance. Total assets must always equal total liabilities, i.e. the sum of debt and equity. The balance sheet measures the state of the business. If it does not balance, then, the business has not fully, accurately, or consistently recorded its entries.

Producers need to deploy specific means of production to produce the goods or services that consumers ask for. These means of production appear as assets. To finance them, producers need capital that appears as liabilities either as debt or equity, both of which can come from the producer or an outside source. Productive assets are the physical or tangible capital that producers use during production. They include current and fixed assets. Current assets include cash, accounts receivable resulting from providing goods or services on credit, inventory, or prepaid expenses. Fixed 
assets include for instance buildings, equipment, or land, minus the accumulated depreciation. Table 5 below shows how assets typically appear in the accounts. Assets appear in the table in a sequence that ranks them from the most to the least liquid.

\title{
Table 5: Assets
}

\author{
Current assets \\ Cash (bank account, others) \\ Accounts receivable (customers) \\ Other current assets (current accounts) \\ Inventory \\ Prepayments (at year-end)
}

Total current assets

\section{Fixed assets}

Financial assets (loans, investments)

Productive assets (buildings, equipment, land)

(Accumulated depreciation)

Intangible assets

(Accumulated amortisation)

\section{Total fixed assets}

\section{Total assets}

Source: Adapted by the author from the International Financial Reporting Standards (LEVY et al, 2018).

Liabilities show how businesses finance their assets, either in the form of debt or equity. ${ }^{16}$ Current liabilities include accounts payable (resulting from purchasing goods or services from suppliers on credit), accrued expenses payable, or notes payable (such as tax liabilities). Long-term liabilities include loans, which investors can demand to secure with collateral. Own Capital or Equity includes invested capital and retained earnings. Table 6 on the next page shows how liabilities typically appear in business accounts. The conventional rule for payment of liabilities is specific. Debt or bond

\footnotetext{
${ }^{16}$ Producers can finance their operations with debt and equity. Equity investments are made by shareholders and are represented by shares in the producer's business. When shareholders invest in a business, they partake in the capital but also in the risks linked to the entire life of the business. Shareholders can earn capital gains either by receiving dividends or by selling the stock at a higher value than they bought it. They receive capital gains and repayment schedules that both vary. Producers can also get cash by incurring debt, provided by lenders. Loans contrast with shares in that they have a fixed maturity of their own, with the interest rate and repayment schedules established in advance. When businesses borrow money, they enter into financial obligations that continue to exist until they have fully repaid the debt.
} 
holders are legally due to receive their capital with interest, while stockholders do not have this guarantee. The hierarchy of payments starts first with senior debt, then preferred or non-voting stock, and ultimately common or voting stock, and only then junior debt follows (i.e. debt not secured by assets, like high yield bonds or accounts payable to suppliers).

Table 6: Liabilities

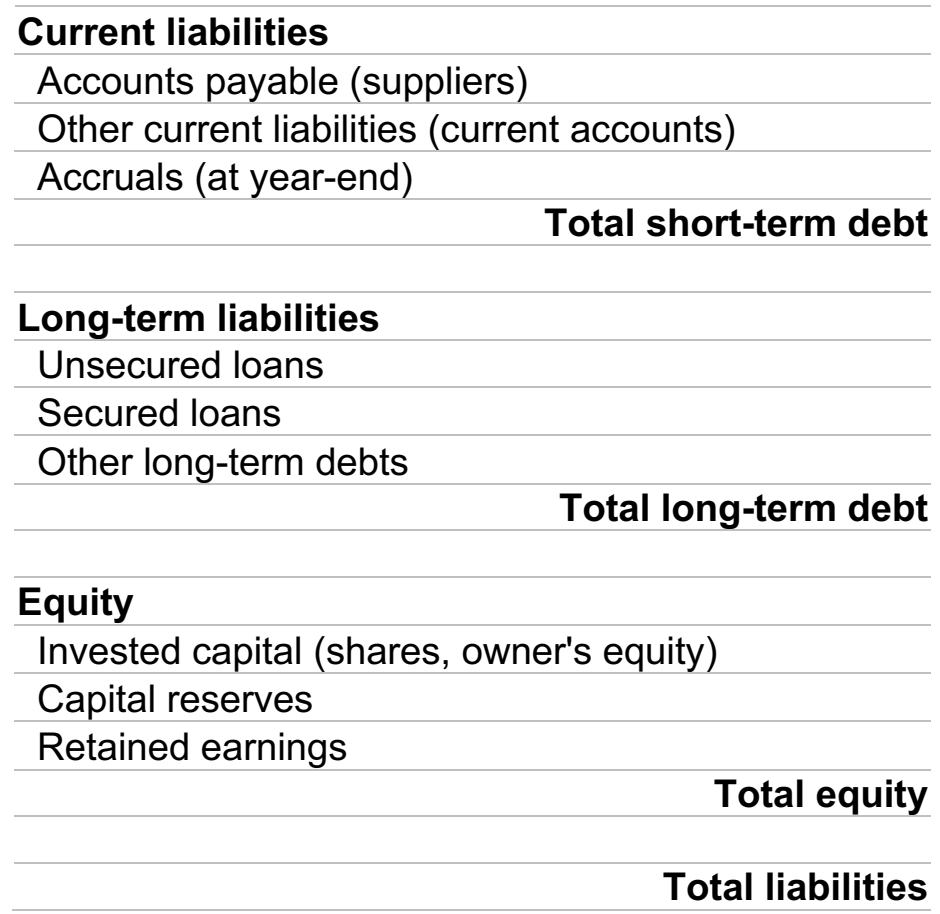

Source: Adapted by the author from the International Financial Reporting Standards (LEVY et al, 2018).

Businesses use the cash flow statement to track both paid and unpaid transactions. A cash transaction is for example a sale or purchase immediately settled in cash. Non-cash transactions include amortisation and depreciation and accounts payable and receivable, among others. The cash flow identity states that:

\section{Cash Flow $\equiv$ Net Income + Non-Cash Expenses - Increase in Working Capital - Capital Expenditures}

If businesses do not have access to enough liquidity to finance all their paid and unpaid transactions, they incur negative cash flow. Over time, they become less and 
less liquid and may go out of business as the process continues to unfold. We can distinguish three main categories of cash flow. Cash flow is either linked to:

i. operating activities (cash flow that producers generate from their regular operations);

ii. investing activities (cash flow from the purchase and sale rather than use of productive assets);

iii. financing activities (movements of cash between the business and its creditors - comprised of lenders and shareholders - in the form of decreases or increases in debt or equity).

Businesses maintain relationships with their direct economic partners and indirect relationships with other economic agents. Direct partners are the economic agents with whom businesses exchange all the time, for example suppliers, consumers, and investors. Businesses can also indirectly impact the balance sheets of other economic agents. For instance, if a business generates externalities or avoids taxation, other businesses or governments will incur these costs or liabilities. Conceptually, in an economic exchange, if businesses record a debit, their economic partners must record a corresponding credit. Conversely, if they record a credit, their partners must record a debit. When two economic counterparts are involved in the exchange or transfer of goods, services, wealth, or externalities, debit on one counterpart's account corresponds to credit on the accounts of others. These accounting entries must match with records in the accounts of the counterpart as changes in the value of income, expenses, assets or liabilities. Income or expenses for producers correspond respectively to expenses or income for their trading partners. Similarly, the liabilities of producers mirror the assets of their financial counterparts. Internally also, any increase or decrease in debt on the passive side is reflected in a decrease or increase of assets on the active side.

One implication is that if we hold that a producer gets too little income or has too many liabilities, it may be because his or her trading partners do not pay him or her enough, (i.e. their expenses are too low) or his or her financing partners have overvalued their assets or have too many. Another implication is that if two economic counterparts identify any mismatch between the credits and the debits that each party 
recorded, then they must find and correct the error. The mismatch may be in the value of the record, but also may be a question of wrong timing or inconsistent taxonomy. Admittedly the argument is conceptual in the first place, for in practice the accounts of two entities are not connected and need not be. Businesses are not normally required to share their accounts in the way the idea of mirrored bookkeeping implies, nor would they. But that is indeed part of the problem: thinking in terms of separated entities does not capture how relationships among different entities could result, indirectly or in the aggregate, in more or less sustainability. That understood, we represent the accounts of producers and their relationships with those of their economic partners in Figure 4 below.

Figure 4: Representation of the mirrored relationships between the accounts of a producer and his or her economic partners

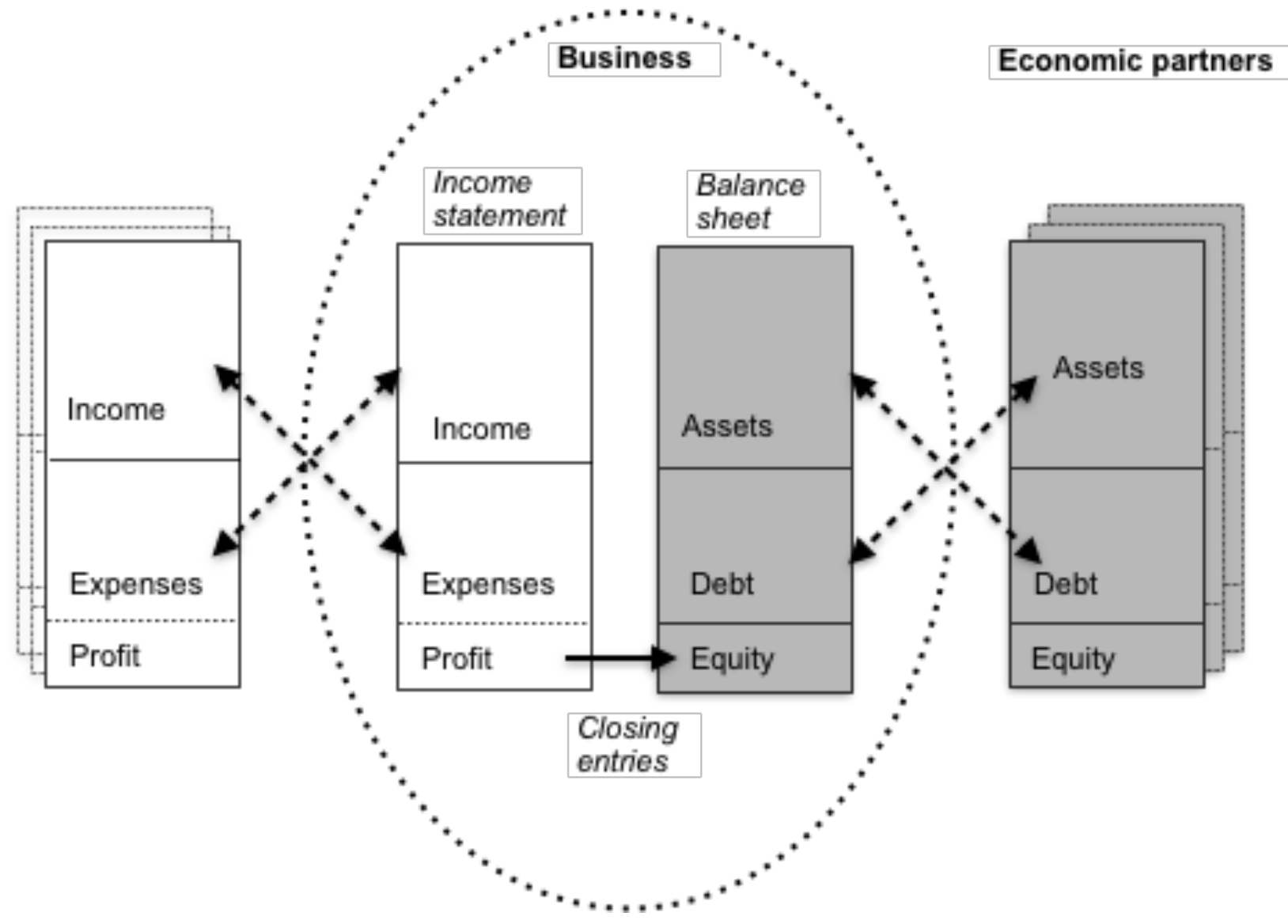

Source: Adapted by the author from sketches by Houghton Budd (2011, p. 216). 


\subsection{Overview of the proposed causal model}

In this section, we conceptualise a causal explanation - based on the logic of doubleentry bookkeeping that we just explained - which reveals how untrue prices force producers to adopt unsustainable financial responses that are predictable. We start our model with an individual producer (a business entity managed by an entrepreneur) who runs a business which generates his or her primary source of income by delivering goods or services. This producer uses specific means of production to generate a stream of operating income. ${ }^{17}$ When producers receive untrue prices, they need to adjust their accounts. Which compensating strategies are available to them?

If prices are untrue, then the level of income is insufficient to cover the needs of producers. They are compelled either to fund this gap in another way or to reduce it. To cope with untrue prices, producers can alter inflows and outflows that appear on their income statements, or alter their assets and liabilities on their balance sheets. Our model identifies four distinct strategies depending on which type of account is involved:

1. Income: increase reliance on non-operating revenues;

2. Expenses: decrease or transfer expenses by avoiding costs;

3. Assets: deplete or sell (i.e. lose access to) assets;

4. Liabilities: increase debt, other liabilities, or negative net worth to unviable levels.

Our model starts with one independent variable (untrue price) which triggers changes in four other intermediary variables (changes in the four accounts listed above). In turn, these intermediary variables activate the dependent variable (unsustainability).

Figure 5 on the next page represents the four compensating strategies that we just enounced. An untrue price or the falsification of prices corresponds to the red arrow pointing down in the figure. Each compensating strategy is represented by an arrow and a number. The direction of the arrow represents what happens in accounting

\footnotetext{
${ }^{17}$ In the case of an individual producer, we need to look at two sets of accounts: the first describes the finances of his or her business and the second the household finances that the producer must also maintain and upkeep. While one can separate personal finances and activities from those of one's as a business, these distinct accounts must be analysed in tandem.
} 
terms. If the arrow points upward, it is an increase in the account. A downward-pointing arrow represents a decrease in the account. A horizontal arrow represents a transfer between accounts. We use the same numbering of strategies as on the above list (number 1 stands for income, 2 for expenses, 3 for assets, and 4 for liabilities). The red arrow symbolises the falsification of a price that may lead to any combination of the four black arrows because of the need to balance the accounts. This figure is a heuristic device that helps us to understand more clearly how the accounts of different actors are linked and to figure out how businesses or individuals receiving untrue prices close or compensate for the gap by changing their accounts.

Figure 5: Representation of the four compensating strategies on a set of accounts

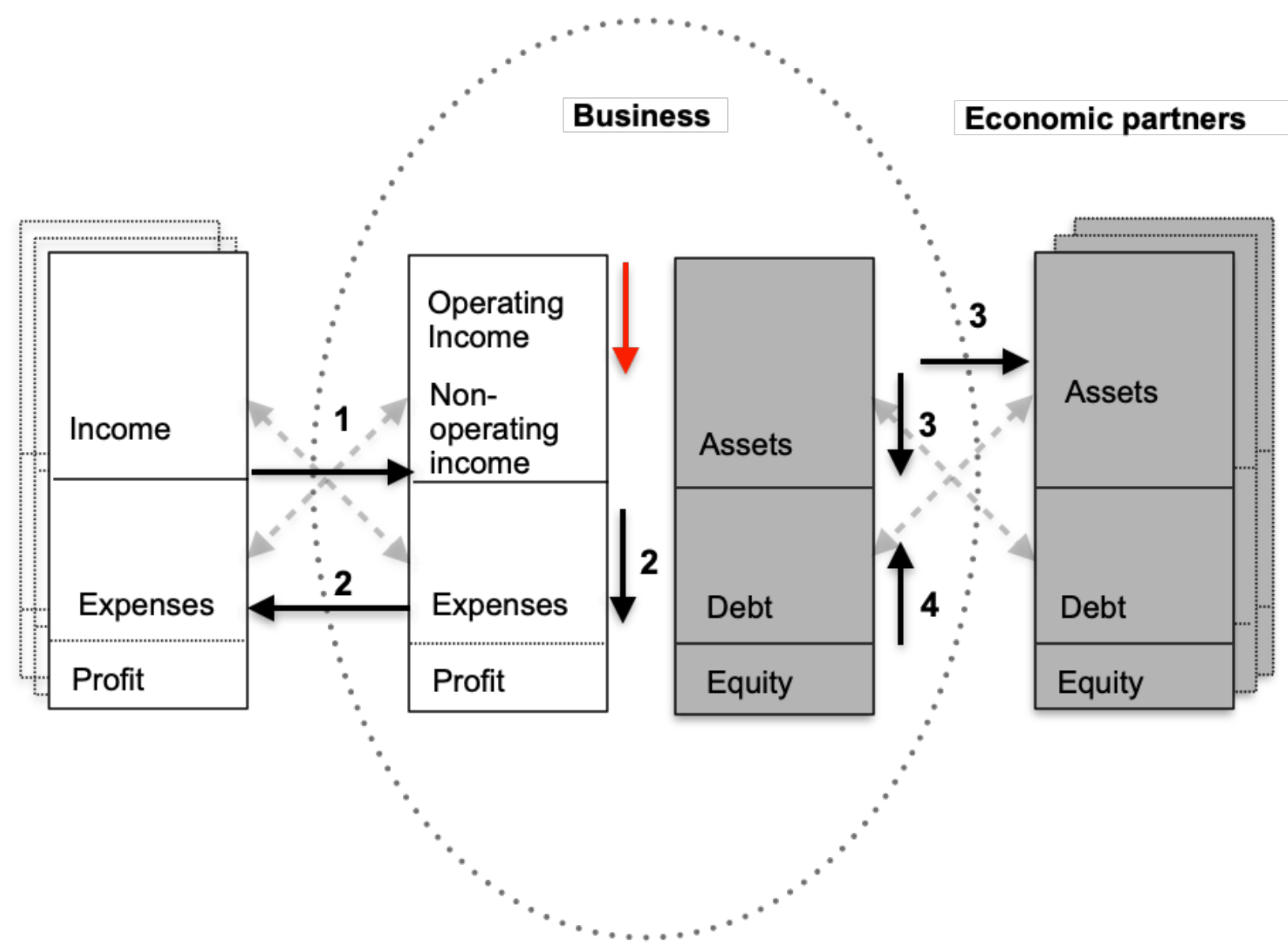

Source: Author, based on previous figures.

Arguably, it is hard in today's world to know if the prices we pay are untrue. How would we know? If we do not have access to data to directly tell if the price is untrue, we can check instead if symptoms indicate that untrue prices are likely to be present. Reliance on non-operating income, cost avoidance, overuse or sale of assets, and rise 
in debt and other liabilities are signs indicating that prices are untrue. The more producers depend on these strategies, the more prices are likely to be untrue.

A producer may choose a specific combination of strategies, depending on how much untrue the price is and his or her peculiar balance sheet. Producers are differently endowed with means of production and operate in different contexts. The specific options that are available to them depend on their access to land, labour, and capital, or opportunities and constraints in terms of markets, credit, or input. We can also differentiate strategies based on whether producers mobilise internal or external resources. Untrue prices may lead to even worse sustainability outcomes if it is financially constrained businesses or individuals who receive them. Such producers do not have assets (such as cash reserves or other liquid assets that can readily be converted into cash) to buffer themselves against untrue prices and may be more impacted than well-capitalized producers.

We have now developed a causal mechanism which is constituted of an initial condition that triggers this mechanism and entities and parts that transmit causal forces, resulting in unsustainability. Our entities are businesses who have interactions with other entities acting as consumers, suppliers, workers, investors, or governments, for instance. Businesses can perform four types of activities which are triggered by untrue prices. They can either decrease or increase four accounts: income, expenses, assets, or liabilities. These activities result in changes in the financial flow and net worth of these businesses and the economic agents they are linked to.

Figure 6 demonstrates another representation of the purported causal mechanism. It clarifies how the different components link the trigger and the outcome. It also spells out the observable evidence anticipated for each component in order to operationalise and test the mechanism.

The causal mechanism or model that we have theorised describes what it is that links each of the parts (the four strategies) together: the need to compensate for untrue prices or lack of income. There is productive continuity between the independent variable or initial trigger (untrue prices) and the dependent variable or outcome (unsustainability). We have yet to describe exactly which specific activities would businesses undertake if they adopted any of these four strategies and how and why such activities would be unsustainable. Specifying an uninterrupted chain of causes 
and effects between untrue prices and unsustainability is our goal in Sections 2.4 to 2.8. Once we have clarified how untrue prices can generate unsustainability through each of the four parts of the mechanism, we will have fleshed out a more theoretically complete model. We will also know more clearly what empirical evidence we should find if the mechanism exists. We will have operationalised the model, by linking the theory to the empirical world. This operationalisation will allow us to test it, to verify its practical authenticity. The logic behind the approach to testing the model is explained in Section 2.9.

Figure 6: Representation of the causal mechanism and its four parts

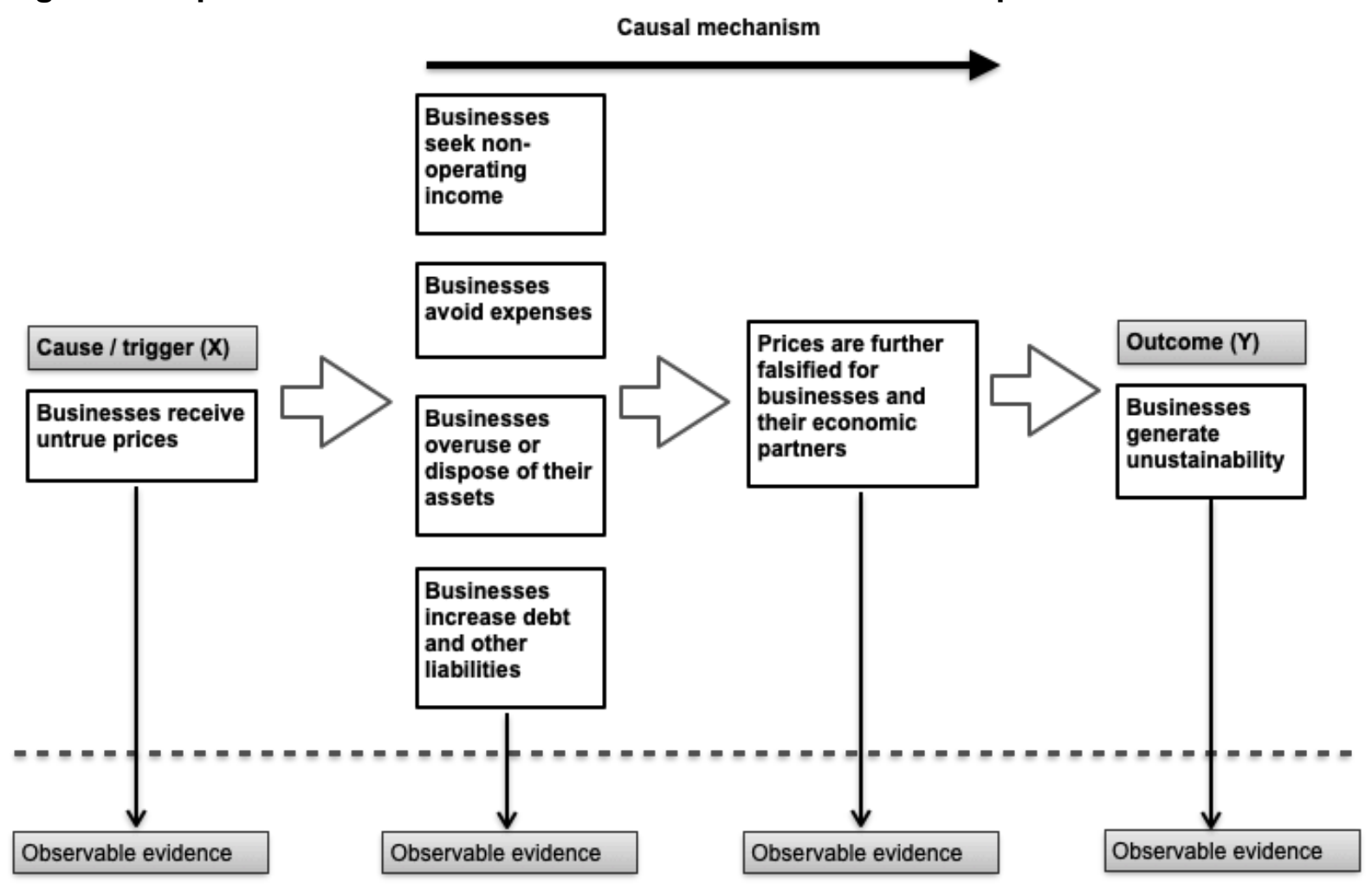

Source: Author.

Before we get into model testing, we first need to fledge out each of the four components of the model. In the next four sections, we will investigate each component or part in more detail, discuss what could happen from the points of view of accounting and economics, and infer what the sustainability outcomes could be. We illustrate our analysis using the case of agricultural producers because they will be the subjects of the case studies. The examples that we use help to operationalize and therefore test the model. This focus of operationalization does not mean that the model is reduced 
to farmers. In theory, the model applies to any economic entity which maintains a set of accounts, given the universality of the accounting identities. Any type of business can be included in the scope of the model. Giving concrete examples of what would happen in practice for other types of actors is a significant task that goes beyond the remit of this thesis.

\subsection{Income: reliance on non-operating income}

If prices are untrue, producers may supplement their income with or shift to other sources of operating or non-operating revenues.

i. Intensification or increase in productivity. Producers could raise productivity to compensate for the lack of income. We suppose that when prices are untrue, financially constrained producers are less likely to make capital investments because they lack capital. Furthermore, untrue prices limit their ability to pay for the operating and capital expenditures that are often needed to intensify production. They are more likely to raise productivity through strategies that obviate capital and operational costs. For example, they can intensify household labour to increase production without raising labour costs, as discussed in Section 2.5 .

ii. Diversification. Producers can engage in other on- and off-farm activities to diversify their revenues (other crops, jobs, or earners). As just discussed, we expect financially constrained producers to engage in activities that obviate rather than intensify capital. Examples could be off-farm wage work or cultivating crops that need little capital. Wealthier producers are more apt to diversify into business activities that demand capital or involve more exposure to financial risks. At this stage, it is not clear whether the sustainability impact of diversification would, overall, be more positive than negative or vice versa.

iii. Capital gains. Producers may use capital gains to compensate for negative operational results. They could raise income through interest on loans or earn income from renting land or equipment. We suppose such income to be more 
difficult to generate for financially constrained producers than for wealthier ones. We discuss further capital gains in Section 2.6 on assets.

iv. Subsidies and remittances. Producers may rely on transfers of income or wealth from third parties. For example, they could receive remittances from kin, their close community, or government subsidies. We argue that this reliance on income transfers is unsustainable. Producers who receive any form of subsidies to compensate for untrue prices are not thereby made more profitable. Such transfers of income, voluntary or not, mask rather than solve the profitability issue, a key requirement of sustainability.

\subsection{Expenses: cost avoidance}

When an event falsifies prices, producers have insufficient income relative to their needs. One straightforward response is to reduce the gap and to keep costs to a minimum. Producers incur four types of costs: expenses related to one of the three means of production - land, labour, or capital - and operating or consumption expenses that we may attribute either to the business or the household. In this section, we discuss how a producer can reduce these four types of expenses.

Expenditures related to land, labour, and capital cover the use, maintenance, and renewal of the means of production. If producers fail to reproduce their means of production through appropriate remuneration of workers, stewardship of natural endowments, and sufficient depreciation and amortisation, their productivity goes down. Producers enter a vicious circle where untrue prices induce a decline in productivity, which further falsifies prices.

i. Land. Producers can reduce the expenses needed to maintain the environment. They can reduce the input or labour expenses required to maintain land fertility or water quality, for instance. If producers reduce these expenses, they deplete their own and others' environmental assets. If they do not incur the costs and instead off-load them onto third parties, they generate externalities for the community. Producers may also adopt cheaper types of input or practices that may do more damage to or fail to replenish the environment and the productive value of land. By 
avoiding costs, producers may fail to maintain the landscape and increase pressure on natural resources. The impact could range from vegetation loss and degradation of fragilized areas, to the pollution or lowering of the quality of soil, water, and air.

ii. Labour. Producers can decrease labour costs. They may stop hiring workers, pay lower wages, provide more precarious working conditions (such as unhygienic housing or lack of adequate equipment), avoid social security or pension payments, or increase the duration of shifts for the same wage. Producers could also increase their reliance on unpaid household labour by involving men, women, and children more intensively and for more time in production. The consequences may be a worsening of the household's livelihood, including for example less expenses for, less time to attend to, and reduced attendance to the household's needs, for instance in terms of health, education, and sanitary or hygienic conditions.

iii. Capital. Producers can reduce capital expenditures. They may fail to depreciate their assets correctly. Depreciation accounts for the costs of using and maintaining the business's assets. Cutting these expenses reduces the productive value of assets, such as buildings, equipment, or land. Productivity drops as a consequence. Producers may also stop repaying the principal or interest of their debts (see Section 2.7).

iv. Operating and household costs. If we consider household producers, their needs include both operational expenses as a business and consumption expenses as a household. Depending on how much income is lacking for needs, the operational context and the current needs as a business and as a household, producers could decide to forego many types of expenses. They could stop purchasing input, services, or insurance that they need to produce efficiently. They may first forego household expenditures on durable goods before making more drastic cuts of expenses like basic goods and services, such as food, education, or medication. Producers can also pool the purchase of input, the sales of output, or share resources to lower relative costs. They could, for example, share the rent of a house or the costs of a tractor with others. Producers may also avoid and evade tax payments. Tax evasion hinders the government's ability to provide the infrastructure that producers need, such as roads, electricity, access to water, or sanitation. 
In the next two sections, we discuss the impacts of untrue prices on the two accounts which combine in the balance sheet: assets and liabilities.

\subsection{Assets: depletion and disposal of productive assets}

Producers need access to means of production in optimal quantity and quality to deliver sustainable goods and services at viable prices to consumers. Producers record their productive assets on their balance sheets. They can compensate for untrue prices by using their assets in at least four ways:

i. Depletion of current assets. When prices are untrue, producers may expend their current assets to compensate for the lack of income. At the end of an accounting period, businesses close their entries. They transfer the net profit or loss that they recorded onto their own capital or equity account. If businesses incur a net loss, they have to decrease their own capital account and their cash reserves. When cash reserves diminish, producers have less working capital available to finance the intermediate input needed for production. The capacity of producers to produce and create income is reduced.

ii. Depletion of fixed assets. Fixed assets, such as buildings and equipment, do not last forever. They depreciate from the moment producers buy them. To depreciate a tangible asset means to spread its costs over its expected useful life. (To amortise is to do the same thing for an intangible asset, such as patents or copyrights.) If prices are untrue, producers may fail to depreciate their assets, that is, to compensate for their 'ageing'. The reduction in the value of productive assets results in drops in output and productivity, which further falsifies prices. Producers may also overuse their assets. They can reduce their value to stretch production and reduce costs. For example, they can deplete soil fertility or degrade farm equipment by overusing them. Producers may also not be able to wait for natural resources to regenerate therefore increasing exploitation to levels that do not allow for their renewal. Again, this lack of renewal causes producers to be less productive and hinders future income. 
iii. Sale of assets. When producers have used all their cash reserves, they may sell other current assets, such as inventories (such as livestock or trees). When producers have used or sold all current assets, they can sell or mortgage productive assets such as land, buildings, or tools and machines. The loss of assets can cause environmental or social harm. For example, the sale of timber stock could result in deforestation. Moreover, the sale of assets to other producers worsens the social distribution of assets and income. The sale of assets jeopardises the producer's livelihood, hinders future production, and further falsifies prices. When producers sell their assets, their productivity levels decrease and, consequently, their income declines. Prices must be even higher to be true for the same producer. Over time, the loss of productivity leads to an ever-widening gap between prices received and the true price threshold. Producers enter a spiral of destitution.

iv. Capital gains from speculation. Producers can earn income by renting or selling their productive assets to other businesses. If prices are untrue, they may find capital gains from speculation more attractive than the returns on investment from their own production. Producers can earn capital gains because they hold assets whose values have considerably increased. These gains arise either through the rent, lease, or sale of these speculated assets. The indirect effect of renting or selling at speculated prices is to raise the costs of the means of production for other producers. This diversion of resources damages the productive economy. As production costs increase, prices are further falsified. We do not claim that capital gains and speculation only arise when businesses respond to untrue prices. Indeed, businesses receiving true prices can also seek this type of capital gain, and speculation can be a cause rather than a consequence of untrue prices, as we will discuss in this thesis. Nonetheless, if businesses lack income, they have an economic incentive to seek such gains. 


\subsection{Liabilities: rise in debt and other liabilities}

Businesses can respond to untrue prices by increasing their levels of indebtedness. If they lack income, producers may avoid payments to their economic partners. For example, accounts payable build up by not paying suppliers. In this case, current debt levels increase for producers and their suppliers lose income. Producers can also finance operational and household expenses with debt. When they borrow to operate or consume, debt servicing increases. This debt covers needs in the short run, but also raises current and future capital expenditures. Impacts may include financial stress, loss of disposable income, a riskier financial position, and greater vulnerability to shocks.

Minsky (2008) notes that producers need loans to finance the production of goods and services, service their debt, or make long-term investments. He differentiates businesses depending on how they use credit. 'Hedge borrowers' are producers who can pay both debt interest and principal with their current operating cash flow and returns on investment. Businesses are 'speculative borrowers' if they only use their cash inflow to service the debt. They only pay the interest but regularly roll over the principal until some future date, expecting that income flow will rise by then. 'Ponzi'18 borrowers' are businesses who can pay neither interest nor principal with their income flows. Their levels of outstanding debt grow. Minsky considers that if most of the debt is in the hands of hedge borrowers, the economy is robust. If speculative and Ponzi borrowers dominate, the economy is fragile.

Producers are less able to service debt when prices are untrue and may seek to reschedule current debt payments and contract new loans. They can also adopt an austerity policy to service debt by reducing spending and investments. Austerity leads to the further intensification of the dynamics of cost avoidance and depletion of assets, described in Sections 2.5 and 2.6. Failure to repay debt places producers in desperate situations. Over time, they may experience increasing difficulties in making debt payments. If producers are unable to pay debt, they may take out further loans to pay off already existing loans. If the proportion of revenues used to pay debt increases, they also have fewer resources available for hiring or to (re)invest in production.

\footnotetext{
${ }^{18}$ Charles Ponzi was notorious for a pyramid scheme that he set up in the 1920s. In essence, the idea is that a Ponzi borrower pays debt by incurring new ones. A Ponzi scheme signifies that the interests received by current investors are paid by attracting new investors, not by returns on investments made.
} 
In other words, untrue prices turn these producers into speculative or Ponzi borrowers, according to Minsky's classification. To avoid adding interest fees to their debt, they may sell their productive assets such as land or their houses as a last resource and become landless or homeless. If untrue prices persist, the risk of bankruptcy surges.

\subsection{Summary of expected sustainability outcomes of the causal model}

Accounting allows us to understand the transmission of causal forces by tracking how untrue prices force producers to adjust their temporal and permanent accounts.

In this chapter, we have disaggregated a model into four parts. All these parts contribute, in one way or another, to unsustainable outcomes. However, none of the four strategies exists independently from the others. The four different parts of the mechanism are in constant interaction. Dynamic feedback loops between activities end up reinforcing the overall mechanism. For example, the rise in the need to service debt may further increase cost avoidance and the need to resort to, say, child labour.

The context (scope of conditions) in which the mechanism is expected to operate is not fully determined. In particular, we are not able to define when the outcome $Y$ would not occur even when prices are untrue. Other causal mechanisms (cultural, social, environmental, or technological for example) could cancel out the one that this study focuses on.

At this point, we need to specify what types of evidence we should expect to find if the model exists and leaves empirical traces in terms of sustainability. Depending on the strategies that producers adopt, we expect adverse impacts on one or more of the sustainability indicators that we identified in Chapter 1.

Table 7 on the next page summarises the sustainability impacts that we expect for each of the strategies that producers can adopt. It shows that we expect a worsening of the sustainability indicators we introduced in Table 1, Section 1.2. The

arrow $\downarrow$ shows that values for an indicator worsen due to one of the four expected strategies. The absence of the symbol indicates that we do not expect any specific 
impact. There is not a single arrow going up because we could not find any positive impact of untrue prices that we could be conclusive about.

The model allowed us to make specific, strong, empirical predictions of evidence that we would find in case studies if it works as predicted, that is, if it transmits causal forces from untrue prices to unsustainable outcomes. We draw these arrows for reasons that are described and detailed from Section 2.3 to 2.7. The main point of Table 7 is to show how systemic are the economic, social, and environmental consequences of untrue prices. True pricing is therefore a crucial element of any theory that purports to explain sustainability and of any policy that intends to deliver it. 
Table 7: Expected sustainability outcomes of the strategies

\begin{tabular}{lcc}
$\begin{array}{l}\text { Optimal } \\
\text { profitability, } \\
\text { income or } \\
\text { productivity }\end{array}$ & $\begin{array}{c}\text { Attendance } \\
\text { to legitimate } \\
\text { needs }\end{array}$ & $\begin{array}{c}\text { Labour conditions } \\
\text { and respect of } \\
\text { human and } \\
\text { community rights }\end{array}$ \\
\hline & & communits
\end{tabular}
Attendance
needs
community rights

$\begin{array}{cc}\begin{array}{c}\text { Distribution of } \\ \text { private or } \\ \text { communal }\end{array} & \begin{array}{c}\text { Healthy } \\ \text { debt } \\ \text { levels }\end{array}\end{array}$

assets
Land use

changes

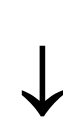

$\downarrow$

$\downarrow$

assets

4. Increase of

liabilities
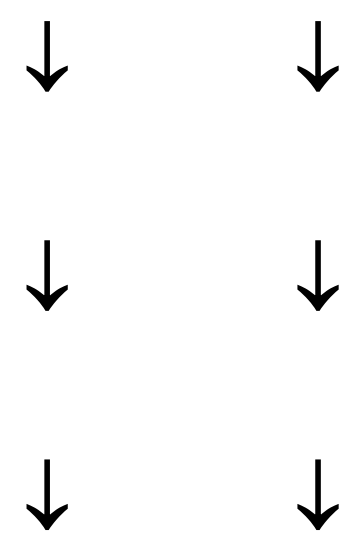

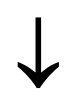

$\downarrow$
Stock,

condition

of natural

resources
Pollution

levels

\section{Source: Author.}




\subsection{Testing the model with case studies}

This section discusses how we will test the model. This chapter specified the process of causation that leads from $X$ to $Y$. Sections 2.4 to 2.8 operationalised the causal mechanism because we itemised what observable evidence we should expect if each of its four components is operative in the real world. Now that we have theorised and operationalised the model, we can test its external validity. Sugden highlights the importance of convincingly applying theories, models, or causal mechanisms to realworld cases:

[l]f the theorist is offering a tool that is intended to be used in explaining real-world phenomena, a convincing demonstration must display the tool explaining something. ... [and] . . . has to produce a real explanation of the phenomenon. . . . I have suggested that one should be sceptical whenever a theorist claims to have discovered a significant social mechanism, but is unable to give a concrete example of how that mechanism can be part of an explanation of some real-world phenomenon; and I stand by that. (SUGDEN, 2009, p. 25)

To verify the empirical existence of the causal mechanism, we would need to show that the it has been operative in singular and relevant cases. The logical starting point to test our purported causal mechanism is to find typical cases where everything indicates that it should be operative. The scores for both $\mathrm{X}$ and $\mathrm{Y}$ must be significantly higher than a qualitative threshold to ensure that the mechanism is most likely to be present. If observations indicate that the mechanism does not operate in cases where $X$ is high, we have strong reasons to reject the causal mechanism. If we identify a case where $X$ is high (prices are significantly untrue), then if the causal mechanism actually exists it should clearly operate under these circumstances and we should find strong empirical manifestations of its workings. Why would the causal mechanism exist if it is not even operative in the most-likely cases?

We also need to choose cases where both $X$ and $Y$ are present. Choosing cases where $\mathrm{X}, \mathrm{Y}$, or both are absent would not teach us anything about what happens when the mechanism is present or help us answer the hypothesis. We also need to choose cases where the correlation $\mathrm{X}: \mathrm{Y}$ is high enough, but we are uncertain about causality.

This thesis tests the model by performing two complementary case studies. The first case study discusses the responses of coffee farmers and their outcomes in terms of sustainability during the price falsification that occurred throughout the 1999-2003 
coffee crisis. This study answers the question: "can we find evidence confirming that the causal mechanism and its parts were operative in this case?". The second case study focuses on farmers on deforestation fronts of the Brazilian Amazon. This study both responds to the first question and answers another one: "do changes in the intensity of untrue prices (X) generate changes in the pattern or intensity of unsustainability (Y) ?". To create exhaustive and unbiased datasets, we collected data through a systematic review in the first case, and we used census data in this second case. The coffee crisis is a global historical case where rich empirical material is available through a large number of publications. The Amazon case is a more recent case, where we have access to census data which is made available in a way that allows to check if the causal mechanism operates more or less intensively or differently when $X$ varies. The combined analysis of these two independent cases minimises the risk of misattributing causal relationships, and recognises the complexity and variety of situations in which the causal mechanism could operate, since the interplay of a wide range of independent variables can result in untrue prices, and businesses could respond to untrue prices with many different combinations of strategies.

To analyse the two cases, we employ two methods of analysis: process tracing (within-case) techniques and comparative (cross-case) studies. The within-case analyses allow us to check whether enough evidence links $X$ to $Y$ and whether its parts function and leave empirical evidence as predicted within specific cases. The comparative studies across cases let us infer how generally valid the causal mechanism is. To control for other causes, we will not set a control group where we analyse cases where these other triggers are not present. What these other causes should be is arguably not clear, and the research design would probably be unworkable or dubious. We will rather control for other causes by analysing whether there exists unique evidence of the workings of the mechanism within and across cases by using process tracing techniques and comparative studies.

What we need to find in each case is evidence of the empirical events that each part of the mechanism predicts, of the interactions among these parts, and of the causal mechanism as a whole. We will analyse four types of evidence $(\mathrm{BEACH}$; PEDERSEN, 2013, pp. 99-100):

i. Pattern evidence: when prices are untrue, patterns would appear, for example, in the form of a much higher number of publications documenting unsustainable 
outcomes than sustainable ones. If a broad set of observations confirms its existence and no observations refute it, the causal mechanism likely operated.

ii. Sequence evidence: we can compare the temporal and spatial chronology of real events with the model's predictions. We must identify a precise sequence where: i) an intervention falsifies prices, ii) then producers respond with one or more of the expected strategies, and then iii) unsustainable outcomes occur. If the timing of events shows a sequence that matches our expectations, we have sequence evidence. If the succession of events is not right, then the evidence refutes the model.

iii. Account evidence. Accounts of how producers responded to price falsification may include interviews with producers, surveys, or census data. This data should confirm or refute that producers adopted the four expected strategies as a response to untrue prices, with the expected sustainability outcomes.

iv. Trace evidence. This kind of evidence proves that the mechanism or its parts exist because of its mere presence. For example, the increase in hunger in a coffee-growing household after the crisis is a strong proof that households avoided costs.

Testing the model through case studies entails evaluating whether the explanations that it provides are not only backed by observations but are also logical; they must make sense. Are they good or acceptable explanations of how the phenomenon of unsustainability was generated in the studied cases?

If the explanations are solid and the empirical expectations are confirmed in our two cases, the model will be generalisable to some extent. We do not claim that we can reach statistical generalizability, that is, that these two case studies provide sufficient 'samples' which allow us to statistically test the model. Instead, we hope to generalise the model from an analytical point of view. We will analyse if these two case studies show that the same causal mechanism operated under distinctive contingent conditions, and check if the same processes were at work in clearly different populations and contexts. Using two cases also allows to explore if the causal mechanism changes depending on the context. Does the model display empirical heterogeneity, expressing itself differently from one case to another? 
In short, the causal model expects that we should find specific evidence that producers relied on non-operational income, avoided costs, depleted or sold their assets, or increased their liabilities in response to untrue prices, and that these responses caused more unsustainability. Evidence in the two cases that we will study may:

i. align with the predicted results and confirm the validity and reliability of the model;

ii. be discrepant from or even opposed to our theoretical predictions, in which case we will have to reject the external validity of the model or;

iii. be too vague to interpret these findings with a sufficient level of confidence.

\subsection{Summing up}

This chapter shaped a theoretical causal model explaining how untrue prices hinder sustainability. Time precedence is not enough to prove causation. Causality is different from the idea of an event that precedes or associates with another event. ${ }^{19}$ To say that untrue prices cause unsustainability, we need to identify a complete, unbroken chain that links together the initial trigger, intermediate chains of causes and effects, and final outcomes. Our model is based on a concrete, accounting-based, understanding of causality. All financial transactions are credit/debit operations, and businesses are subject to the logic of accounting. They respond to untrue prices in ways that are conditioned by the need to balance credits and debits for the two basic accounting identities. The model starts with a trigger condition - untrue prices - under which producers adopt four strategies linked to the four main accounts. A theoretical exploration of these strategies indicates that they produce dynamics that are inherently unsustainable. Depending on their situation and operational context, businesses can build different combinations of these strategies. We also identified a wide range of specific tactics that businesses can use to execute each of these strategies, as

${ }^{19}$ Using a classic example, roosters crow before sunrise, but it would be irrational to say that rooster crows make the sun rise. 
presented in Sections 2.4 to 2.7. We do not claim that the list of tactics that we explored is exhaustive.

The main contribution of this theoretical model is that it sustains the claim that true prices are a sine qua non or necessary condition of sustainability. Conventional (neoclassical) economics contends that the lowest market prices are the most beneficial to consumers, shareholders, and society as a whole. The causal model shows that this affirmation does not hold when market prices are untrue. In this case, the market cannot be considered efficient because businesses are bound to act unsustainably. Their behaviour is born out of the need to compensate for untrue prices, not the wish to maximise profits and shareholder value. Sustainability may begin with a more widespread recognition that there is a problem with the economic mantra that says that the lowest price is the most social price, which underlies modern pricing institutions and conventions. Most of us are caught within an economic worldview which makes the critical error of not observing and understanding how prices affect businesses, people and nature in their full scale. Understanding and correcting this mistake is critical to stopping the perpetuation of unsustainability. The causal model also shows that sustainability would not arise even if we managed to price and internalise externalities, as argued by externality theorists. Many of the impacts that the model exposes are not externalities and could not be, by their very nature, apprehended and managed by this concept.

As Steiner puts it, true price is at first only an abstract concept. This concept only becomes a concrete and useful principle when we devise an instrument of measurement that allows us to relate with it. Chapter 2 translated the concept of true price into financial and accounting language. Accounting is the instrument that measures prices (the thermometer), and true price is the reference point indicating that prices cross a fundamental qualitative threshold (the zero-degree mark). The distance of prices from true prices and their variations, slow or fast, indicate how healthy the economic situation is. Just as temperatures below zero indicate frost, untrue prices indicate unsustainability. Accounting allows us to monitor if prices are true or untrue, to perceive the conditions that underlie prices, to modify these conditions, and to observe the effects of prices on income statements and balance sheets. In colloquial terms, effectivity refers to 'doing the right thing' and efficiency to 'doing things right'. True price allows us to be effective towards sustainability, and we can employ 
accounting to foster true prices and sustainability efficiently. The set-theoretical pairs of concepts of true/untrue price and truthening/falsification of prices are useful because they are sharply bounded. They allow us to differentiate unequivocally unsustainable from sustainable economic activities. The model has significant methodological ramifications because of its grounding in accounting. The conclusions that it draws are hard to disprove from a theoretical point of view. If one is to refute that untrue prices negatively affect the balance sheets and the income and cash flow statements of businesses, then one has to reject the universal logic on which double-entry bookkeeping is based and has been practiced for centuries.

The model can apply to many different types of cases independently of the specific details and captures a limited number of central features of high relevance to the causal explanation of the phenomenon. If the model has any practical validity, then these features should be able to explain unsustainable development in the real world. In the next two chapters, we verify if this is so by exploring the cases of farmers during the 1999-2003 global coffee crisis and on deforestation fronts of the Brazilian Amazon. 


\section{Chapter 3: Case study of the 1999-2003 global coffee crisis}

Chapter 3 is the first case study to test the causal model that we developed in Chapter 2. We first show why the 1999-2003 coffee crisis is a significant, global, case of price falsification. If this is so, empirical evidence during the coffee crisis should be consistent with the producer responses and sustainability outcomes that the model expects, otherwise we should discard the model. After explaining the systematic review methods that we applied to select the material for this case study, we proceed with the test itself. We discuss if evidence shows that each of the four parts of the model was operative during the crisis. We then draw conclusions about the manifestation of the model during the coffee crisis. Does the case of the coffee crisis confirm the theoretical arguments made in the previous chapter and help us refine the causal model?

\subsection{The 1993-2003 global coffee crisis}

The 1999-2003 global coffee crisis is one of the most significant price-falsifying events that simultaneously affected large numbers of producers in recent history. With the end of the International Coffee Agreement's (ICA) system of quotas in 1989 when the USA did not support the renegotiation process, international prices of raw 'green' coffee became deregulated. Producing countries abandoned export quotas and retention schemes, and public agencies transferred the control of stocks to private trading companies. 
The breakdown of the ICA led to a collapse in prices in 1989. The coffee market entered a phase of booms and busts reflecting the rise in production (see Figure 7, p. 72) and the release of surplus stocks on the global markets. The 1989 collapse in prices was followed by years of relative scarcity resulting from the disorderly exit of many producers after the breakdown and adverse climatic conditions, which increased prices. Prices dropped again in 1999 and stayed low until 2003, mainly due to overproduction - especially in Brazil and Vietnam - in relation to demand (DAVIRON; PONTE, 2013).

The crisis resulted in five consecutive years of significantly low farm-gate prices for millions of producers around the world (BACON, 2008). The average international price was 134 USD cents per pound for the five years before 1999 (with a brief topping at 250 USD). They were almost halved (at 77 cents) for the five years after (DAVIRON; PONTE, 2013) and down to 41 USD cents per pound in 2002. With the collapse of the international market, farm-gate prices declined to levels not experienced for a century. Since producers receive around $55 \%$ of international prices, farm-gate prices therefore went down to around 20 USD cents per pound. The minimum threshold for covering minimal production costs was at the very least 100 USD cents per pound and more likely between 120 and 150 for most farmers in Latin America (RENARD, 2010). We can indubitably say that the coffee crisis falsified prices, since incomes dropped to levels that were five to seven times lower than those needed to cover the bare minimum production costs for most producers.

Figure 7 (p. 72) shows the prices received by coffee growers in eleven major producing countries for the period running from 1990 to 2017, and Figure 8 (p. 73) averages these prices. Figure 9 (p. 74) provides more contextual information for the same period. It shows the area harvested (ha), the total production (tonnes), and the yields (tonnes/ha) in these countries. All these elements are inter-related and help to understand important aspects of the coffee crisis. Figure 9 shows how production increased rapidly starting in 1995. These years of surplus production and accumulation of coffee stocks played a role in triggering the crisis in 1999. The production chart also shows clearly that Brazil and Vietnam continued to increase production quickly during the whole period when prices were significantly down, from 1999 to 2005 in particular. Overproduction had an important influence in the unfolding of the crisis. The production chart shows two-year cycles in production, which are normal in coffee production, 
when a year of good harvest is generally followed by a year of weaker yields. The chart of the harvest area shows that producers did not reduce the harvested area during the crisis. We will discuss the different reasons they made this decision in the next sections. Finally, the chart on yields in Figure 9 shows how yields dropped sharply in key coffee-producing countries during the crisis. We will also discuss why this drop in yield was the result of untrue prices. The crisis was also heightened by shifts in the distribution of value across the supply chain. Roasters and retailers absorbed more and more of the added value and farm-gate prices reduced as a consequence (BACON, 2005; TALBOT, 2002).

The 1999-2003 coffee crisis synchronously affected 25 million producers who grew coffee across Asia, Latin America, and Africa (BACON, 2008). At that time, family farmers tending plots of less than 10 hectares represented $70 \%$ of the world's coffeegrowers. These smallholders tended over 11 million hectares of plantations (RICE, 2003). In Mexico, Guatemala, and Honduras, the majority of coffee farmers planted on less than 2 hectares (EAKIN et al. 2005). Smallholders represented up to $98 \%$ of coffee growers in India (AMBINAKUDIGE, 2009). Coffee production was the primary source of income for over 4 million producers in Mesoamerica (BATHFIELD et al., 2010).

Between 1998 and 2001, Nicaraguan coffee households decreased their income by $40 \%$, while non-coffee households suffered a $25 \%$ decrease in income (VAKIS, KRUGER; MASON, 2004). In Mexico, producers lost 65\% of their income from 1989 to 2002, and Colombian producers lost 32.6\% between 1985 and 2004 (RETTBERG, 2010). During the crisis, $60 \%$ of surveyed coffee growers in Mexico, Guatemala, or Costa Rica mentioned prices as their primary concern (EAKIN et al., 2013). Researchers usually consider that the height of the crisis occurred from 1999 to 2003. One can argue that for producers, the crisis continued until 2009, when the international market price finally covered the minimum production costs of most producers (see Figure 6).

How did coffee growers deal with the coffee crisis and fare with the sudden falsification of prices? In the rest of this chapter, we analyse if producers decreased or increased values for items on one or more of their two temporary accounts (income and expenses) and two permanent accounts (assets and liabilities). Before we do so, we present the methods we used. 
Figure 7: Nominal prices received by coffee growers before, during, and after the crisis in major producing countries (in cents USD per pound)

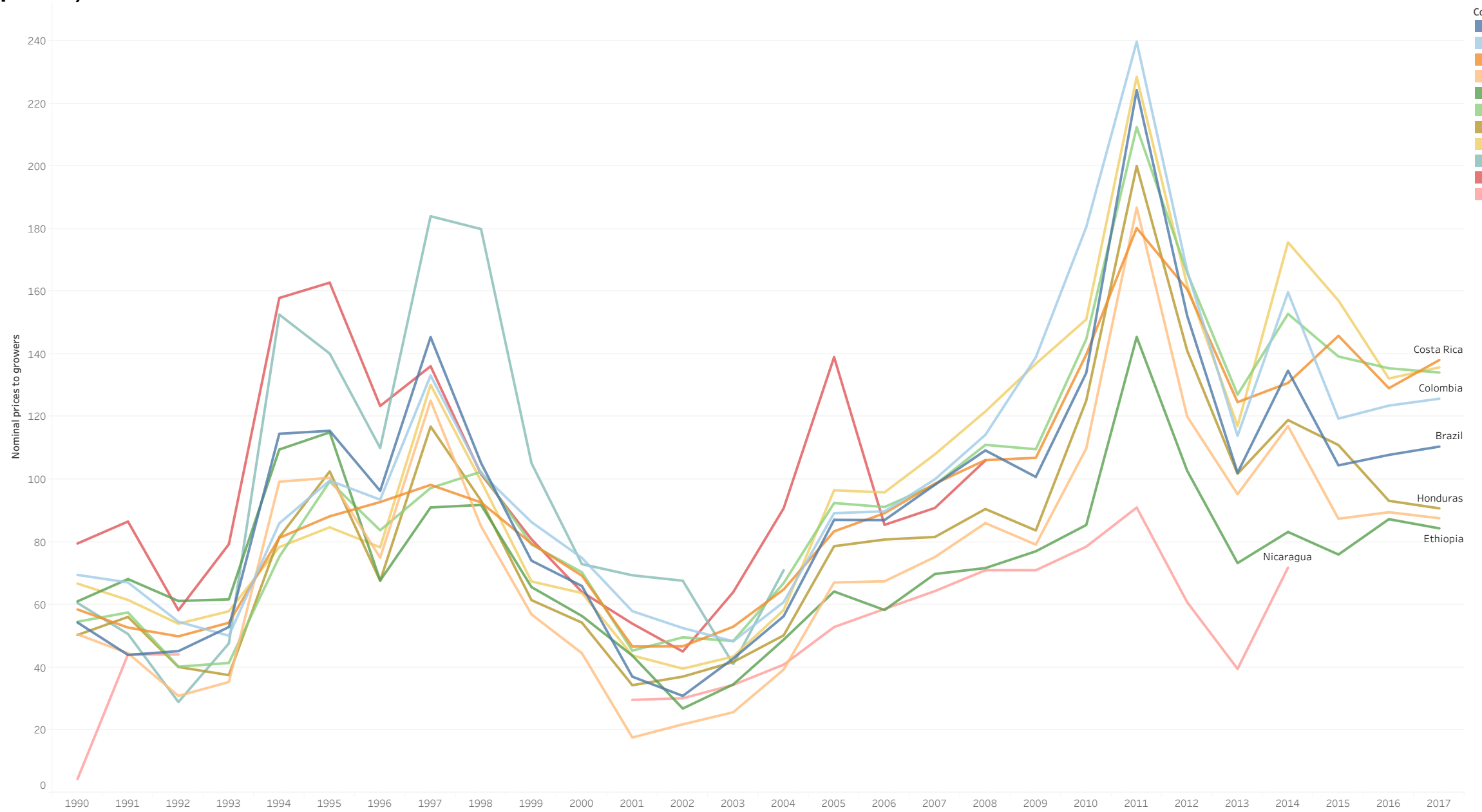

Source: Elaborated by the author with data from the International Coffee Organization (2019). 
Figure 8: Average nominal prices received by coffee growers before, during, and after the coffee crisis, combining prices in major producing countries (in cents USD per pound)

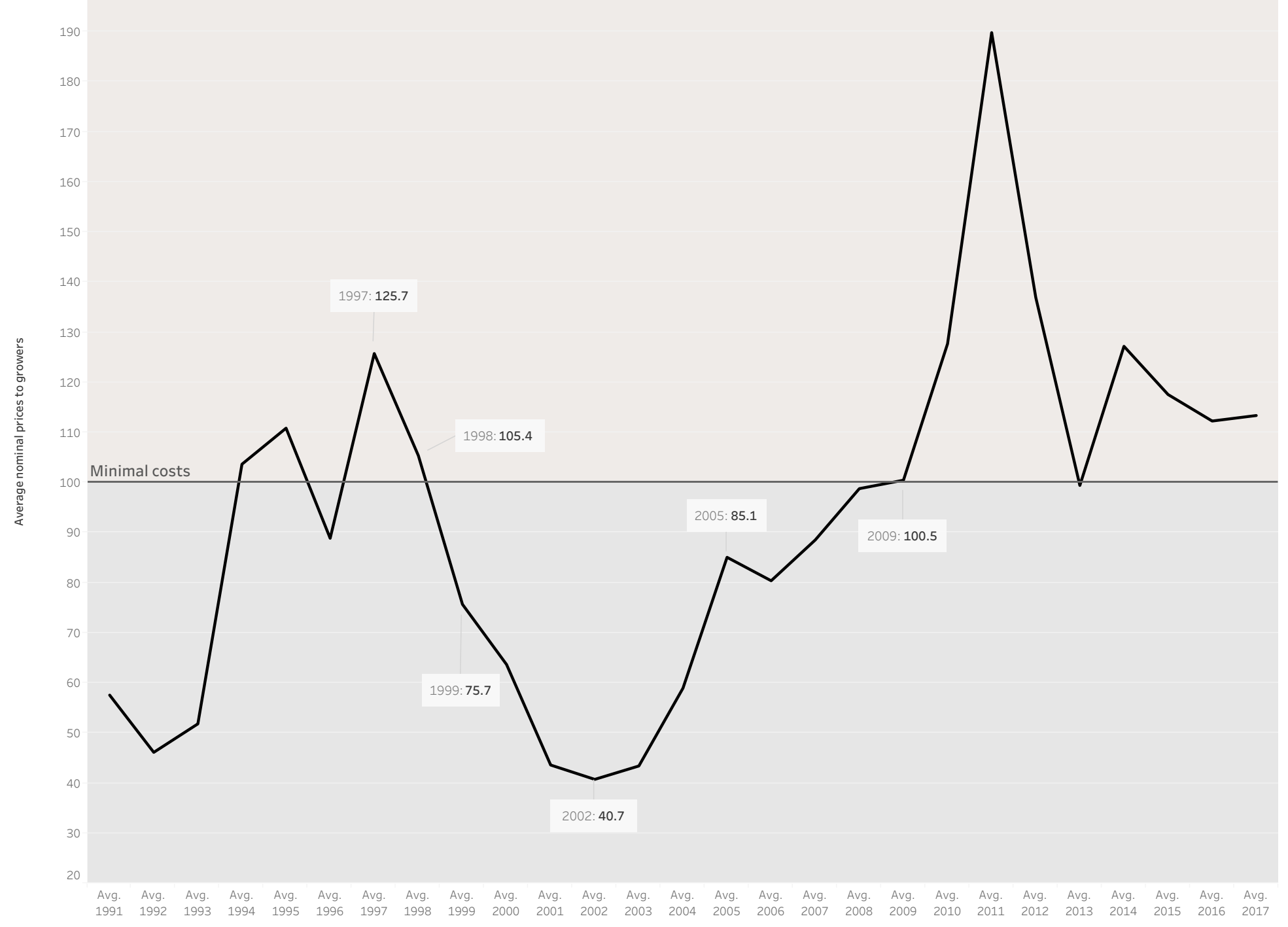

Source: Elaborated by the author with data from the International Coffee Organization (2019). 
Figure 9: Average nominal prices to coffee growers; total area harvested, production and yields for major producing countries
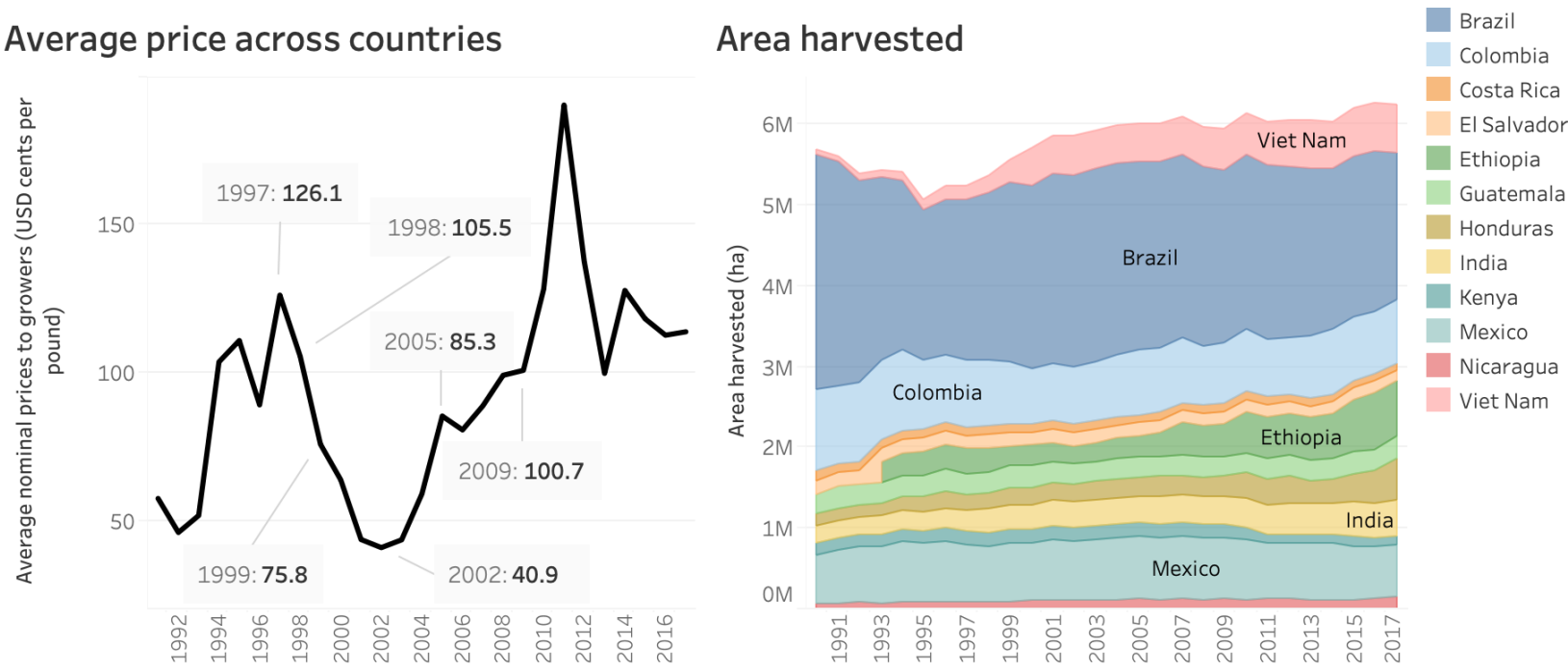

\section{Production}

Yields
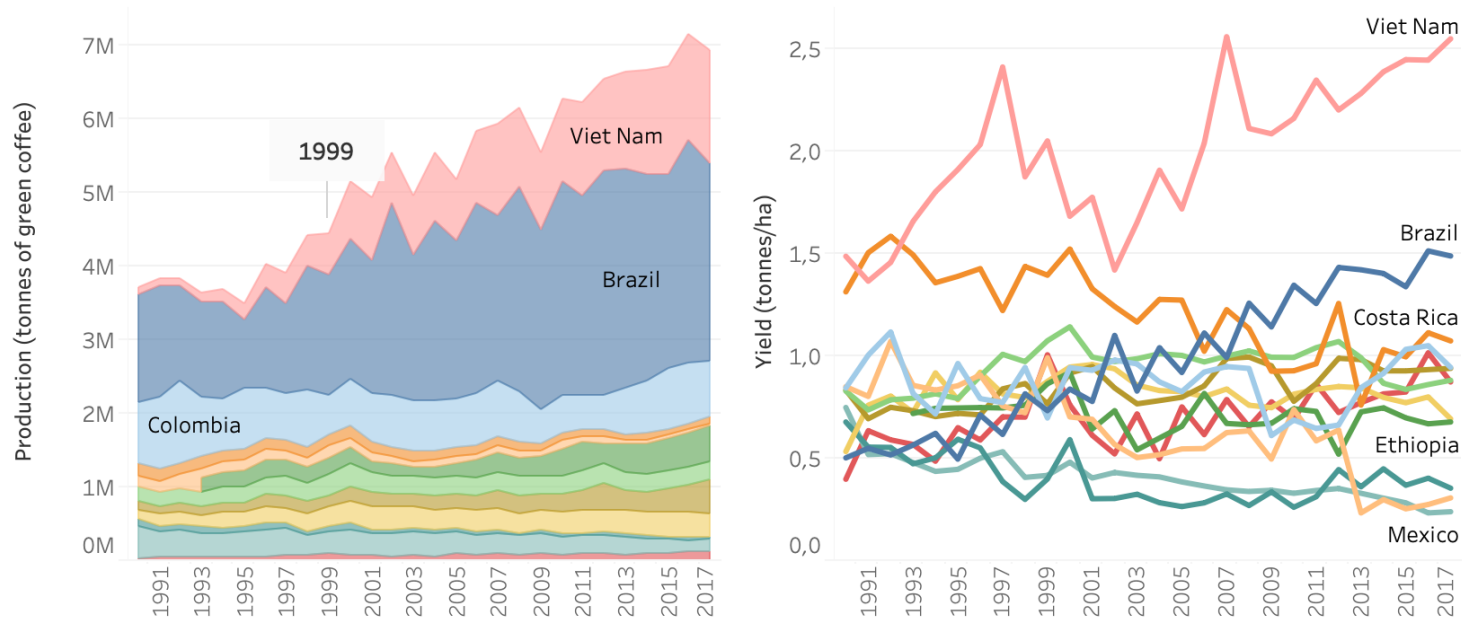

Source: Elaborated by the author with data from the International Coffee Organization (2019) and FAOSTAT (2019). 


\subsection{Material and methods}

Chapter 2 developed a plausible and testable model, but we still do not know if empirical evidence supports it. We, thus, need to perform a test that verifies or refutes if the theory exists in the real world. To have confidence in the model, we need to perform at least one serious test where it clearly explains a case or a number of bounded cases, and we can find empirical evidence of its existence and workings.

To test the model, it is key to choose and study these publications without bias. To do so, we used systematic review methods. We used the PICOS protocol to calibrate the review. PICOS stands for Participant population, Intervention, Comparisons, Outcomes, and Study Designs. This acronym refers to common standards that academics use to test the impacts of interventions, such as Cochrane reviews (HIGGINS; GREEN, 2008). Researchers use the PICOS procedure to choose relevant cases and to clarify the questions that the review seeks to answer. Our choice of case studies should allow us to answer two questions: Did the falsification of prices compel producers to adopt the predicted strategies? And did these strategies result in the expected outcomes (see Table 7)?

Our participant population is a set of coffee growers who were affected by the 1999-2003 coffee crisis, a market event that falsified prices. We select the 1999-2003 coffee crisis as the intervention. The crisis is a robust example of price falsification and a good test of the hypothesis because both $X$ and $Y$ were visibly present. Prices were significantly untrue for most of the coffee growers during the crisis.

The crisis affected large numbers of farmers, for a prolonged time. Its impacts were covered by a relatively large number of publications, which gives more evidence material to test the model. The coffee crisis also allows us to test the model in many different contexts, which will help us to assess if confounding or third variables could also explain $\mathrm{Y}$. In most countries, the farm-gate prices that coffee producers get depend mostly on the global coffee market. Researchers could not establish a control group of coffee-growers left unaffected by the crisis to make comparisons. Instead, we compare producers before and after the intervention.

We use systematic review methods to ensure the unbiased and exhaustive selection of relevant publications. For this systematic review, we filter potential case 
studies based on their designs following the protocol shown in Table 8 . We consider questions marked with an asterisk $\left({ }^{*}\right)$ to be eliminatory.

\section{Table 8: Questionnaire for selecting case studies}

1. Does the study cover causal links between the decrease of prices during the coffee crisis and sustainability impacts? (yes/no*)

2. Does the study include data that describe the strategies that producers adopted or activities they engaged in? (yes/no*)

3. Does the study include data on at least one of the two vectors of analysis of sustainability impacts: socio-economic and environmental (yes/no*)

4. Does the study use primary data? (yes/no)

5. Does the methodology use a randomised experimental or a quasi-experimental design (yes/no)

6. Did the study appear in a peer-reviewed publication? (yes/no)

Source: Author.

We searched for studies that covered the period of the coffee crisis: from 1999 to 2003. We searched on the SCOPUS and Web of Science electronic databases ${ }^{20}$ in January of 2019. Table 9 shows the search query in English, which we also performed in French and Portuguese. We found 241 results on SCOPUS and 267 on Web of Science. We analysed the titles and abstracts of all these results. We finally included 36 studies in our database. These studies included peer-reviewed papers, books, book chapters, conference papers, and one doctoral thesis.

\footnotetext{
${ }^{20}$ Source types included journals, book series, conference proceedings, and trade publications. We restricted the search on SCOPUS to the following subject areas: Agricultural and Biological Sciences; Forestry; Business, Management and Accounting; Decision Sciences; Economics, Econometrics and Finance; Environmental Science; Multidisciplinary; and Social Sciences. On Web of Science, we searched the Social Sciences Citation Index.
} 


\section{Table 9: Search query in English}

(coffee) AND (farmer* OR rural AND household OR rural AND producer*) AND (pric* AND income* OR economic* OR fall OR decrease OR crisis* shock* OR stress*) AND (compensating OR livelihood OR strateg* OR behavio* OR sustainab* OR dynamic* OR impact* OR evaluat* OR effect* OR environment* OR social OR impact* ${ }^{\star}$ AND (case* OR experiment ${ }^{\star}$ )

Source: Author.

\subsection{Analysis of reliance on non-operating income}

Cross-case analysis shows that few producers chose to intensify coffee production. Increasing production generates more labour and input costs, but a high-input, highoutput production strategy did not fit the operational reality of financially constrained farmers receiving untrue prices. In Mexico and Honduras, some producers expanded their production. Such farmers trusted that they would profit when the prices went up again. These producers had significant wealth or other ways to buffer the crisis that most of the farmers did not have (EAKIN et al., 2006; TUCKER, 2013; TUCKER et al., 2010). Tanzania is another exception. Half of the Tanzanian growers expanded their fields. They did so for three reasons. First, they converted corn fields into coffee because only coffee could cope with the low fertility of their soils. Second, they used the newly-formed plantations as collateral to take on loans. Third, they anticipated a price recovery (MHANDO; ITANI, 2007).

Farmers who tried to diversify on-farm activities encountered financial difficulties. They needed new income streams to substitute for the decrease in coffee prices. Many farmers already held debt before the crisis. Those farmers preferred first to pay their debt before investing in new sources of income. Farmers also often lacked the skills required to diversify production. The majority of the farmers planted both coffee and subsistence crops and responded to the crisis by planting more staple crops and expanding home gardens. They, thus, consumed own-produced foods and needed to spend less cash. Instead of converting coffee plantations, most producers used other agricultural, fallow, and forested lands to diversify production. They converted these lands to produce corn, beans, rice, cassava, and other staple crops in Mexico, Central America, India, or Vietnam (AMBINAKUDIGE, 2009; BLACKMAN et al., 2006; EAKIN 
et al., 2006; HA; SHIVELY, 2008; JAFFEE, 2007; PONETTE-GONZÁLEZ, 2007). In Tanzania, producers increased the production of milk, eggs, manure, or bananas. These sales helped families increase cash inflows (MHANDO et al., 2013). In Costa Rica and Honduras, an estimated $90 \%$ of coffee producers planted at least one new subsistence crop after the crisis started (EAKIN et al., 2013). The strategy of planting staple crops to meet consumption needs presented limits. First, these crops did not provide the cash that producers needed to pay for basic needs beyond food, such as health care or education. Second, producers often only had access to marginal lands with degraded soils. The low quality of land reduced crop outputs. We further discuss this diversification strategy in Section 3.5, where we explore the impacts of the crisis on the farmers' assets. Some farmers responded to the crisis by expanding illegal drug fields. Many of them faced debt and received little external support when the crisis hit their incomes. They also often lived in regions where it was possible and lucrative to cultivate drugs. Studies show how the drop in coffee farmers' incomes influenced their choice to plant drugs. Growers in Mexico, Colombia, Ecuador, Peru, and Bolivia started to plant coca, opium poppies, or marijuana. These crops were more profitable and required less work and investment than coffee (RICE, 2003). Dube and Vargas show evidence that the decrease in coffee prices led to a rise in drug production and violence in Colombia (2013). In Ethiopia, many coffee growers cut down their coffee trees and planted khat, an amphetamine-like drug. At some point, khat surpassed coffee as Ethiopia's main export (JAFFEE, 2007).

Migration was common among coffee-growing households. Farmers compensated for the loss of income by sending family members off the farm to bring in further income. Many members of coffee-producing households emigrated to cities or abroad to earn money. They then sent remittance to support their families. In Mexico, hundreds of thousands of coffee farmers and pickers left the State of Chiapas, a significant Mexican coffee-growing region, to find work in Northern Mexico and the United States of America (USA). By 2005, Chiapas received 500 million USD in remittances from the USA (PONETTE-GONZÁLEZ, 2007; RENARD, 2010; TUCKER et al., 2010). The State of Veracruz, Mexico, ranked $30^{\text {th }}$ in emigration in 1995 . By 2002 , the State ranked $4^{\text {th }}$, and an estimated 800,000 residents emigrated, mainly to the US, and were sending remittances from abroad (WINKELS, 2008). During the crisis, Colombia's three main coffee departments had the highest international 
emigration rates. In 2004, one billion USD in remittances entered the country and went to residents of these departments (RETTBERG, 2010). Farmers also compensated for the loss of income with remittances from emigrated relatives in Honduras and Guatemala (EAKIN et al., 2013) as well as Indonesia (ALOYSIUS GUNADI, 2007). In Nicaragua, large numbers of producers ended up in makeshifts and encampments by the sides of local highways. These images circulated around the world (WILSON, 2013). In Indonesia, Titus and Burgers found that in a major growing region, $60 \%$ of coffee farmers abandoned their land and migrated to the cities (2008). In India and Tanzania, most coffee households sent kin to the cities to work and send remittances back home (AMBINAKUDIGE, 2009; MHANDO et al., 2013; NEVINS, 2007).

Many producing countries launched public policies in response to the crisis. Measures included diverse forms of financial compensations for farmers. However, researchers could not determine to what extent this financial support contributed to avoiding unsustainable outcomes. They indicated the lack of access to information and bureaucracy as key barriers (EAKIN et al, 2005). In Nicaragua, a study indicates that producers who received state subsidies during the crisis fared better than those who did not. These farmers reduced their expenditures and increased household and child labour to a lesser extent than those who did not receive subsidies (MALUCCIO, 2005). In El Salvador, Guatemala, and Honduras, governments responded with price support, rescue capital, and moratoriums on debt repayments (WILSON, 2013). In Tanzania, the coffee crisis had the reverse effect. Farmers reduced their reliance on state subsidies (MHANDO; ITANI, 2007). The above-cited researchers agree that although the total amount of subsidies is difficult to estimate, they were insufficient to bridge the crisis-induced income gap.

\subsection{Analysis of cost avoidance}

One expectation was that producers would reduce expenses to cope with untrue prices. How did producers deal with costs in the wake of the coffee crisis?

We identified in the literature several sub-strategies that producers used to avoid costs. The first strategy was to reduce operating expenses. Before the crisis, many producers had high operating costs, for example, the purchase of input and hiring of 
labour. Many of these producers cut these costs when prices dropped. The most impoverished farmers had much fewer operating costs to reduce, as they used fewer inputs and hired less labour (TUCKER et al., 2010).

Coffee growers reduced expenditures on land conservation. They diminished the use of purchased chemical inputs and stopped maintaining their plantations. They reduced activities such as pruning, weeding, and pest control. They also reduced the use of fertilisers. As a consequence, productivity levels diminished. Some producers shifted to organic production because they could not cover the costs of inputs. Studies in Guatemala, Honduras, Mexico, and India document the same pattern (EAKIN et al. 2006; MHANDO; ITANI, 2007). Reduced use of agrochemicals benefited the environment in the short term but led to the spread of diseases that degraded plantations, such as leaf rust. In Vietnam, $57.9 \%$ of producers reduced or eliminated fertilisers. Moreover, $18.7 \%$ of farmers who irrigated their farms ceased irrigation (HA; SHIVELY, 2008). By reducing such costs, producers lowered coffee yields and productivity in the mid-term (AMBINAKUDIGE, 2009). Producers also reduced their labour costs. They either reduced the input of paid workers or increased the input of unpaid workers. In Nicaragua, around 300,000 growers reduced weeding, pruning, and fertilising activities (RICE, 2003). Lower coffee prices significantly affected local economies when farmworkers lost their jobs. The crisis impacted both permanent and part-time workers. Part-time workers included many small coffee growers in need of complementary income. Between 2000 and 2001, permanent and seasonal employment fell $54 \%$ and $21 \%$ among coffee workers of Central America (BACON, 2008; VARANGIS et al., 2003). In Nicaragua, a World Bank study found that 200,000 permanent and 400,000 temporary coffee pickers lost their jobs in 2001 . The loss of income was equivalent to 140 million USD (WILSON, 2013). Unemployment rose $22 \%$ between 1996 and 2000 in Colombia's coffee-growing regions (FORERO ÁLVAREZ, 2010). Furthermore, producers intensified the use of household labour. Producers pay family out of profit rather than by paying wages. By intensifying the use of household labour, they saved on labour costs. Women and children became more involved in coffee production. There was no income to hire external workers, and men often migrated for work. Studies found that women suffered the most, with the extension of their workdays and more strenuous work to perform. Children also provided another source of unpaid work. They became involved in labour practices that had been 
unseen for decades in countries such as Colombia and Nicaragua (BACON, 2008; FORERO ÁLVAREZ, 2010; WILSON, 2010). In India, producers relied more on the community as a safety net. Households intensified arrangements to pool work together with other farmers (mostly informally) to minimise expenses for all involved (AMBINAKUDIGE, 2009).

For many of the affected producers, coffee was the primary or only source of cash. When prices dropped, a prevalent response, especially among the more impoverished growers, was to reduce household expenses. Studies in Mexico, Honduras, Guatemala (EAKIN et al., 2013), and Indonesia (ALOYSIUS GUNADI, 2007; TITUS; BURGERS, 2008) show that producers reduced their expenses on essential consumer goods, medical and health care, or school fees. Coffee prices affected the food security of many households, who had to reduce the quality and frequency of their meals. In Nicaragua, from 1998 to 2001, coffee farmers reduced food consumption by $16 \%$. In the meantime, non-coffee farmers increased consumption by $15 \%$ (WILSON, 2010). Coffee farmers were more affected than coffee workers (BACON et al., 2014). Vakis, Kruger, and Mason (2004) show that most of the decrease in overall consumption was mainly due to the fall in food intake. In 2003's Nicaragua, an estimated 30,000 coffee-growing families suffered from chronic hunger (RICE, 2003), and 100,000 people suffered acute malnutrition caused by the drop in coffee prices and income (BACON et al., 2014; WILSON, 2013). Studies also report that the price drop caused more malnutrition in several coffee-producing regions of Mexico (PONETTE-GONZÁLEZ, 2007; RENARD, 2010; TUCKER; EAKIN; CASTELLANOS, 2010). In the coffee-producing regions of Colombia, the proportion of households living under the poverty line increased. The number of people with unmet basic needs rose from $32 \%$ to $52 \%$ during the coffee crisis (FORERO ÁLVAREZ, 2010). In El Salvador, rural households in extreme poverty grew from $27 \%$ in 1999 to $36 \%$ in 2001 , and rural poverty grew from $54 \%$ to $66 \%$ (BLACKMAN et al. 2006). Premand (2010) reports that many Nicaraguan farmers moved below the poverty threshold. Studies also link school drop-outs to the increased use of children for farm work (JAFFEE, 2007; RENARD, 2010). 


\subsection{Analysis of depletion and sales of assets}

The systematic review indicates that most of the farmers did not convert their coffee plantations to other uses. The crisis transformed plantations into unprofitable productive assets. By and large, producers rarely took the drastic step of converting their plantations, even when they showed interest in doing so. They feared that replanting coffee during good times would be expensive and slow. Farmers divested from rather than converted their plantations. Divestment is the reduction of some asset - the opposite of investment. It was not rational for farmers to keep investing in and maintaining their plantations at such low prices. Producers also failed to extend the productive life of their plantations. Renewing or extending the productive life of plantations required sacrificing short-term yields and implementing costly or timeconsuming activities. Producers were often small-scale farmers working on marginal lands. They worked on steep slopes and degraded soils. After years of crisis and minimal involvement in upkeeping fertility, preventing erosion, or the spread of diseases, the value of plantations as productive assets decreased. It is only when productivity had dropped too much that producers turned plantations over to cattle grazing or abandoned them altogether. An exception was in Brazil, where some farmers tried agronomic improvements on their plantations, such as intercropping with leguminous crops to raise fertility and diversify income (WATSON; ACHINELLI, 2008). From 2004 to 2005, Mexico saw coffee production fall 15\% because of farm abandonment (RENARD, 2010). Some of the farmers left their estates vacant altogether to live in Mexican cities or across the border (JAFFEE, 2007). Farmers abandoned at least 100,000 hectares in El Salvador and Honduras (BACON, 2008).

Producers responded differently to the shock in terms of asset management, depending on their financial situation. The liquidity-constrained producers cut down more on costs and labour input on their plantations and divested more from production than the less constrained ones. In relative terms, they worked more off their farms and reduced investments in coffee to stabilise current consumption than farmers who had enough assets to buffer the crisis. As a consequence, these farmers compromised their future capacity to produce and their forthcoming income and consumption levels.

For producers struggling with lack of income, dealing with environmental issues was not a priority. From an agronomic standpoint, removing coffee trees on poor tropical soils to cultivate other crops was also not a realistic alternative. By converting 
coffee plantations, producers would have also lost significant long-term investments that they had previously made (AMBINAKUDIGE, 2009; TUCKER et al., 2010). Farmers instead tended to sell the trees forming the shaded forest that covered coffee plantations as timber or firewood. The removal of shade trees decreased biodiversity, water quality, and natural habitats, and reduced productivity and coffee quality (OSORIO, 2004; VARANGIS et al., 2003).

In Mexico and Nicaragua, some farmers opted for the conversion of coffee to other crops with better financial returns. These crops included sugar cane or palm oil. Some of the producers located in areas closer to cities sold their land for urban development (EAKIN et al., 2005). In India, while prices for coffee were low, prices for ginger were high. Growers planted ginger on former rice fields. This crop degrades the soil because it requires high doses of fertilisers and pesticides (AMBINAKUDIGE, 2009). Producers then had to make significant investments and labour inputs to revert the land degradation caused by ginger production. It took them several years to restore the fertility of their soils (AMBINAKUDIGE; CHOI, 2009).

In the coffee-growing regions where farmers had access to forest areas, farmers often used deforestation as part of their coping strategy. They converted forests to other land uses where these forests were relatively abundant, as in Honduras. They needed to clear areas to plant corn or other subsistence crops. Producers who converted forests explicitly framed this strategy as a response to the collapse in prices rather than as investments (JAFFEE, 2007; TUCKER et al., 2010). In countries with less land and forests available, such as Mexico and Guatemala, this strategy was less common. It is important to note, though, that the literature indicates that most coffeerelated deforestation occurred before the crisis when prices were higher and coffee more attractive to farmers (AMBINAKUDIGE; CHOI, 2009). Comparatively, producers deforested less areas during the crisis. Indeed, the goal was different but still linked to coffee production (diversification because of low prices). In summary, the behaviour of producers led to deforestation (although the restoration of secondary forests due to the abandonment of plantations compensated in part for this loss), land degradation, soil compaction, and erosion as well as loss of habitat.

Many producers mortgaged or sold their tangible assets. For example, producers sold their agricultural tools or other relatively liquid assets. During the crisis, $43 \%$ of Tanzanian producers used their coffee income to buy livestock, a liquid productive 
asset that could be quickly sold on the market (MHANDO; ITANI, 2007). Ha and Shively also report the sales of livestock for cash in Vietnam (2008). Another asset that many producers sold was land. As discussed in the next section, the debt burden increased for many farmers, and they had to sell their land to pay back their loans. Wealthier farmers used the coffee crisis to expand their estates. They did so by buying land from indebted small and medium producers. The crisis worsened the social distribution of land in coffee-growing regions, such as in Vera Cruz, Mexico (BACON, 2008). In India, some producers started to lease their land to immigrants. They used the rent thus generated to repay their loans during the crisis. Leasing land provided wages for landless and tribal people (AMBINAKUDIGE, 2009).

\subsection{Analysis of liabilities and indebtedness}

Before prices fell, many farmers already had large amounts of debt. They borrowed money to invest in their farms and finance their working capital from private banks, cooperatives, and input suppliers. As the coffee crisis unfolded, producers became more and more unable to repay the debt that they had contracted before and after the start of the crisis (BACON, TITUS et al., 2008; VAKIS et al., 2004). Many banks continued to lend them credit despite non-repayment. They knew producers were not able to repay past debt with coffee income at current prices. Winkels (2008) reports that farmers on the Vietnamese agricultural frontier used debt to consume and maintain the productivity of their assets. In Nicaragua, after the coffee-growing households had used all their cash reserves, they mortgaged their crops to fund consumption (WILSON, 2010). In El Salvador, the outstanding debt of coffee growers ranged, on average, from 1,200 to 1,500 USD per hectare after the crisis (BLACKMAN et al., 2006). In India, the rate of recovery of crop loans reached a historical low during the crisis (AMBINAKUDIGE, 2009). With their income reduced and increasing debt loads, farmers struggled to pay both the interest and the principal during the crisis (WILSON, 2010). They became, in effect, Ponzi borrowers. Even after prices recovered in 2004, growers still had to repay the hefty debt obligations that they had contracted before and during the crisis. They had also become less productive because of divestment from plantations. Many producers fell into a vicious circle of reduced incomes and 
growing debts that continued long after 2003. Many growers became insolvent and foreclosed or filed for bankruptcy. Bacon (2008) documents widespread farm seizures due to debt default in El Salvador, Costa Rica, and Honduras. In Nicaragua, $80 \%$ of coffee farmers faced imminent risks of foreclosure in 2002 (JAFFEE, 2007). The smallholders who lost their farms left for the cities and across borders, adding to the flow of migrants seeking to complement the income of still-existing farms.

By and large, the analysis of indebtedness indicates that it tended to be a strategy generally used at the later stages of the crisis and as a last resort by farmers. Few producers could take advantage of loans or governmental attempts to help them refinance debt. Many farmers did not have debt because they did not have access to bank loans in the first place. The producers who had the private land titles needed to access loans generally had already used this collateral as debt to finance production (for example loans to buy fertilizers) before the crisis. These farmers mostly reacted in two ways. Part of them managed to pay their debts and the crisis did not increase their levels of indebtedness. Another part of these producers (the main part in many countries) accumulated debt and were compelled to sell their land or even to foreclose because of their over-hanging debt and negative equity.

\subsection{Results of the test}

The systematic review allows us to verify if producers responded to untrue prices as expected by the model.

i. Income. The crisis provoked sharp losses of income from coffee. Jobs and income opportunities dropped while unemployment grew in coffee-growing regions. Farmers and farmworkers increased their reliance on remittance from kin relationships. Creating these new forms of income involved a considerable rural exodus. Producers also turned to the production of illicit drugs. Governments extended subsidies in some countries.

ii. Expenses. Significant numbers of producers became poorer. The rates of school drop-outs and malnutrition increased among producer families. The reduction of 
hired labour to tend plantations decreased employment rates in rural areas. Within households, women and children participated more in strenuous farm work.

iii. Assets. Farmers often disinvested from or abandoned their plantations. They also converted fallow and forest lands into pastures for livestock or to plant subsistence crops. Farmers removed the trees shading the plantations. They also stopped performing important activities or investments to maintain their productive assets and protect their environment.

iv. Debt. Indebtedness reached unsustainable levels for farmers. Many producers became speculative or Ponzi borrowers, according to Minsky's classification. They were unable to repay the interest or the principal of their debts with their operating income. Because the productive value of their assets was decreasing, the efforts of many farmers to refinance the debt often failed. Many of them went bankrupt.

The analysis shows that the strategies and impacts vary significantly depending on the financial profile of producers, the countries, local infrastructure conditions, and opportunities. Producers reacted variedly and the unsustainable impacts have appeared in different combinations and intensities but, overall, unsustainability increased across producers and regions.

For analytical purposes, we have treated the four strategies in separate sections (3.3 to 3.6), but their interweaving is clear across the literature. The analytical model proposed in this study allows us to 'read' cases more comprehensively and perform better comparisons. We illustrate this point by looking at the responses of two Honduran farmers to the crisis. They chose different strategies based on their needs and the state of their balance sheets:

José had three children, his wife Eva was pregnant, and he was supporting his widowed mother. [the producer attends to the needs of six direct dependants.] They lived in a two-room adobe house with a dirt floor. [clear signals of cost avoidance.] He had no debts, but no savings. [no financial buffer against price falsification.] Besides one hectare in coffee, he had a hectare to grow maize and beans for household consumption, and several hectares of forested land. During the coffee crisis, José cut back on fertilizer to save money [cost avoidance leading to further drop in income]. He did not hire help to work on his plantation [cost avoidance leading to unemployment] he was able to keep up with weeding, maintaining, and harvesting his plantation with help from his children and brothers [cost avoidance through unpaid family labour]. To compensate for lost income, he cleared a patch of forest [liquidation of forest assets] to plant more 
corn and beans [diversification of income and avoidance of monetary expenses]. He experimented with a fishpond and joined a group that organized to grow vegetables for local markets [cost avoidance through asset sharing]. With funds from the sale of a team of oxen [liquidation of assets], he purchased more land and planted coffee seedlings to expand his plantation. He wanted to be ready when coffee prices rose. (TUCKER, 2013, p. 163 - notes in brackets are ours.)

The last sentence in this quote shows an important informational gap to address when price falsification occurs. Many farmers thought that the crisis was a normal event and that prices would rise again soon. They adopted strategies that increased their exposure to financial risks and indebtedness down the road. The only strategy that does not appear clearly in the case above is the rise in liabilities. Maybe the farmer in this case was relatively capitalised and did not need to take this more drastic step, or perhaps he did not have collateral available to get access to loans.

The second farmer was more financially constrained. He had to take more radical steps, probably because he depended more on coffee, had higher needs and no financial buffer.

As the coffee crisis began, Luís Cortés . . . was still recovering from damage caused by Hurricane Mitch in November 1998. [an event had already fragilized the farmer's balance sheet prior to the crisis.] The nine members of his family lived in a three-room adobe house with a cement floor [cost avoidance]. He had two hectares of land, nearly all of it in coffee. [the crisis hit him harder than the first farmer because he relied more on coffee.] When the coffee prices fell, he couldn't afford to buy fertilizer. Even though his plantations produced higherquality, "hard bean" coffee, the price was too low to pay coffee pickers. He and his family picked some of the coffee and left the rest to rot. [cost avoidance leading to drops in productivity and negation of income for workers.] He took on temporary jobs, his wife Matilda found a job at a maquila factory in a nearby town, and their eldest child left school to work in San Pedro Sula [increased reliance on off-farm labour and income.] Finally, he made the painful decision to sell a third of his land. [sales of assets impairing future income generation.] (TUCKER, 2013, p. 171 - notes in brackets and in bold are ours.)

This second farmer first tried to improve his income and expenditure statement by avoiding costs and finding alternative means of income. This was not sufficient, and he had to take the more dramatic step of selling a significant proportion of his productive assets thus hindering future income generation.

In Chapter 2, we made strong predictions about what empirical evidence we should expect, represented in Table 7, Section 2.8. The results of the empirical test are consistent with these expectations. We identified pattern, sequence, account, and 
trace types of evidence which prove that the mechanism was operating in the case of the coffee crisis, with different combinations of impacts depending on producers and countries. Furthermore, if we claim that untrue prices cause unsustainability $(X \rightarrow Y)$, we should find plenty of evidence that the coffee crisis was a $(1,1)$ case and no proof that it was a $(1,0)$ case. The systematic review did not identify any evidence that contradicts the model or makes it untenable. In Popper's terms, the test did not falsify the theory.

We are of the view that our chosen case has representativeness and was not one-off. There are other examples, especially in regards to food and agriculture, where 'world prices' are at odds with local economics. For example, Figure 10 on the next page shows the volatility and long-term decline of the prices of coffee and cereals (barley, corn, rice, rye, and wheat) for the period 1850-2015, relative to real prices in the year 1900. These charts show that the coffee crisis was not a singular event and is part of a more structural trend of declining and volatile prices for cereals, coffee, and most of agricultural products. 
Figure 10: Long-term world price index for coffee and cereals dating $1850-2015$, measured relative to real prices in $1900(1900=100)$

Real coffee price index

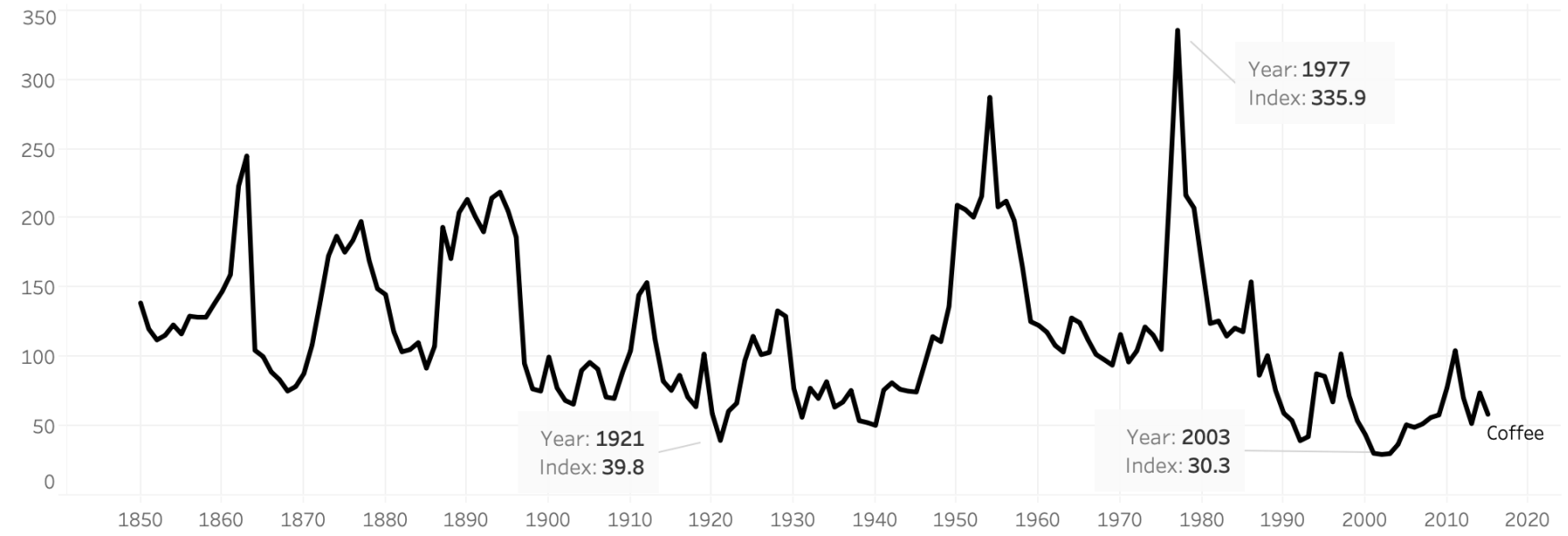

Real cereal price index

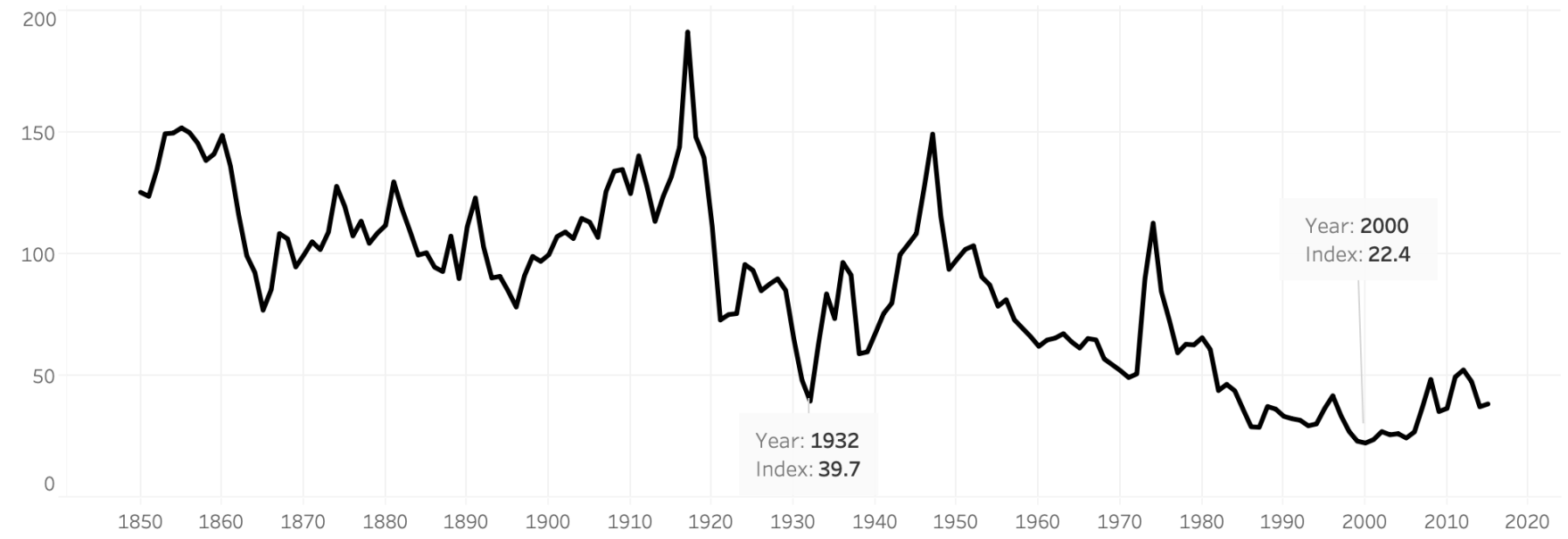

Source: Elaborated by the author based on a dataset provided by Jacks (2013). 


\subsection{Summing up}

The coffee crisis illustrates how untrue prices generate unsustainability. Unsustainable outcomes arise from four types of coping strategies. Each strategy creates feedback loops and vicious circles. For example, by cutting down on their operating costs and degrading their productive assets, producers hindered their capacity to raise income. As a result, many producers needed to take on more debt to keep their finances afloat. Since prices were untrue, producers could not make a profit and meet their needs. They became 'Ponzi borrowers' who often faced insolvency because their income and their wealth failed to increase, and instead dropped. During the coffee crisis, producers stretched the labour and resources of their households. For instance, they deprived themselves of basic needs and received remittances from emigrated family members. By stretching themselves thin, producers reduced their own welfare. In that sense, the coffee crisis resulted much more in self-exploitation ('internalities') than in the generation of externalities. The case proves that the concept of externality is not comprehensive enough to capture unsustainability in all its forms.

The analysis of this case also questioned the belief that unsustainable behaviour is always a matter of choice. To foster sustainability, we must understand the distinction between compelled and uncompelled economic behaviour. Unsustainability brought about by necessity is qualitatively different from unsustainability generated by free choice. This study made it clear that producers reacted to the coffee crisis in selfdefeating and distressing ways, like the crew that jettisons the ship's cargo during a tempest, in Aristotle's metaphor. Such producers should not be forgotten, vilified, or criminalised (as were the farmers who emigrated or turned to drug production). Producers who receive untrue prices have no real choice in operating unsustainably. However, producers may also generate unsustainability while receiving true prices. In this case, they are not economically compelled to operate in this way. They may generate unsustainability because of other economic motives, for example, to maximise profit and shareholder value.

This case also helped us to reflect on the effectiveness of 'Fairtrade'21, one the most significant attempts to deal with low farm-gate prices in modern history. A 2017

${ }^{21}$ Fairtrade advocates 'fair prices and a margin for producers for investment in order to sustain business and livelihoods' and 'direct purchasing from producers, a transparent trading system, equal partnership 
study shows that the floor price was lower than the production costs of Brazilian coffeegrowers since it was last updated on April 2011 and until the time of publication (PEDINI et al., 2017). This floor price is determined in a foreign rather than a local currency, calculated against 'average costs', and applies for long periods. Fairtrade's definition of a 'fair' price does not guarantee that this price is true and all needs are met. This is not to deny that Fairtrade has a more positive impact on producers than the status quo of the conventional market, but it is unrealistic to expect that Fairtrade alone will solve the producers' issues, because Fairtrade prices do not amount to true prices nor address the balance sheet issues of farmers.

The coffee crisis showed that vulnerability to price falsification varies greatly depending on the producers' relative access to land, capital, labour, and the quality of their socio-economic networks. Producers with substantial assets coped with the crisis by using their savings and receiving more financial support. In that sense, they were more buffered from the price collapse. They maintained higher levels of investments in coffee and could buy the land from other debt-ridden producers. These investments paid off when coffee prices rose again. In contrast, financially-constrained farmers mostly dealt with the crisis by emigrating, not meeting some of their needs, selling assets, or through debt. Price falsification worsened the social distribution of both assets and income.

Furthermore, the case of the coffee crisis showed that producers can move to speculative and Ponzi positions against their will. During the crisis, producers' expected cash flows from coffee sales were not realised due to the sudden collapse of market prices. Many producers already held debt before the crisis. The threshold for prices to become true rose with the market collapse, which compounded the cycle of increased debt, decreased productivity, and divestment as the crisis unfolded. In such a situation, it would have been more rational for investors to acknowledge that producers could not and so would not pay part of their debts, and to resolve the debt overhang differently, by altering the size of payments, interest rates, the composition of the debt, or the repayment schedule during the period of crisis. They could have

and exclusive contracts' (UDOMKIT; WINNETT, 2002, p. 45). To get the Fairtrade certification, buyers must pay a minimum price. This minimum or floor price supposedly covers the producers' average costs of production. Buyers must pay the floor price if it is higher than the market price. Fair Trade also pays a premium that is transferred and used up by the cooperatives to which producers must belong in order to access the system. 
written down part of the debt if the borrower's and the lender's balance sheets showed that the former needed the relief and the latter could afford it.

This chapter tested the explanatory power of the model, which illuminates and connects the seemingly unrelated events and practices that occurred during the coffee crisis. It allowed us to combine insights from diverse researchers and disciplines into a coherent and multi-layered explanation of how and why the crisis unfolded.

Empirical evidence has confirmed the existence of the purported causal mechanism in at least one significant case. But one success in explaining a case does not make the causal mechanism generalisable enough. We can question if it exists in other cases. If we analyse another case and find further evidence of the existence of the causal mechanism, it would be more difficult to reject the external validity of the model. Connecting theory to another real-world case is also the opportunity to test the model in a different context and to use different scientific methods. It will allow us to enrich our understanding of our causal model and verify to which extent it is flexible and fit enough to explain other unsustainable situations. Analysing this other case is the focus of the next chapter. 


\section{Chapter 4: Case study of farmers in the Brazilian Amazon}

This chapter provides the second test of the causal model developed in Chapter 2. We focus on how untrue prices are linked to unsustainable rural development on the deforestation fronts of the Brazilian Amazon ${ }^{22}$. This second test complements the analysis of the coffee crisis because we check the validity of the model using quantitative methods. Census data allows us to categorise producers based on their income levels and to discern the practices they adopt accordingly. After introducing the case and our methods for its study, we estimate how untrue are the prices received by different groups of producers. We then analyse if empirical data corroborates the model's expectations regarding reliance on non-operating income, cost avoidance, depletion of assets and raise in liabilities.

\subsection{Context of the study}

Chapter 3 has only confirmed the existence of the causal mechanism and its parts in one case. Also, we could not explore some of its nuances. In particular, the case of the coffee crisis did not allow us to verify whether different levels of untrue prices $(X)$ lead to different patterns of unsustainability $(Y)$.

Chapter 4 focuses on farmers operating in municipalities of the Brazilian Amazon which have high deforestation rates. It tests two hypotheses. The first is that the farmers' responses to untrue prices and the sustainability outcomes of these

\footnotetext{
22 When we use the term Brazilian Amazon, we refer to the Brazilian Legal Amazon, that is, municipalities in the nine States of the Brazilian Amazon basin: Acre, Amapá, Amazonas, Maranhão, Mato Grosso, Pará, Rondônia, Roraima, and Tocantins.
} 
responses depend on the relative untruthiness of prices and income levels. The more prices are untrue (if $X$ rises), then the more the negative impacts predicted by the model will occur (then the four parts of the causal mechanism operate more pronouncedly, raising $\mathrm{Y}$ ). The second hypothesis is that untrue pricing is an intermediate variable ${ }^{23}$ that channels the different drivers of unsustainable development in the region through the causal mechanism. This hypothesis postulates that untrue prices form a causal pathway that links different independent variables (drivers identified in the literature which are presented below) to the dependent variable of unsustainable development on these deforestation fronts.

The problems of unsustainable rural development on the deforestation fronts of the Brazilian Amazon, and how to solve them, have generated vast amounts of literature. The ways to look at what generates the problem vary significantly among academics. They have identified a series of interrelated drivers of unsustainable development, including: i) lack of land governance and weak property rights (REYDON et al., 2015); ii) changes in agricultural commodity prices, domestic depreciation, and related public policies such as subsidies (FERREIRA \& COELHO, 2015); iii) the rise of land prices and speculation (REYDON et al. 2017), the demand for land resulting from the expansion of cattle and soy farming (SILVA, 2014; VALE, 2015); iv) predatory timber logging (BECKER, 2013; VERÍSSIMO \& PEREIRA, 2014); v) built infrastructure and urbanization (SOUZA et al., 2015); vi) and the creation of agrarian reform settlements (CALANDINO et al., 2012; DUCHELLE et al., 2014; FEARNSIDE, 2005; LE TORNEAU et al., 2010; SOARES-FILHO et al., 2005). All the above drivers play a role in causing unsustainable development on these deforestation frontiers.

Most analyses do not explicitly link the factors listed above together or explain how they interact to produce unsustainability. So, how can we make sense of the relationships between these different drivers? How do they converge at the level of farmers, leading them to adopt unsustainable practices and, in particular, deforestation? Looking at what happens to farmers with varying levels of lack of income (or untrue prices) can help us understand how farmers respond to these drivers and become concomitantly more subject or conducive to unsustainable development.

\footnotetext{
${ }^{23} \mathrm{An}$ intermediate variable is not to be confused with a confounding factor. If our hypothesis was that untrue prices are a confounding factor, we would postulate that untrue prices predict both the drivers and unsustainability, yet are no part of the causal pathway that connects drivers to outcomes.
} 


\subsection{Material and methods}

Our general goal is to verify whether unsustainable dynamics on the deforestation fronts of the Brazilian Amazon can be explained by, provide empirical evidence of, and refine the causal model. This chapter asks three questions about rural development on the deforestation fronts of the Brazilian Amazon:

i. Can we identify whether different groups of farmers receive different levels of income in relation to the true price threshold? (Section 4.3.)

ii. Does empirical evidence confirm the existence of the causal model? Do attributes for these different groups of farmers confirm that higher magnitudes of $X$ (untrue prices) correspond to the more pronounced occurrence of the four expected strategies and higher levels or different patterns of $Y$ (unsustainability)? (Sections 4.4 to 4.7 .)

iii. Does the model help us to make sense of the interplay among the different drivers of unsustainable development identified in the literature? (Section 4.8.)

To achieve our goals, we need to develop a dataset allowing us to check if and how farmers with diverging income levels operate differently, sustainability-wise. To create the dataset, we gathered data from multiple sources, including the Brazilian agricultural census (IBGE, 2019) and deforestation data (INPE, 2020) for the year 2017, as well as data on land prices for 2015 (AGRAFNP, 2015), complemented by a review of the literature.

We limit the scope of our dataset to municipalities that we can identify as being clearly located on deforestation fronts. There are three types of regions in terms of their geographical and historical relationship with the deforestation process: i) areas of recent deforestation, ii) fertile consolidated areas, and iii) barren consolidated areas (SABLAYROLLES, 2004). Smallholders have different options, strategies and limitations depending on the type of area they operate in. We focus on the first type of area, deforestation fronts. To do so, we focus our analysis on the top 100 municipalities (out of 772) in the Brazilian Amazon in terms of the increase of the deforested area (in hectares) between 2016 and 2017. These top 100 municipalities contributed to $81,3 \%$ of the total deforestation in the region for that period. Appendix 1 (p. 163) lists 
deforestation data for these municipalities for 2016-17. By focusing on these municipalities, we are able to select only data from farmers that are undoubtedly operating on deforestation fronts. This methodological choice makes the analysis more thorough because it limits the risk of mixing it with data of producers operating out of these deforestation fronts, in highly different settings. For instance, the municipality of Cametá, Pará, had 12,819 farmers but only deforested $1.3 \mathrm{~km}^{2}$ in 2017 . It is excluded from the dataset, while the municipality of Lábrea, Amazonas, which had only 2,122 farmers but deforested $283.7 \mathrm{~km}^{2}$, is included. Figure 11 is a map of the municipalities in the Brazilian Amazon, coloured by their levels of deforested area in 2016-17. Labels of deforested area $\left(\mathrm{km}^{2}\right)$ are provided only for the top 100 municipalities to help locate them. The map displayed in Figure 12 shows that many producers of the Brazilian Amazon are settled in consolidated areas with low deforestation rates, for example near the coast or urbanised areas, where access to markets and infrastructure are more developed.

The most prominent source of data in this study is the Brazilian agricultural census performed by IBGE (2019) in 2017 and released in late 2019. The data is publicly available and provided at the level of granularity of municipalities. The census allows us to differentiate groups of farmers based on their endowment with land. We will see in the next section that this data allows us to make comparisons and contrast groups of farmers differentiated by their levels of $X$. Table 10 provides data on the farms included for the top 100 municipalities. It shows the number of farms and the corresponding area for each farm group, and provides these numbers as fractions of the total. 
Figure 11: Map of the distribution of deforestation in 2016-17 across municipalities $\left(\mathrm{km}^{2}\right)$

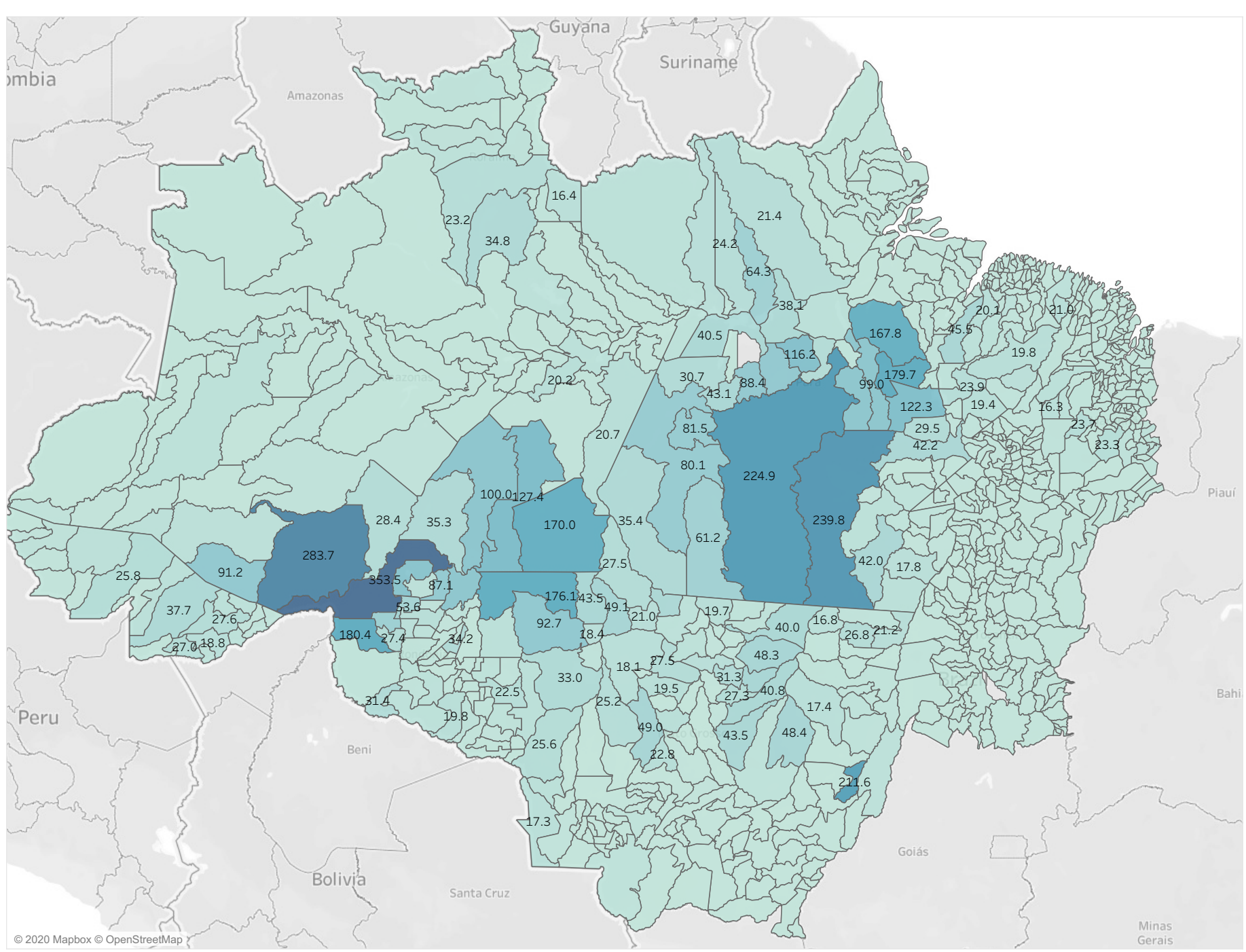

Source: Map elaborated by the author based on INPE data (2020). 
Figure 12: Map of the distribution of farms across municipalities in the 2017 agricultural census (number of farm units)

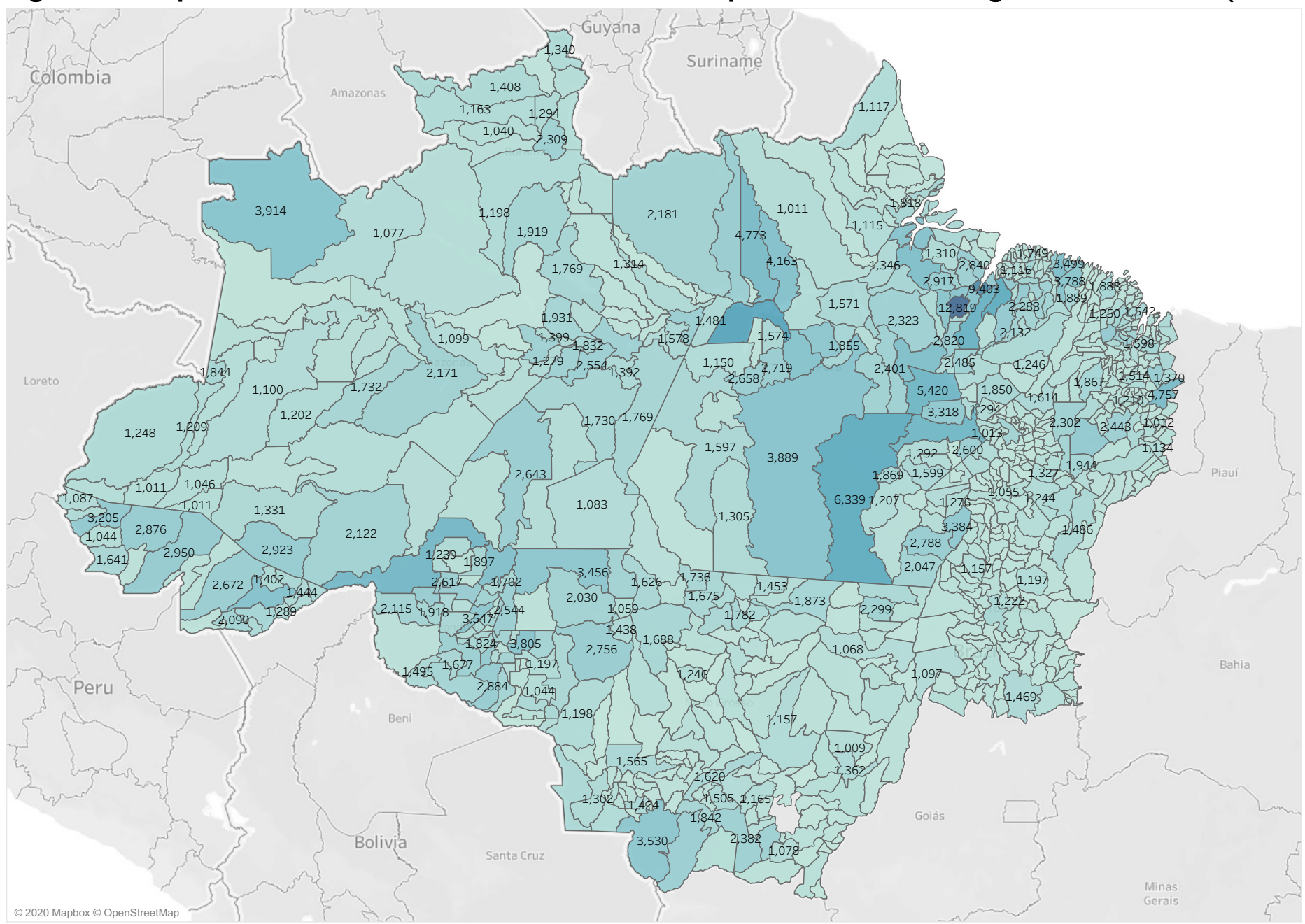

$26 \quad 12,819$

Source: Map elaborated by the author with IBGE data (2019). 
Table 10: Number of farms, total area, percentage of total farms and area, and average area in the dataset

\begin{tabular}{|c|c|c|c|c|c|c|}
\hline Group & Farm size (ha) & $\begin{array}{l}\text { Farms } \\
\text { (units) }\end{array}$ & $\%$ of total farms & Area (ha) & $\begin{array}{l}\% \text { of total } \\
\text { area }\end{array}$ & $\begin{array}{l}\text { Average } \\
\text { area (ha) }\end{array}$ \\
\hline 1 & No area & 2,306 & 1.1 & 0 & 0.00 & 0 \\
\hline 2 & $0-<0.1$ & 2,193 & 1.1 & 88 & 0.00 & 0.04 \\
\hline 3 & $0.1-<0.2$ & 1,336 & 0.6 & 169 & 0.00 & 0.13 \\
\hline 4 & $0.2-<0.5$ & 2,289 & 1.1 & 672 & 0.00 & 0.29 \\
\hline 5 & $0.5-<1$ & 3,185 & 1.5 & 2,023 & 0.00 & 0.64 \\
\hline 6 & $1<-2$ & 6,430 & 3.1 & 7,989 & 0.02 & 1.24 \\
\hline 7 & $2-<3$ & 6,406 & 3.1 & 14,397 & 0.03 & 2.25 \\
\hline 8 & $3-<4$ & 3,890 & 1.9 & 12,463 & 0.03 & 3.2 \\
\hline 9 & $4-<5$ & 4,266 & 2 & 19,046 & 0.05 & 4.46 \\
\hline 10 & $5-<10$ & 11,121 & 5.3 & 77,007 & 0.19 & 6.92 \\
\hline 11 & $10-<20$ & 15,569 & 7.5 & 214,061 & 0.52 & 13.75 \\
\hline 12 & $20-<50$ & 46,938 & 22.5 & $1,647,369$ & 4.00 & 35.1 \\
\hline 13 & $50-<100$ & 47,346 & 22.7 & $3,257,994$ & 7.92 & 68.81 \\
\hline 14 & $100-<200$ & 29,372 & 14.1 & $3,675,589$ & 8.93 & 125.14 \\
\hline 15 & $200-<500$ & 14,405 & 6.9 & $4,309,419$ & 10.47 & 299.16 \\
\hline 16 & $500-<1,000$ & 5,284 & 2.5 & $3,675,954$ & 8.93 & 695.68 \\
\hline 17 & $1,000-<2,500$ & 3,730 & 1.8 & $5,675,761$ & 13.79 & $1,521.65$ \\
\hline 18 & $2,500-<10,000$ & 2,172 & 1 & $9,745,510$ & 23.68 & $4,486.88$ \\
\hline 19 & $10,000+$ & 462 & 0.2 & $8,817,319$ & 21.43 & $19,085.11$ \\
\hline $\begin{array}{l}\text { Grand } \\
\text { total }\end{array}$ & & 205,932 & 100 & $41,152,830$ & 100 & 199.84 \\
\hline
\end{tabular}

Source: elaborated by the author based on IBGE data (2019).

We exclude groups 1 (no area) and $19(10,000+$ ha) from the dataset because we do not consider them relevant or reliable enough. We ignore group 1 because most of our analysis of strategies and impacts has to do with land use, and these farmers are landless. We exclude group 19 for two reasons. First, the population $(N)$ is too small (462 farms, $0.2 \%$ of the total) to be meaningfully compared to other groups. Second, it is too heterogeneous, conflating farm realities that are too diverse to make reliable and meaningful calculations. For instance, the average area is 19,085 ha for group 19, almost twice above the minimum area for this group. Groups 2 to 18 have both a minimum and maximum farm size and are more likely to be meaningful aggregates. We are aware that farm group 19 is highly relevant to analysing land use 
because it represents $21 \%$ of the total farm area. ${ }^{24}$ But our main focus here is on applying and testing the causal model, hence this methodological decision.

We therefore include in our final dataset of farms only groups 2 to 18 , consisting of 203,164 or $98.6 \%$ of the farms. Together, they represent $78.6 \%$ of the total area of properties in the study region. Farms from $0+$ to 500 ha represented $89.6 \%$ of the total number of farms, while groups 10 to 15 (between 5 and 500 ha) represent $79 \%$ of the farms. Only four groups (12 to 15 , between 20 and 500 ha) represented $66.1 \%$ of farmers.

Table 11 shows the indicators of the 2017 agricultural census that we analysed. We selected these specific indicators because they are unambiguous and are directly related to the expectations of the causal model.

\begin{tabular}{|c|c|c|}
\hline Table & Topic & Indicators used \\
\hline 6780 & Context & Access to technical assistance \\
\hline 6880 & Context & Average land size \\
\hline 6882 & Depletion of assets, rise in liabilities & Forms of land use \\
\hline 6896 & Context & Access to credit \\
\hline 6846 & $\begin{array}{l}\text { Cost avoidance, degradation of assets, rise in } \\
\text { liabilities }\end{array}$ & Land use practices \\
\hline 6889 & Cost avoidance & $\begin{array}{l}\text { Farms employing workers with and without } \\
\text { kinship tie }\end{array}$ \\
\hline 6900 & Cost avoidance, depletion of assets & Operational costs \\
\hline 6906 & Cost avoidance, depletion of assets & Animal treatment \\
\hline 6950 & Reliance on other income, depletion of assets & Income from timber or charcoal \\
\hline 6961 & Context, rise in liabilities & Condition of farmers in relation to land \\
\hline 6898 & Reliance on other income & Value of production \\
\hline 6902 & Reliance on other income & Origins of non-agricultural income \\
\hline
\end{tabular}
Source: author, selected from the IBGE dataset (2019).

We extracted IBGE data for each group of farm size and for each selected indicator, for all the 100 selected municipalities, and aggregated the data provided

${ }^{24}$ Table 10 also shows high levels of land concentration or inequalities in the area of study, with all their implications for the development of these rural communities. 
separately for each municipality. We then obtained the total values for each group of farm size for the selected indicator (e.g. the total number of farmers receiving a certain type of income against the total number of farmers, and the total value of this income). We then made two kinds of calculations on this aggregated data, depending on the nature of the data: percentages and average values for each group of farm size. This normalisation allowed us to mitigate the effects of having different populations $(\mathrm{N})$ for each group of farm size.

One limitation of our methodological approach is that even if we selected municipalities on deforestation fronts, some farms may be located closer to urban areas and operate under different conditions (for instance in terms of access to input, better logistics, or access to markets). Another limitation is that it is a static picture and does not allow us to observe dynamics over time. (The 2017 census data cannot provide sequence evidence.) The coffee crisis, however, allowed us to do so.

\subsection{Estimating the agricultural net income in different groups of farm size}

IBGE data allows us to estimate the situation of farmers in each group of farm size regarding the relative 'truthiness' of the prices they get for their produce. We use Agricultural Net Income as a proxy for this estimate. Given that:

\section{Agricultural net income $=$ Farm gross production - Costs of production}

Thus, we can estimate the average agricultural net income for each group of farm size with data provided by the census and approximately assess if the price is true or untrue. If we assume that the average household in the study region has five family members (a conservative number), we can also estimate the agricultural net income that is available for each member of this average household. The results of these calculations are shown in Table 12.

These estimates only deduct operational costs from the farm income, while other expenses such as amortisation, depreciation, interest, or taxes, among other expense categories are not included. Agricultural net income should not be conflated 
with the real disposable income that farmers get, whose value is lower. Furthermore, household expenses are also left aside from the calculation.

Table 12: Average farm gross income, costs of production and estimated agricultural net income per group of farm size (BRL)

\begin{tabular}{|c|c|c|c|c|}
\hline $\begin{array}{l}\text { Farm size } \\
\text { (ha) }\end{array}$ & $\begin{array}{l}\text { Farm Gross } \\
\text { Production/ } \\
\text { year (IBGE) }\end{array}$ & $\begin{array}{r}\text { Costs of } \\
\text { production/year } \\
\text { (IBGE) }\end{array}$ & $\begin{array}{l}\text { Agricultural net } \\
\text { income/year }\end{array}$ & $\begin{array}{r}\text { Agricultural net } \\
\text { income/capita } \\
\text { /month }\end{array}$ \\
\hline $0-<0.1$ & 6,034 & 2,933 & 3,102 & 52 \\
\hline $0.1-<0.2$ & 7,525 & 2,522 & 5,003 & 83 \\
\hline $0.2-<0.5$ & 6,258 & 3,242 & 3,016 & 50 \\
\hline $0.5-1$ & 7,463 & 3,884 & 3,580 & 60 \\
\hline $1<-2$ & 9,793 & 3,689 & 6,104 & 102 \\
\hline $2-<3$ & 12,865 & 4,156 & 8,708 & 145 \\
\hline $3-<4$ & 17,161 & 5,475 & 11,686 & 195 \\
\hline $4-<5$ & 15,663 & 6,645 & 9,018 & 150 \\
\hline $5-<10$ & 20,542 & 6,994 & 13,548 & 226 \\
\hline $10-<20$ & 20,385 & 8,434 & 11,951 & 199 \\
\hline $20-<50$ & 23,189 & 10,846 & 12,343 & 206 \\
\hline $50-<100$ & 34,148 & 17,991 & 16,156 & 269 \\
\hline $100-<200$ & 48,737 & 27,209 & 21,529 & 359 \\
\hline $200-<500$ & 122,902 & 77,100 & 45,802 & 763 \\
\hline $500-<1,000$ & 320,443 & 205,731 & 114,711 & 1,912 \\
\hline $1,000-<2,500$ & 939,296 & 593,664 & 345,632 & 5,761 \\
\hline $\begin{array}{l}2,500- \\
<10,000\end{array}$ & $2,973,193$ & $1,748,860$ & $1,224,333$ & 20,406 \\
\hline
\end{tabular}

Source: calculations by the author with data from IBGE (2019).

The average agricultural net income was below the minimum wage ${ }^{25}$ for the bottom half of the groups. Given the results from the table, we argue that most farmers received untrue prices in 2017 in the study area, with varied degrees of intensity. For instance, each of the fourteen groups of farms with less than 200 ha, representing $87.6 \%$ of all the farmers, generated an average net agricultural income of 359 $\mathrm{BRL} /$ capita/month or less (almost a third of the minimum wage), a level of income that is evidently untrue. The absolute poverty line was $1.9 \mathrm{USD} /$ day in 2017 , or $188^{26}$ $\mathrm{BRL} /$ month in Brazil - above the average net agricultural income per capita for seven

\footnotetext{
${ }^{25}$ The minimum wage was $937 \mathrm{BRL} /$ month or $11,244 \mathrm{BRL} / \mathrm{year}$ in 2017 , arguably far below the true price threshold. For whoever lives in or knows Brazil's economic reality, it would be hard to make the case that one can meet all one's needs, let alone those of one's dependants, with this minimum wage. ${ }^{26}$ If we consider an exchange rate of 3.3 for 2017 . The exchange rate in 2020 is around 5, which would represent $285 \mathrm{BRL} /$ capita/month.
} 
out of seventeen groups of farm size. We could also consider that the groups 1,000$<2,500$ and $2,500-<10,000$ are above or much significantly closer to the true price threshold. We need to keep this in mind when we compare these two groups with the others. The group $500-<1,000$ can be seen as a transitional group.

One should not worry too much about the actual position of each group regarding the true price threshold. The important point here is that there is a clear gradation in terms of how far income and prices are far above or below this threshold among the groups of farm size. In other words, we have a dataset of groups of farms with varying levels of $X$ which we can compare in terms of evidence of the existence of the causal mechanism and its parts, and $Y$. We can use the decrease of farm size as a proxy for the increase of $X$ : prices are more untrue in smaller farms.

In the figures displayed in the remainder of this chapter, we present the percentages not only in the form of numbers but also of bar charts to facilitate the visual analysis of patterns. Figure 13 on the next page shows that most of these farmers had no access to extension services, $88 \%$ on average, but these levels diminished with the size of the farm.

In general, all groups of farmers had little to no access to credit, either to make productive investments, to use as working capital and keep liquid, to maintain their assets, or to commercialise their products. The highest average percentages are found for producers from 20 to 50 ha for investments, but they are still low, as shown in Figure $14 .{ }^{27}$ It is unclear whether farms with the highest size did not get access to credit or did not need to get access to it because they have sufficient capital internally available. Assunção et al. (2016) have found that better access to credit curbed deforestation in the Brazilian Amazon.

\footnotetext{
${ }^{27}$ To calculate the values in Figure 14, we averaged data provided at the municipality level, rather than obtain the average of the aggregate for all the municipalities in the dataset, because access to finance is more related to the conditions of a specific municipality than those of a specific farmer (e.g. the existence and number of bank agencies in the municipality).
} 
Figure 13: Farms with no access to extension services by group of farm size (\%)

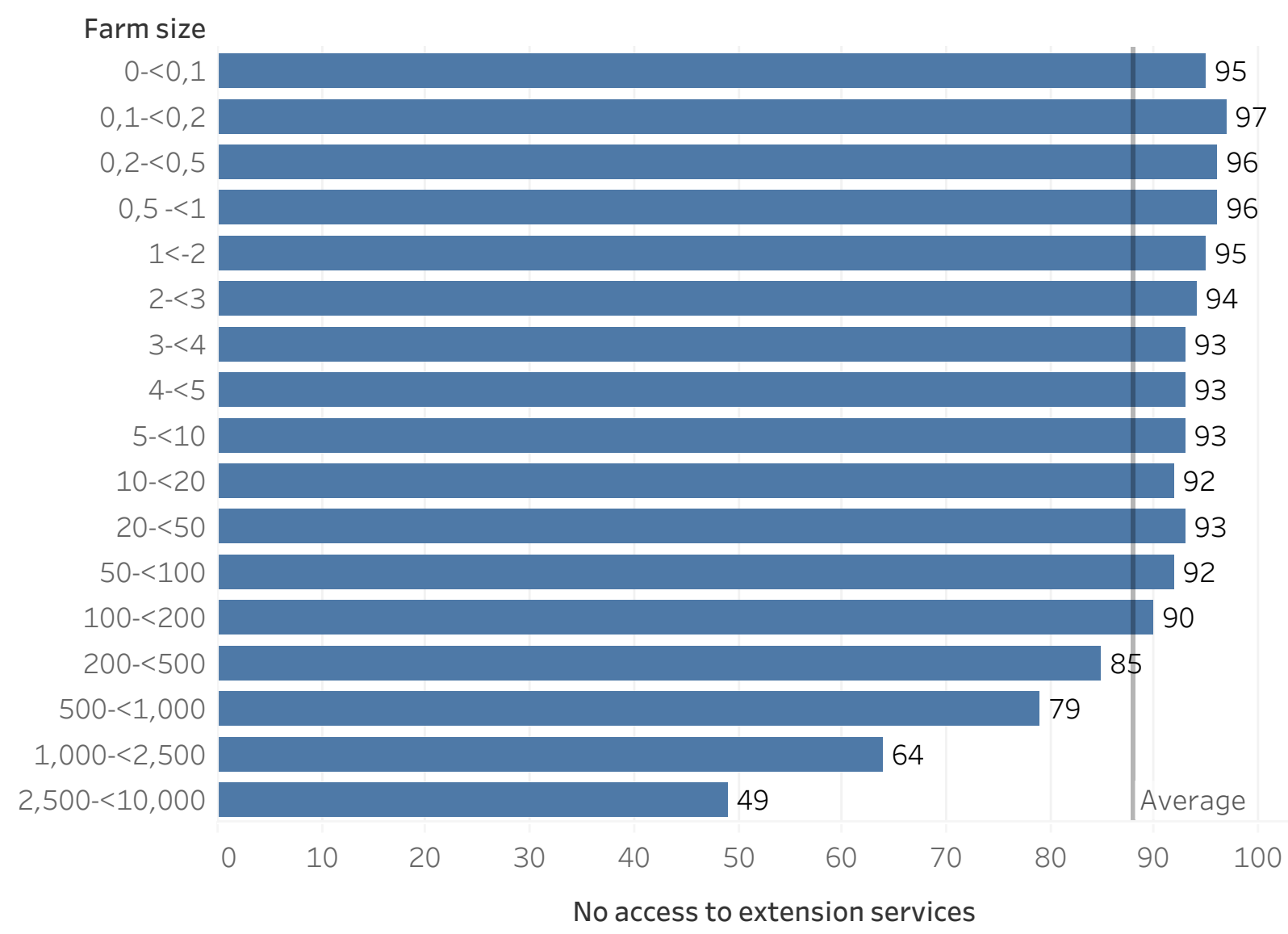

Source: author based on IBGE data (2019).

Figure 15, p. 106, shows how farmers accessed land. Most farmers owned their land. Farmers occupying land rose significantly with $\mathrm{X}$, representing a degradation in terms of access to land, a key productive asset. We will return to these results in Section 4.7, where we analyse the raise in liabilities. Smaller farms were linked to a higher precariousness of access to land, as was also confirmed by the reduction in the percentage of farmers waiting for a land title with the increase in farm size. For a specific group of farm size, the different forms of access sum up to more than $100 \%$ because one farm can have access to land through several forms at the same time. 
Figure 14: Access to credit for different funding purposes by group of farm size (\%)

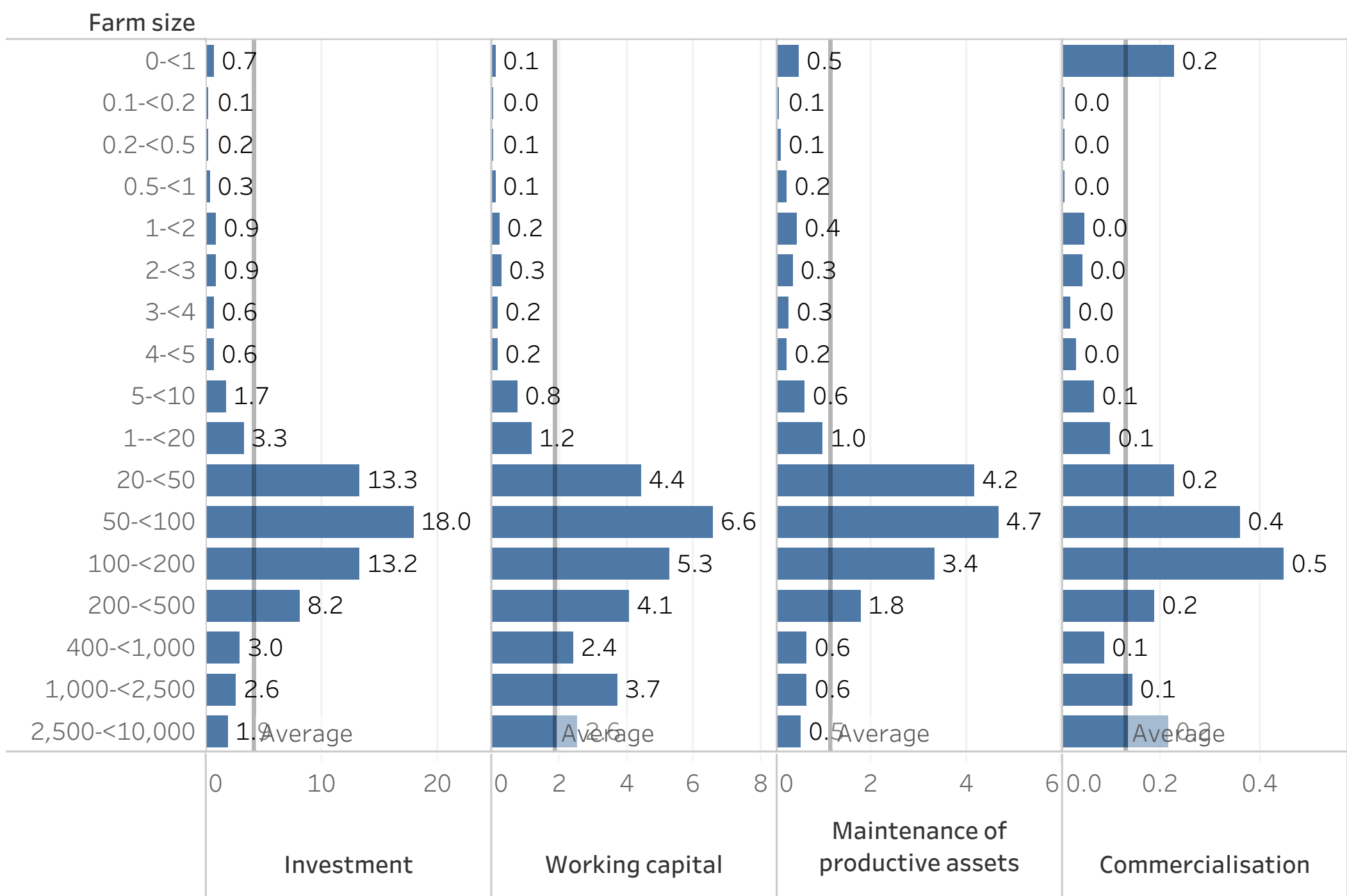

Source: elaborated by the author with IBGE data (2019). 
Figure 15: Forms of access to land by group of farm size (\%)

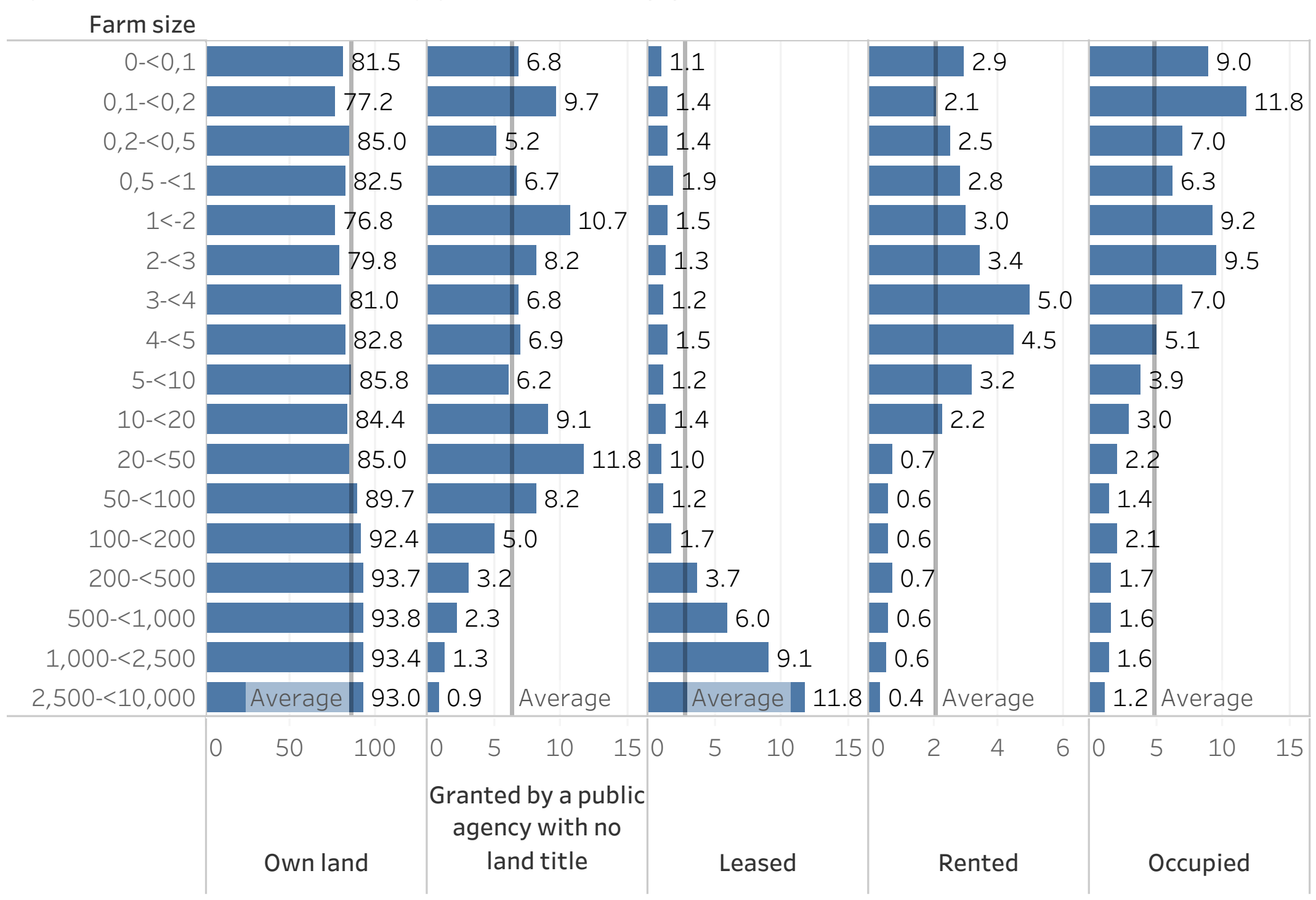

Source: elaborated by the author with IBGE data (2019). 


\subsection{Analysis of reliance on non-operating income}

Figure 16 shows that the smaller the farm size (and the more untrue the price), the more we observe the reliance on i) pension and retirement plans, ii) subsidies, and iii) increased disinvestments. Reliance on off-farm income and pensions decreases steeply for the top three groups of farm size, confirming that, when prices are closer to the true price threshold, reliance on non-operating income diminishes too.

Reliance on pensions and subsidies reduces significantly with the raise in farm size. We observe a fivefold reduction between the group of smallest and the group of biggest farm size for pensions, and almost a threefold reduction for subsidies.

The percentage of farmers receiving income from agroindustry products rises with farm size. This is not surprising, since farmers who can raise income from agroindustry products need to be sufficiently capitalized to produce and process sufficient raw material, which is not less likely to be the case with smaller farm sizes. This trend does not invalidate the model's expectations but highlights the challenges posed by verticalizing production as a response to lack of income for smallholders.

IBGE does not provide data to assess the existence of remittance across groups of farm size, but Padoch et al. (2008) and VanWey et al. (2011) found that smallholders on deforestation fronts relied significantly on migrant remittance as a source of cash income. Urban-rural remittances play an important role in buffering these farmers from climatic or socio-economic factors, such as agricultural price oscillations. 
Figure 16: Farmers receiving non-agricultural income by group of farm size (\%)

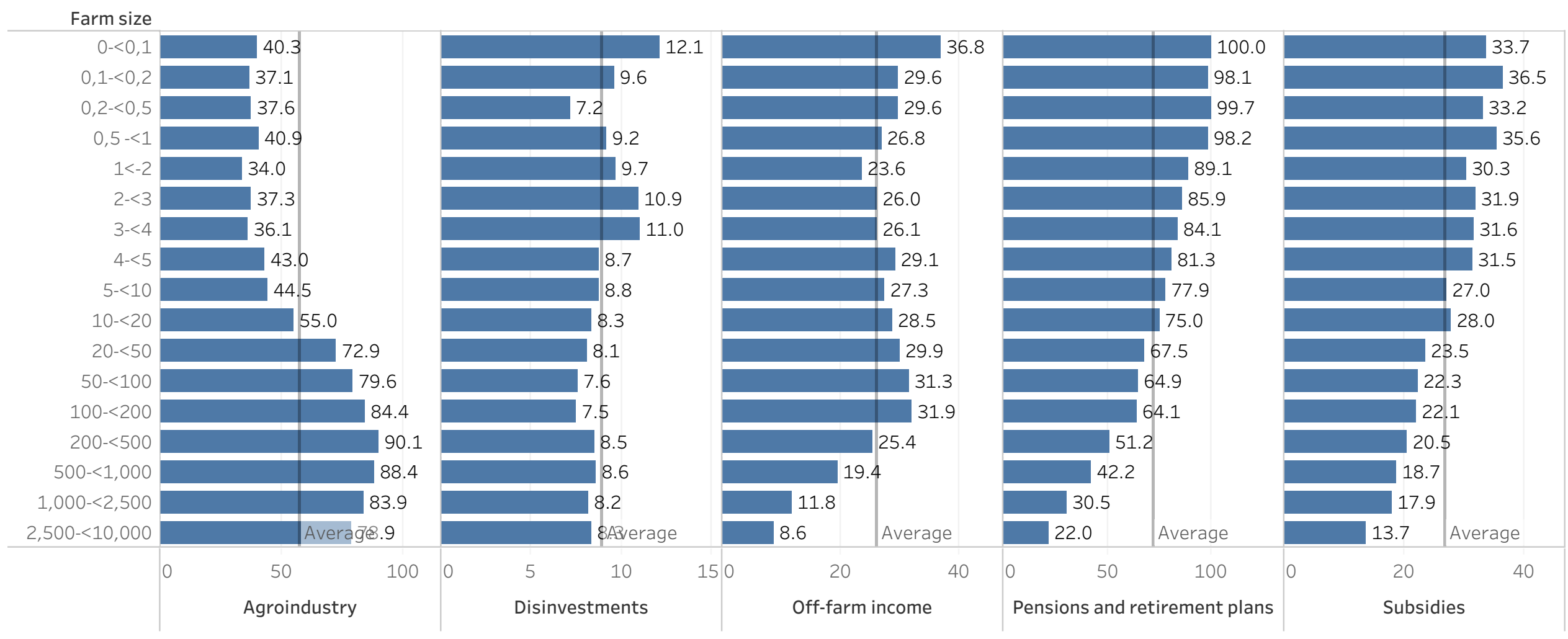

Source: elaborated by the author with data from IBGE (2019). 


\subsection{Analysis of cost avoidance}

Figure 17 on the next page shows the percentage of farms of each group of farm size that make specific kinds of operational expenses and investments that are registered by the census.

In general, we observe a clear relationship between an increase in the size of the farms with an increase in the percentage of producers who make expenses and, vice versa, a decrease in the avoidance of these costs.

Despite this general trend, each type of expense follows a specific pattern. Expenses related to labour (salaries and service hiring), land (rent, pasture formation), and productivity (pesticides, animal medication, animal feed) follow steep patterns.

Smaller farmers would have no economic reason to reduce such expenses if they were not constrained to do so. These expenses are key to maintaining and increasing the productivity and the agricultural gross income of the farm. We can conclude that lack of income is a key factor that explains why low income farmers incurred fewer expenses than high income farmers. 


\section{Figure 17: Farms making different types of expenses by group of farm size (\%)}

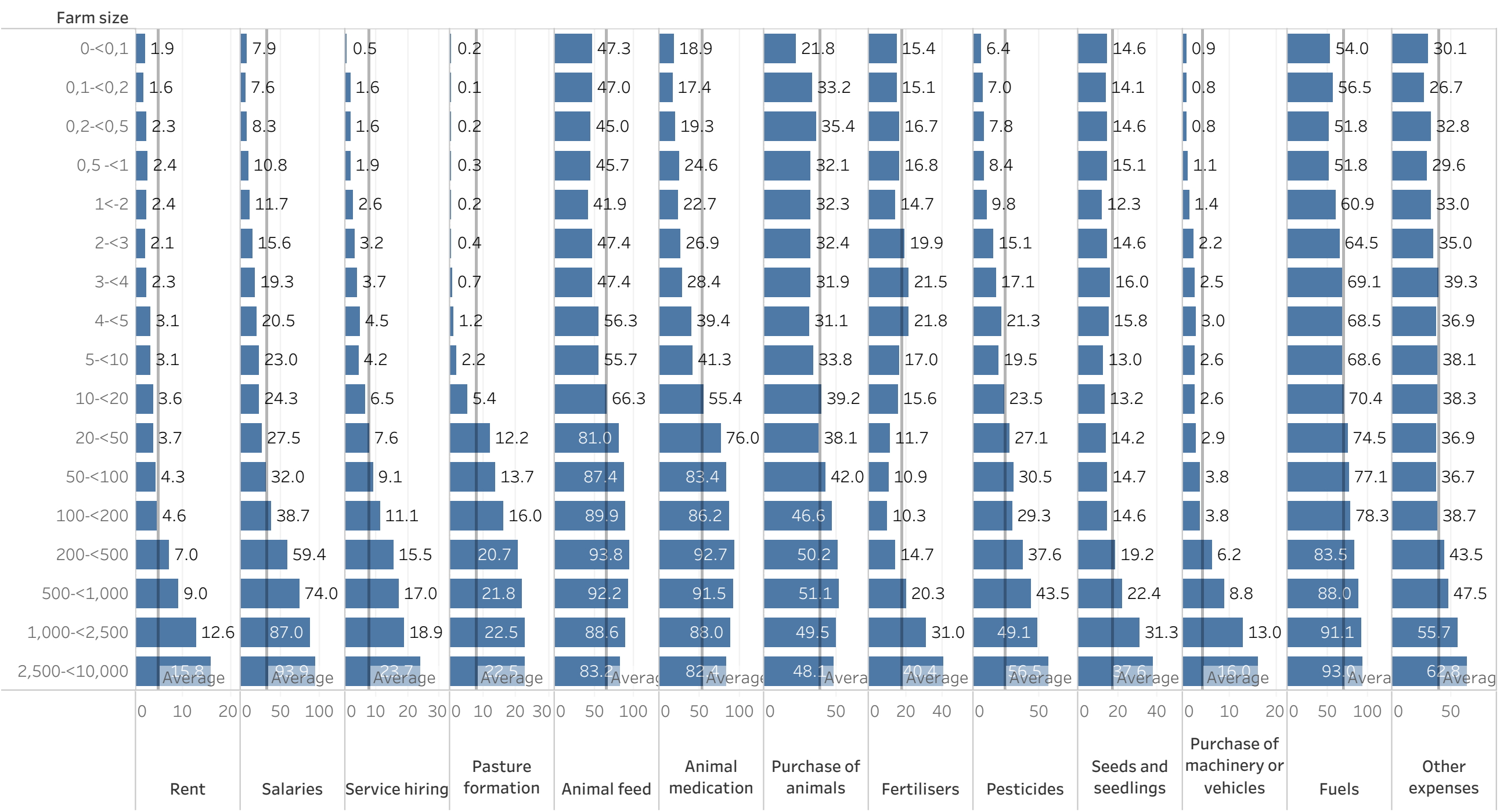

Source: elaborated by the author with IBGE data (2019). 
Data on whether farmers do or do not hire workers confirms that the smaller the size of the farm, the less farmers are likely to hire workers with no kinship tie, as shown in Figure 18. Since employing workers with no kinship tie involves making expenses in the form of wages, these findings may be linked to the fact that farmers tend to avoid more costs when $X$ raises. It may also be that external farm workers are less needed when farmers are endowed with less land to tend.

Figure 18: Farms hiring workers with no kinship tie by group of farm size (\%)

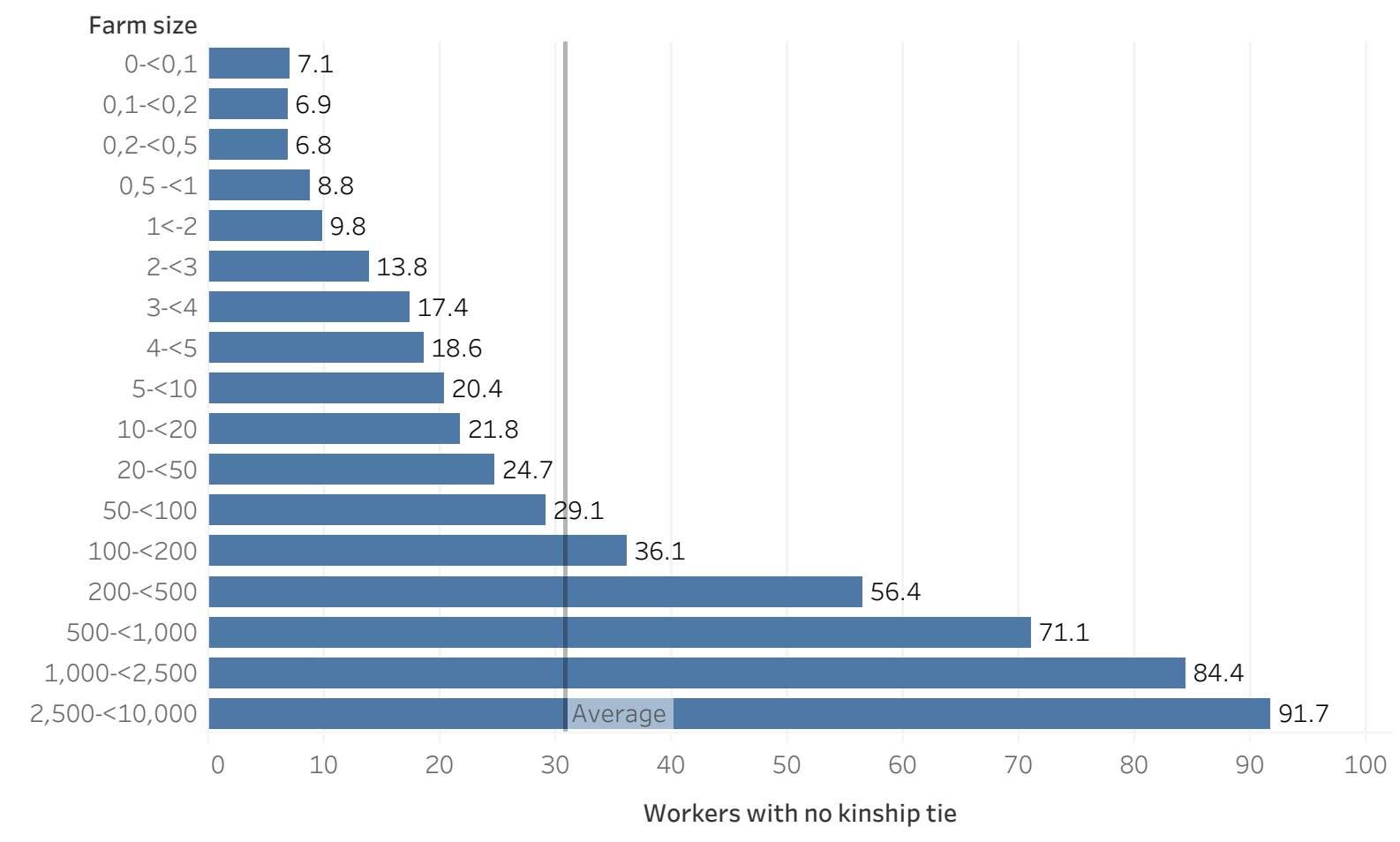

Source: elaborated by the author with IBGE data (2019).

The census also provides data on whether farmers who breed cattle do or do not control diseases and/or parasites or use alimentary supplements. Figure 19 shows that the smaller the farm size, the less farmers are likely to adopt these practices, with negative impacts on productivity and income. 
Figure 19: Farms not controlling diseases and/or parasites and not using supplements by group of farm size (\%)
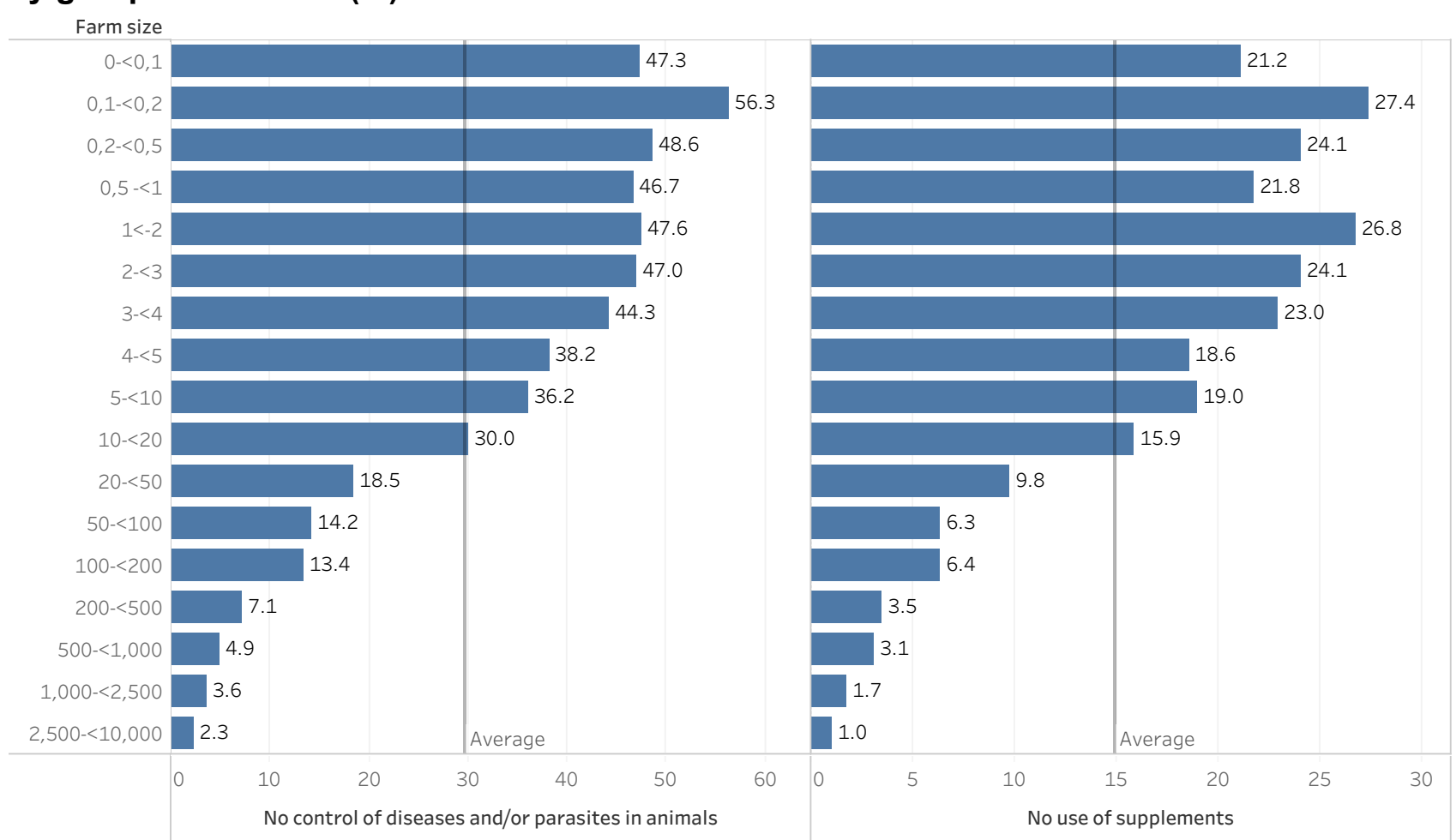

Source: elaborated by the author with IBGE data (2019).

It is important to note that the IBGE census leaves some open questions in relation to the analysis of cost avoidance. The census does not provide data on expenses such as interest, taxes, depreciation and amortization, or household expenses. The causal model and the case of the coffee crisis indicate that such expenses play, nevertheless, a primary role in cost avoidance.

In general, census data clearly points to cost avoidance as a strategy that is highly adopted by farmers when X raises, as expressed by the steepness of the graphs displayed in this section.

\subsection{Analysis of depletion and sales of assets}

Census data indicates an increase in disinvestments when $X$ raises, confirming the intensification of asset depletion when prices are farther away from the true price threshold, as shown in Figure 16, p. 108. 
The census also allows us to analyse patterns regarding forest use. Figure 20 below displays whether farmers produce charcoal or timber in relation to $\mathrm{X}$. Charcoal production can be considered a degradation of assets, since value is generated by removing forest vegetation, generally with no consideration for the maintenance of the forest. Workers also toil in precarious conditions.

In general terms, the pattern confirms that the reliance on charcoal production increases with the decrease in farm size. In particular, the pattern shows a sharp decrease for the groups of farms that receive prices closer to the true price threshold.

Figure 20: Farms producing charcoal or timber by group of farm size (\%)

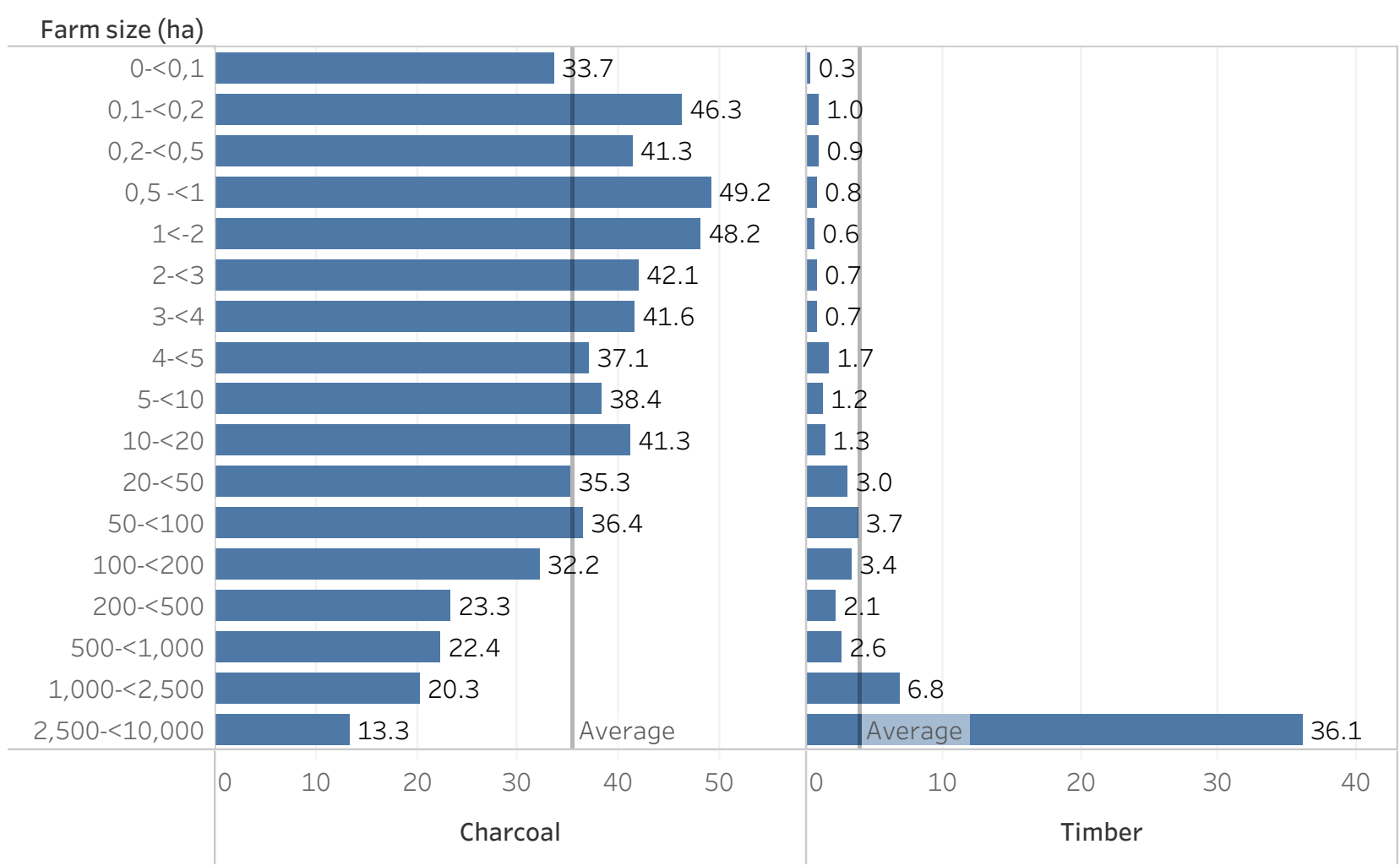

Source: elaborated by the author with data from IBGE (2019).

The pattern for timber extraction indicates an increase with the rise of farm size. We need to consider two contextual elements to analyse this data. First, timber extraction is more likely to be sustainable if it is legal in Brazil, as legislation requires the adoption of reduced impact logging and sustainable forest management practices. Timber logging is very unlikely to be sustainable if it is not legal. Most logging activities 
in the Brazilian Amazon are illegal, ranging from 60 to $85 \%$ depending on the estimation, year, and state. ${ }^{28}$ Smaller farmers, due to the smaller size of their required Legal Reserve and the high costs of obtaining forest management licenses, tend to let logging companies operate the extraction for them, often illegally. They would take risks by declaring these operations to census workers. Second, the census asked if farmers had extracted timber in 2017. Unsustainable timber extraction is a yearly activity, a one-off activity prior to clearing the land or through predatory logging, while reduced impact logging is a long-term activity where the same plot of forest land only generates income every 20 to 30 years. For these two reasons, smaller farmers were more likely to extract timber unsustainably and not to declare timber extraction. In contrast, larger land holders have access to more forest land. For example, if farmers respect the Forest Code and we apply the 50-80\% Legal Reserve rule, farmers 2,500$<10,000$ would have between 5,000 and 8,000 ha of land where logging activities are legal and do not compete with agricultural land uses, which are forbidden by law. Farms with larger sizes were more likely to declare timber extraction in 2017, because the size of their area allowed for constant timber extraction with legal forest management plans (reduced impact logging in the form of year-by-year rotative extraction of timber spread across a sufficient number of plots of sufficient size). If we assume that farmers only declare that they extracted timber when the operations were legal, then timber extraction should be seen as an indicator of sustainability and the results shown in Figure 20 (a decrease of $Y$ associated with a decrease of $X$ ) confirm the model.

Figure 21 displays the percentage of farms with Legal Reserves (LRs) and Permanent Protection Areas (PPAs), two types of environmental protection areas which are required on any privately owned land holding by the Brazilian Forest Code. The smaller the farm size, the less farmers are likely to maintain LRs and PPAs. This indicates that farmers and society benefit less from the environmental services provided by these areas. They also generate more environmental and legal liabilities. The percentage of farmers with pastures in good condition provides another indicator of asset depletion. If $\mathrm{X}$ is higher, less producers have access to or develop pastures in

\footnotetext{
${ }^{28}$ Instituto Centro Vida estimated that $85 \%$ of timber extraction was illegal in the state of Mato Grosso for the period 2018-19 (2019). In Pará, researchers evaluated that $74 \%$ of the volumes of forest inventories were overestimated, the register of fake tree inventories generating a surplus of logging licenses used to launder illegal timber (BRANCALION et al., 2018).
} 
good agronomical conditions, which could be interpreted both as an outcome, the depletion of assets, and as a cause of $X$ (lower productivity levels make market prices more untrue).

The IBGE census also looks at the number of farmers who adopt good environmental practices, such as the protection of slopes, the recovery of riparian forests, and the afforestation of water sources. These practices are all required to be performed by law (PPA requirements), but they are also key to preserving the productive capacity of the farm. Figure 22 shows that these percentages follow a sharp decrease with the size of farms, another indication that farmers receiving more untrue prices tend to degrade their assets more intensively.

Figure 21: Farms with forests allocated as permanently protected areas and legal reserves, and with pastures in good conditions by group of farm size (\%)

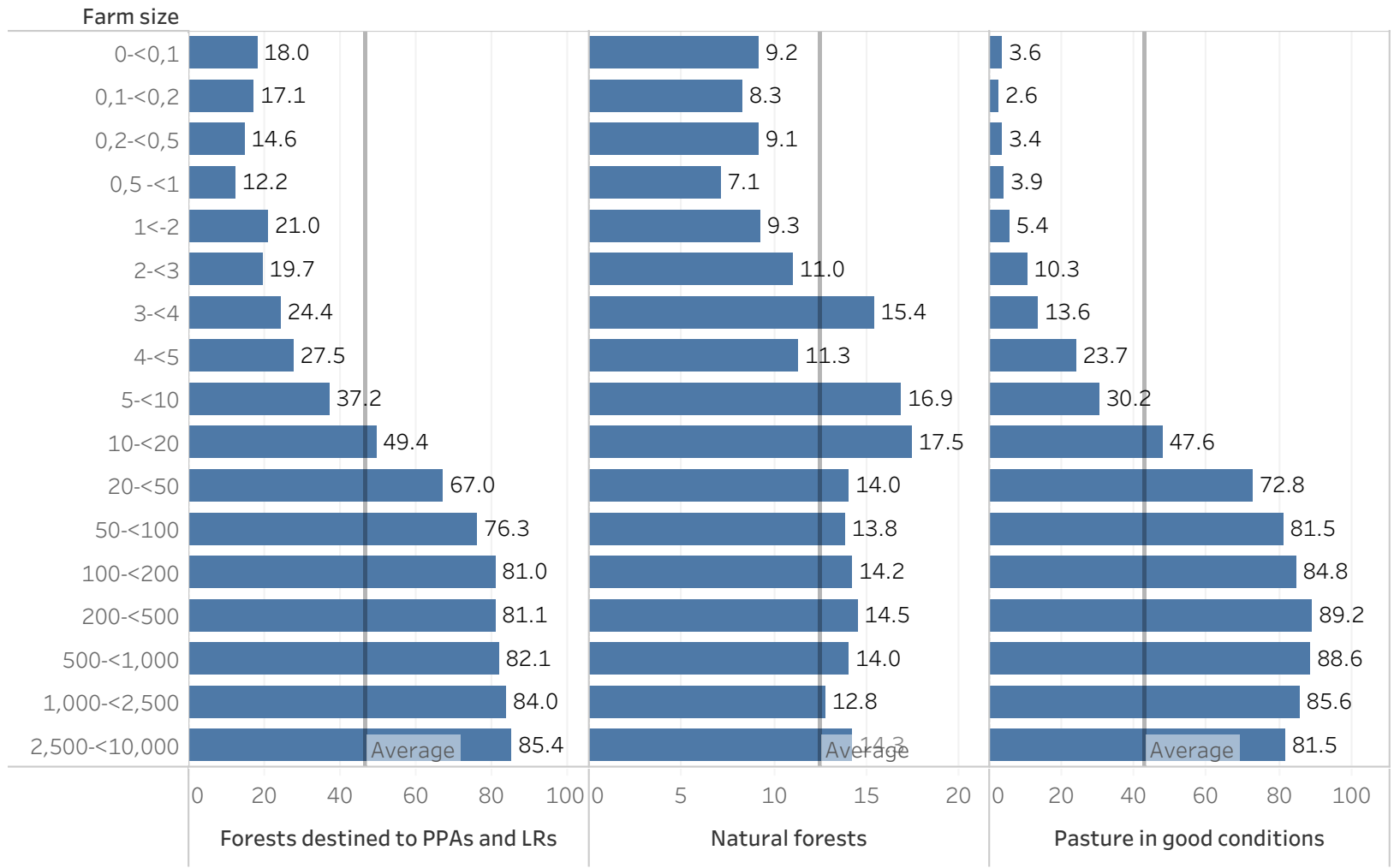

Source: elaborated by the author with data from IBGE (2019). 
Figure 22: Farms adopting good environmental practices by group of farm size (\%)

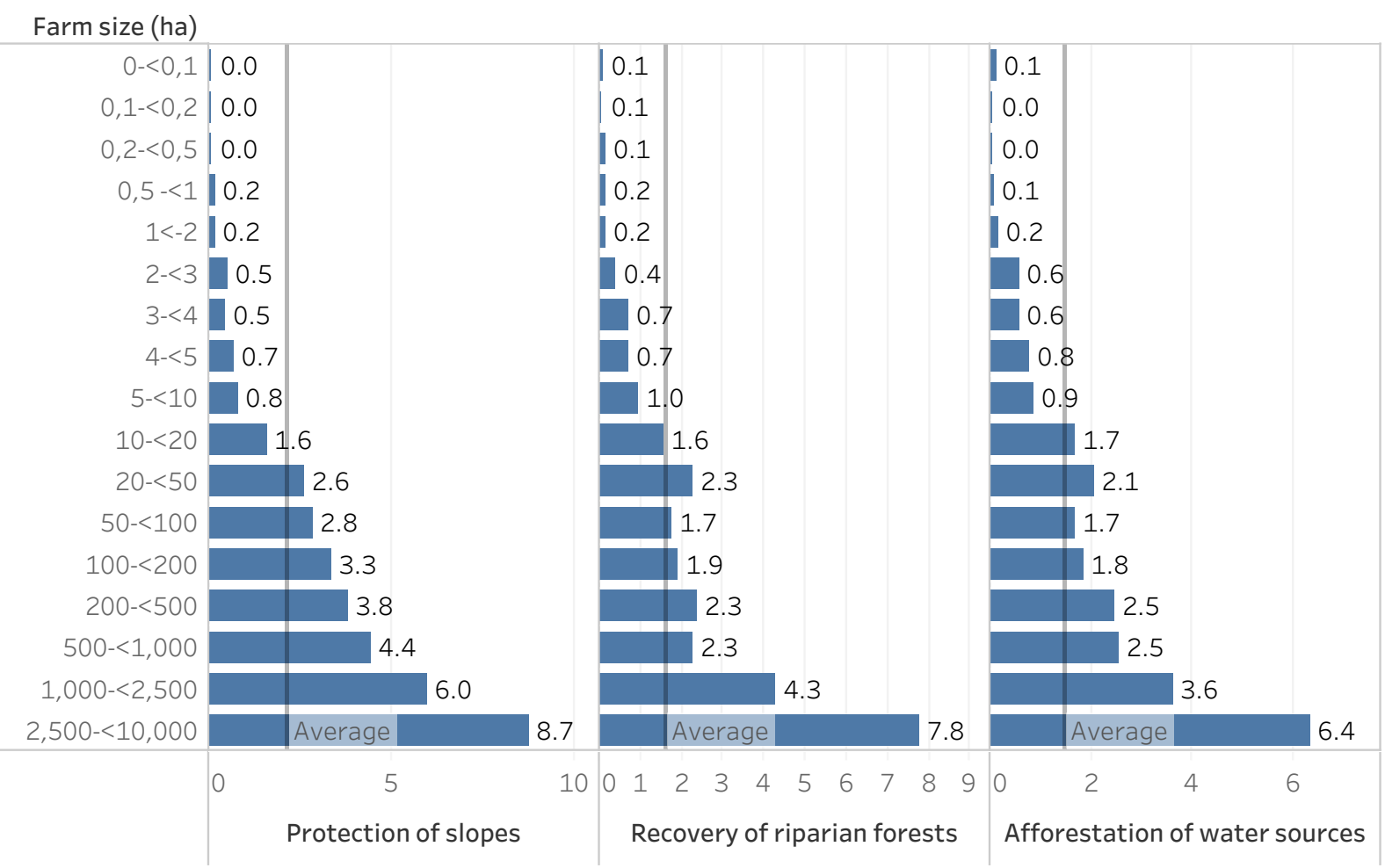

Source: elaborated by the author with data from IBGE (2019).

Several figures in Section 4.5, especially Figure 17, p. 110, indicated farmers avoided costs when $X$ raised. Cost avoidance also furthers asset depletion: the less farmers spend to maintain or improve their productive assets, the more the value of the latter goes down.

A key aspect on which IBGE does not provide data is how much farmers can compensate for lack of income through capital gains from the sale of their land. Farmers can make unmatched capital gains from it, as discussed by REYDON et al. (2015; 2017). Table 13 on the next page provides data from AGRAFNP (2015) on the average prices of forest and productive pasture in the different States of the Brazilian Amazon. Productive pasture is much more valuable than standing forest. The potential capital gains of buying forests ${ }^{29}$, chopping them down, and turning them into pasture

\footnotetext{
${ }^{29}$ If the original forest was occupied or the title was obtained through fraud, the forest would cost even less or nothing.
} 
are very high. On average, productive pastures were sold at prices more than four times higher than forests in 2015 . It is essential to evaluate these potential gains.

Table 13: Prices of forest and productive pasture in some States of the Brazilian Amazon (BRL/ha) and variation (\%)

$\begin{array}{lrrr}\text { State } & \text { Forest (BRL/ha) } & \text { Productive pasture (BRL/ha) } & \text { Variation (\%) } \\ \text { MT } & 1,224 & 5,968 & 487.6 \\ \text { RO } & 1,989 & 7,672 & 385.7 \\ \text { PA } & 1,700 & 3,540 & 208.2 \\ \text { AC } & 570 & 3,447 & 604.7 \\ \text { AM } & 473 & 1,647 & 348.2 \\ \text { AP } & 470 & - & - \\ \text { Avg. Brazilian Amazon } & 1,234 & 5,020 & 406.8\end{array}$

Source: AGRAFNP (2015).

Table 14 below provides an estimate of the net income per hectare, per year, and category of clearing a forest and selling the productive pasture in the scenario of a farmer who performs the whole process in seven years (a typical duration of this process of land use change in the Brazilian Amazon). Over the period, the farmer raises $91.4 \%$ of his or her income from the depletion and sale of assets, where $29.6 \%$ come the sales of timber, which play the role of start-up capital, and the sale of pastures constitute up to $61.8 \%$ of the estimated final income. Only $8.6 \%$ of the net income is derived from the sales of cattle (operational income).

Table 14: Estimated net income from clearing a hectare of forest, establishing a pasture, and selling the land during a period of seven years (BRL)

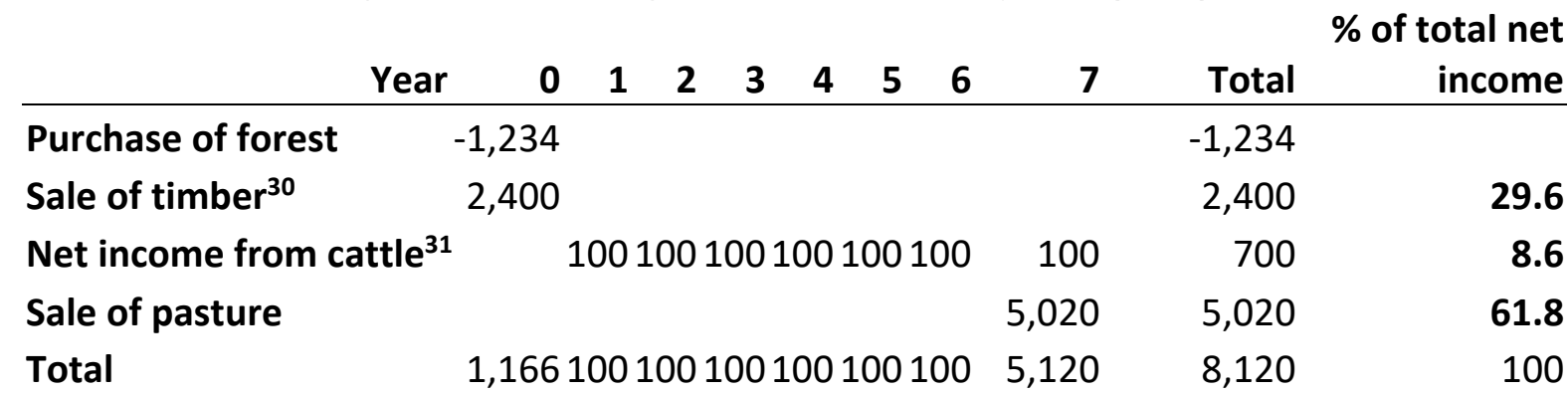

30 The stocking density for extensive cattle raising is around 0.75 cattle heads/ha in the Amazon. Average productivity is $67.5 \mathrm{~kg} / \mathrm{ha}$ of carcass, and the net profit, after having deduced the costs of production, of around $100 \mathrm{BRL} / \mathrm{ha}$.

${ }^{31}$ REYDON (2011) estimates the net income from the sale of timber in Cotriguaçú-MT at around 2,400 BRL/ha. 
Source: Elaborated by the author with data from REYDON (2011) and AGRAFNP (2015).

The conversion of forest into pasture is highly profitable and presents low risks for farmers under current circumstances in the Brazilian Amazon. It is not surprising that farmers have recourse to these sources of income, especially when we take into account the estimated agricultural income for each group of farm size, as shown in Table 12, p. 102. The estimates of capital gains would be even higher (85.4\%) if a farmer had sold mechanisable agricultural land for the production of soy and cotton. AGRAFNP (2015) estimates that he or she would make an average capital gain of 17,000 , more than three times the price of pasture, as shown in Figure 23 below.

Figure 23: Average prices of different types of land in the Brazilian Amazon in 2015 (BRL/ha)

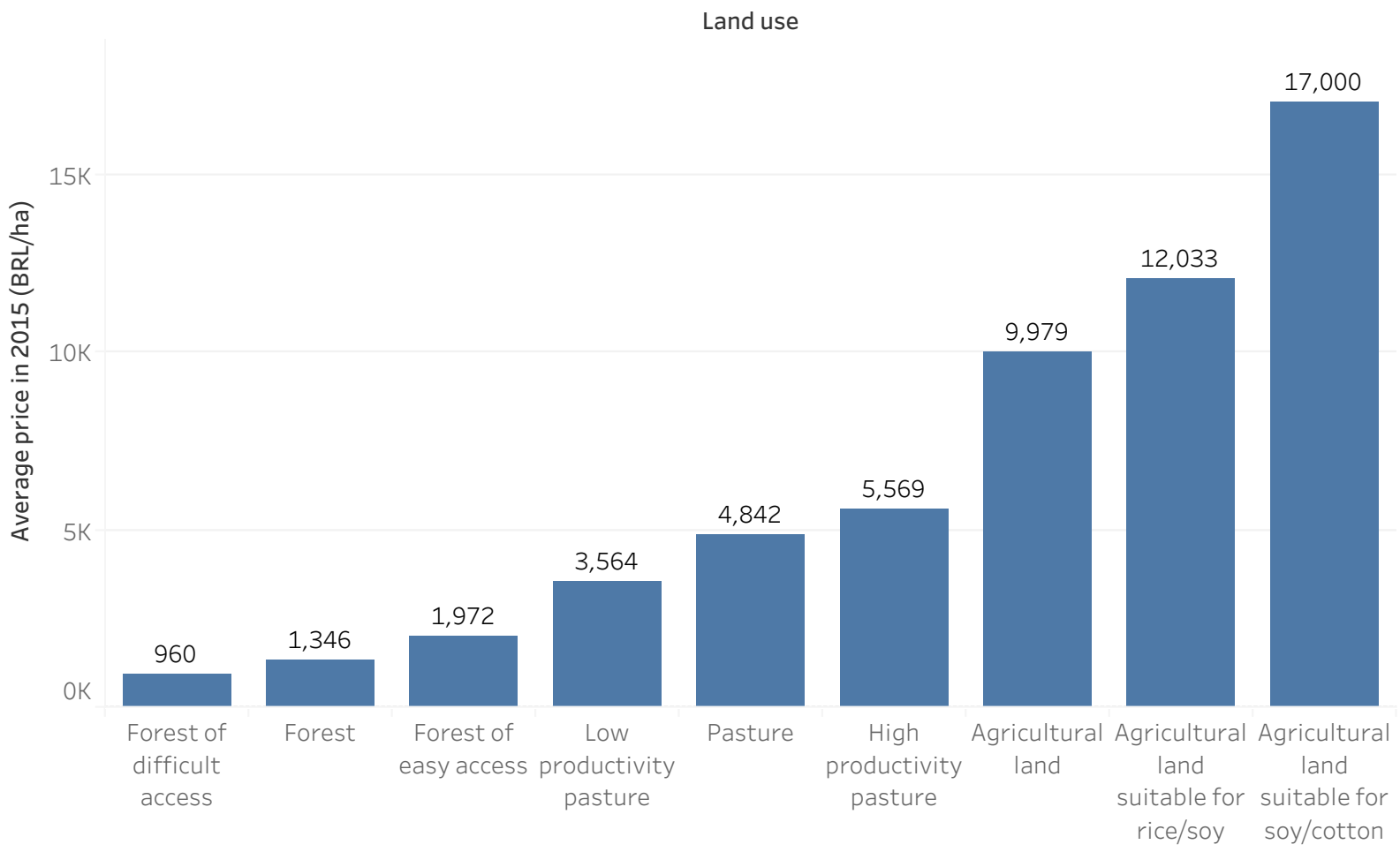

Source: Elaborated by the author with data from AGRAFNP (2015).

Godar et al. (2011) have shown that along the Transamazon highway, the total amount of deforested area on properties is higher for largeholders, while the percentage of the property that is deforested is higher for smallholders. In other words, while smallholders contribute less to total deforestation than largeholders, they nonetheless deforest a relatively bigger proportion of their own areas. Since we focus here on deforestation from the perspective of the farmer (i.e. relative deforestation), 
these findings, included in Appendix 2 (p. 166), support our hypothesis that the depletion of forest assets increases with $X$.

This deforestation process involves other actors than the farmers themselves. Alencar et al. (2016) mapped deforestation polygons within agrarian settlements of the Brazilian Amazon (representing 600,000 families and $8 \%$ of the region's area). $28 \%$ of the polygons were smaller than 10 hectares, coindicant with activities that farmers of this size could perform given their means of production. $72 \%$ were larger than 10 ha, indicating the intervention of external agents through predatory timber logging and land concentration, even though the law forbids these actors to operate in settlements (ALENCAR et al., 2016, p. 13).

The strategy of depleting and selling land partly helps to explain an apparent paradox: cattle-raising generates an annual income per hectare that is substantially lower than for other products, but this does not reflect in actual land use, where cattle dominates $75 \%$ of agricultural land in Brazilian Amazon, as shown in Figure 24 on the next page. The paradox is only apparent because income calculations only compute the revenues from sales of cattle. It neglects timber extraction and land speculation as income sources which are tied to this activity. Researchers have also found that more and more smallholders switch from planting annual crops to raising cattle because i) prices have been volatile for the first, while prices for the latter have followed a more stable, rising pattern, and ii) cattle ('live-stock') is a liquid asset that farmers can sell and convert quickly into cash when needed (AGUIAR GOMES et al., 2012). In a context of little to no access to credit (see Figure 14, p. 105), farmers use cattle as their readily available financial instrument to keep liquid and manage risks.

Cattle production in itself can also deplete assets. Townsend et al. (2010, p. 30) note that pastures implanted after clear-cutting a forest through slash-and-burn follow a relatively similar pattern in the Brazilian Amazon. For the first three to five years, pastures have good levels of productivity, due to the increase in soil fertility gained from biomass ash. Later on, productivity decreases and weeds proliferate, as decreasing levels of fertility weaken forage grass. This process of asset depletion can culminate in highly degraded pastures, with little to zero productivity. Producers get gradually decapitalized, with less and less resources to invest in good pasture 
management ${ }^{32}$ and environmental practices which over time result in pasture degradation.

Figure 24: Average annual gross income (USD) and proportion of land use (\%) for major commodities in the Brazilian Amazon
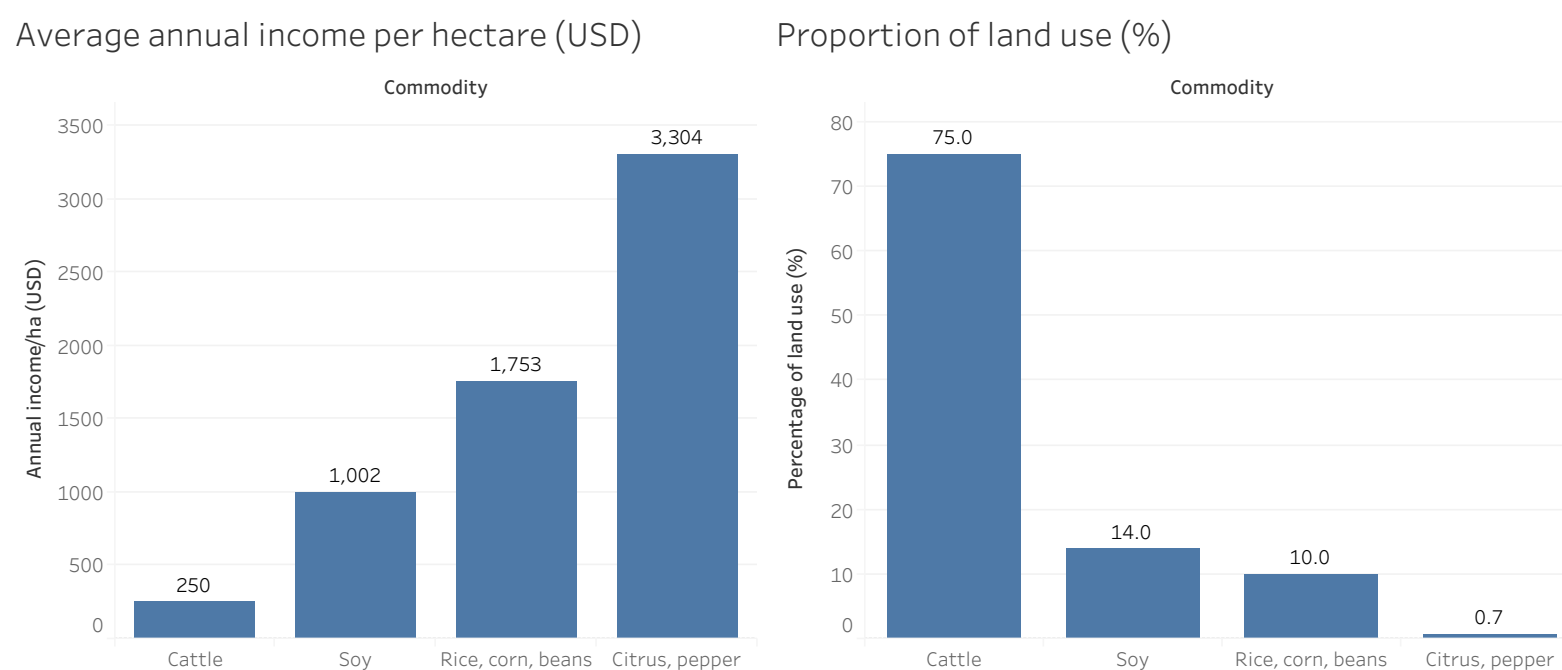

Source: Elaborated by the author with data from GARRETT et al. (2017).

\subsection{Analysis of raise in liabilities}

We cannot determine to its full extent what happens in terms of the rise of liabilities across groups of farm size with the data provided by the census, but available data nonetheless points to concrete aspects tied to this issue.

Data on cost avoidance (Section 4.5) indicates that when $X$ rises, farmers spend proportionally less to maintain the productive capacities of their assets. If farmers fail to spend on fertilisers, for instance, the using up of current fertility amounts to the depletion of assets and futures possibilities to make up for the present lack of income.

Figure 15, p. 106, showed that when $\mathrm{X}$ increased, more farmers occupied land. Land occupation raises farmers' liabilities. Farmers who occupy land, even legitimately, do not own the land. The occupied areas that appear as assets have not been paid for and the corresponding liabilities were not computed into their balance

\footnotetext{
${ }^{32}$ Recovering degraded pastures requires significant investments. For instance, farmers need to remove weeds from the field, re-aerate, fertilise, and lime the soil, and introduce new leguminous plants and forage grass, among other investments.
} 
sheets. These hidden liabilities show up when the owner of the land claims it. In this case, the land is either i) granted (e.g. often in public areas) in which case the liability is written-down, ii) compensated for in which case a liability which was hidden now appears and is paid for on the farmer's accounts, or iii) reclaimed, in which case the liability disappears but land ceases to be available as a productive asset.

Patterns, especially those shown on Figures 20 (p. 113), 21 (p. 115) and 22 (p. 116), clearly indicate that when $X$ rises, liabilities from non-compliance with the Forest Code rise accordingly, with both legal and environmental implications. This is significant empirical evidence of the raise in liabilities when $X$ increases. Noncompliance with the Forest Code and recovering these environmental liabilities is a topic of high importance for sustainability in the Brazilian Amazon. In most of the groups, levels of income indicate that farm size is too small to both generate enough income and, concomitantly, to abide by the Forest Code. Conversely, receiving true prices would allow farmers both to avoid generating liabilities in the first place and to recover these liabilities when they arise. Farmers also need access to appropriate finances to recover these liabilities through afforestation.

We need to look at the literature to evaluate the further effects of untrue prices on the rise of liabilities. Del Giglio (2018, p. 31) reports a default rate of $20 \%$ for smallholders benefiting from agricultural credit from public agency AFEAM in the State of Amazonas in 2018. Amaral et al. (2006, p. 12) report a 33\% default rate for recipients of the FNO credit line in the South of Amazonas. Both AFEAM and FNO lines of credit are awarded to family farmers, defined as a farmer with up to 400 ha of land in the Brazilian Amazon. These default rates indicate high proportions of smallholders who took credit and could not pay it back, which is consistent with the model's expectations. One important caveat in evaluating the rise in levels of indebtedness as a tactic is that few could get into debt in the first place. Data in Section 4.2, Figure 12 indicates very low access to credit. Most farmers either did not have access to credit, did not have collateral (especially land) to pledge, had already used this collateral for another credit, or had already defaulted on previous debt. In these conditions, we might expect that, under untrue prices, farmers would be more inclined to use the other three strategies, since they were more readily actionable. 


\subsection{Summing up}

Empirical evidence confirms that the causal mechanism and its parts were operating on deforestation fronts of the Brazilian Amazon in 2017, providing another successful test that confirms the external validity of the causal model. We observed that when $X$ raised, farmers adopted the expected strategies more markedly, and $Y$ also raised.

Another research question asked whether untrue pricing could be understood as an intermediate variable that channels the different drivers of unsustainable development in the Brazilian Amazon. We have provided a causal explanation that articulates how the different drivers of unsustainability on deforestation fronts interact with each other. The model is a good explanation of how issues ranging from agricultural prices, predatory timber logging, land speculation, the poorly planned creation of agrarian settlements, and the expansion of cattle and soy farming coalesce on the deforestation fronts. The causal model makes sense of how all these factors relate to one another, either because they result from untrue prices or contribute to their generation. All these drivers combine into untrue prices and unhealthy income statements and balance sheets for most farmers. These farmers need to compensate in one way or another for the corresponding lack of income. Many drivers of deforestation are higher-level, distal causes that contribute to generating a proximate cause, untrue prices and lack of income, which in turn lead farmers to adopt the four unsustainable strategies that we identified.

The analysis also confirms that, overall, rural development on the deforestation fronts of the Brazilian Amazon was profoundly unsustainable in 2017, from the points of view of farmers, society, and the environment. The public and private lines of action that are currently preferred to ensure 'zero deforestation', namely command-andcontrol and market restrictions, stigmatise farmers yet do not solve the problem of widespread lack of income in the region. Public and private policies will not work if they do not comprehend the concrete challenges faced by farmers operating under untrue prices. A vast array of private and public policies could be considered to ensure that prices are true for farmers for the kinds of land uses that society deems sustainable. We will not discuss further which policies would make sense in the specific case of the Brazilian Amazon, as the topic is complex, and the purpose of this chapter was to provide a complementary test of the causal model. 
We must make clear that the causal model only illustrates a fragment of the complex reality on the deforestation fronts of the Brazilian Amazon and does not pretend to explain it exhaustively. Other theories are extremely helpful in understanding the unsustainable dynamics observed in the region, such as institutional economics or public administration and governance literature. Applying the causal model to this case does not and should not preclude us from looking at it through these other lenses. The model only complements a range of valid perspectives, whose discussion is beyond the remit of this thesis.

In the next and final chapter, we draw conclusions about the existence of the causal model in light of the two cases that we explored in the current and the previous chapter, draw policy implications, and suggest avenues for future research. 


\section{Chapter 5: Conclusions, policy implications and suggestions for future research}

This chapter is constituted of three parts. In the first part, we draw conclusions about the hypothesis that untrue prices contribute to unsustainability. We also propose four indicators to measure progress towards true pricing and sustainability. In the second part, we then reflect on a series of policy implications that arise for four types of actors: producers, buyers, investors, and public policymakers. This section intends to explore rather than make definitive statements about the implications of true price as a condition of sustainability. It would be a vain effort to try to cover all the possible policy implications. We only offer a few pointers, which would require more research. In the last part, we discuss the limitations of this thesis and suggest how future studies could remediate them.

\subsection{Research conclusions}

Academia and businesses are still relatively in the dark regarding what sustainability actually means and entails in theory and practice, and many self-declared 'sustainable innovations' actually do not amend the status quo. The influence that pricing (of products, services, assets, or liabilities including debt) has on determining sustainability levels is one of the key blind spots. This thesis has shown that our understanding of sustainability becomes clearer when we consider the economic imperative of true prices. Common sense foresees that an economy running on untrue 
prices is unsustainable in the long run, the more so, the more it becomes one world economy rather than several national economies. But this thesis showed that the concept has far more wide-ranging ramifications. We fleshed out and tested a causal model that locates one of the root-causes of unsustainability as residing in businesses who pay and receive untrue prices. We have contributed to unravelling the mystery of sustainability and to having made this idea less elusive, more coherent and achievable. The thesis also provided tools to measure and move closer to it. In other words, it helped to refine the economic ontology, epistemology, methodology, and practice of sustainability.

We have gathered accounting and empirical probative evidence to support the claim that untrue prices contribute to unsustainability. Accounting conveys theoretical grounding to the model developed in Chapter 2, while the cases of the coffee crisis and the Brazilian Amazon in Chapters 3 and 4 bring empirical foundation to it. We found strong evidence of the functioning of the four parts of the model both in historical record for the coffee crisis and census data for the Brazilian Amazon. The probative value of these two cases comes from the convergence of many different pieces of quantitative and qualitative evidence, with a high level of independence between the two cases, all pointing to the existence of the causal model. The persistent discovery of evidence confirming the existence of the causal mechanism in these two cases, and the simultaneous absence of evidence to the contrary, give enough empirical grounding to grant some level of generalizability to the model. The two case studies show that the model is flexible enough to accommodate different kinds of situations and methods of analysis. Multiple independent variables may interact to generate untrue prices, but we can analyse all these different situations by using the same framework provided by the model. Evidence indicates that producers adopt peculiar combinations of the four strategies and an even more specific set of tactics depending on their operational context. The same mechanism can operate in many different ways, but the same four strategies are, to a smaller or higher degree, generally present and interacting with each other. The model's flexibility stems from the universality of the logic of accounting, which tracks what happens within and between economic agents, regardless of operational circumstances or levels of analysis (e.g. individual, local, regional, national or global). By considering the core structure of double-entry bookkeeping and the constraints it places on businesses, we deployed a promising 
method for understanding how prices affect sustainability. Accounting is an instrument from which we derive clear and reliable information as well as recommendations upon which actors can act in micro-, meso- and macro-economic situations.

Our model identified four causal paths through which untrue prices lead to unsustainable outcomes. But what would have been the pathways and the outcomes had the prices been true? This question asks us to develop a mode of thinking that runs counter to the logic exposed in Chapter 2. Since the four strategies are symptomatic $^{33}$ of untrue prices and alienate sustainability, their absence and the adoption of opposite strategies are a necessary precondition for true prices and sustainability to arise. If we reverse the logic employed in Chapter 2, we derive four indicators which, in combination, provide a series of proxies for or symptoms of the umbrella concept of true price.

Prices are true or being truthened if, over time, businesses:

1. Do not rely on non-operating income to attend to their needs (including rent, speculation, subsidies, or remittance);

2. Cover all the expenses necessary to attend to their needs, including to maintain and improve their productive assets;

3. Have optimal access to productive assets and are not financially compelled to deplete or dispose of them;

4. Decrease debt levels and debt/equity ratio and are able to pay both interest and capital with their operating income (i.e. they are hedge borrowers).

By way of illustration, Figure 25 on the next page represents how progress towards these indicators, and therefore sustainability, would appear in business accounts. The red arrow indicates the truthening of prices and income. The number of each black arrow refers to each of the strategies listed above. Figure 25 shows the symmetries and connections between the different changes in accounts that are caused by or lead to true prices. Businesses can monitor these indicators to measure if they are progressing towards sustainability and to firewall themselves against untrue prices.

\footnotetext{
${ }^{33}$ Of course, these strategies can also be the symptoms of other causes. For example, cost avoidance can either be the symptom of untrue prices or profit-maximizing behaviour. It is by observing the context in which cost avoidance arises in a specific case that we can tell whether it is a symptom of the former or the latter.
} 
These indicators represent four ways which any business can combine to navigate a business into a sustainable situation. They highlight a salutary rather than pathogenic or palliative approach to delivering sustainability. They actively promote sustainability and incorporate all the financial aspects of doing business. True pricing furthers sustainability and prevents (rather than mitigates) unsustainability. The set informs how prices can be truthened and true pricing can be upheld in financial and accounting practices. There are, for instance, significant qualitative and quantitative differences between the accounts of a business that is internalising externalities and those of a business which does not generate externalities in the first place.

Since these four indicators are interrelated, we should not consider them separately. Positive changes in one indicator may cause, or be offset by, adverse changes in other indicators. For example, using productive assets (strategy 3 ) or debt (4) to finance expenses (2) is akin to 'robbing Peter to pay Paul', an inherently temporary and unsustainable tactic. To be truly sustainable, a business or an intervention must simultaneously result in positive changes for these four indicators.

Figure 25: Representation of indicators of progress towards true prices

Business

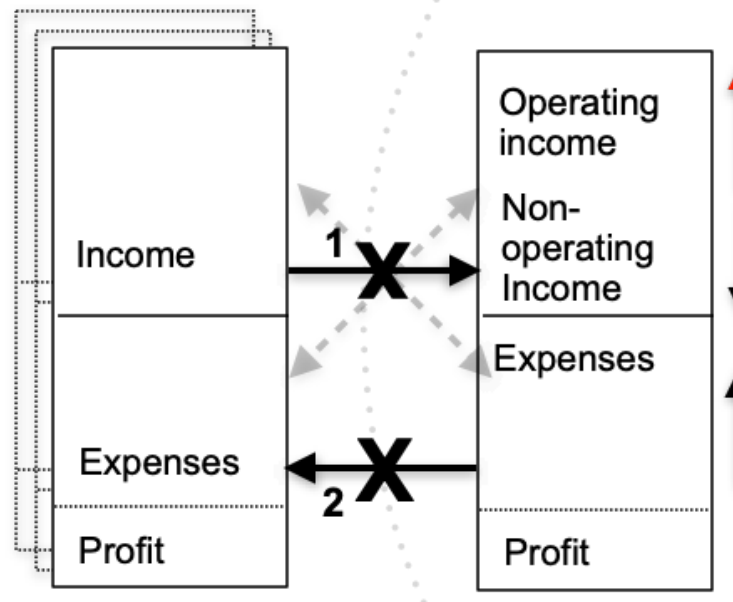

Economic partners

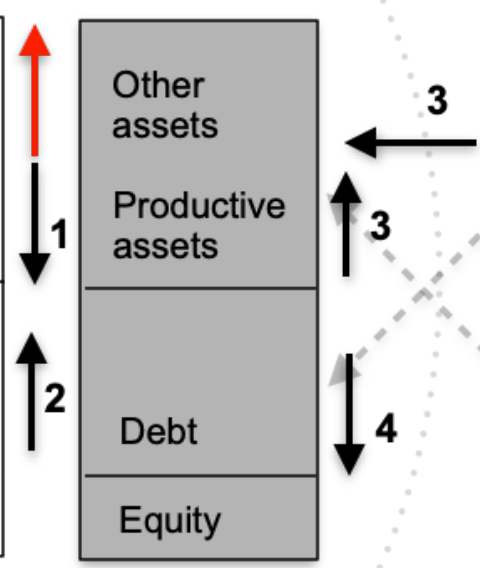

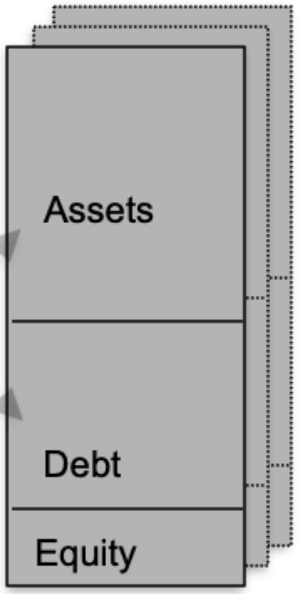

Source: Author. 
The proposed indicators reframe the question of how to move from unsustainability to sustainability into a transition from untrue to true pricing. They are devoid of academic or corporate jargon and permit not only economists but also nonspecialists to connect theory and practice and further true prices. These indicators satisfy three important practical criteria. First, they derive from the universal logic and practice of accounting, and therefore apply to all types of businesses, regardless of operational specifics, thus allow for benchmarking and comparisons among companies and aggregated entities. Second, they capture progress towards the three dimensions of sustainability (economic, environmental, and social) in an embedded manner and delineate clear directions for pricing policies, legislations, investments, and private and public behaviour. Third, they are unambiguous, verifiable, simple to measure and assess (businesses have direct access to the data needed) and meaningful.

The purpose here is not to provide 'metrics' and define clear limits. A metricbased approach is limited because it does not allow for conceiving of sustainability in a dynamic way. What matters most when observing the proposed indicators is not the values of a specific indicator at a specific moment, but to evaluate whether development strategies are healthy and going in the right direction. In that sense, the usefulness of this set of indicators lies more in that it allows us to reflect more dynamically about the causes, inter-relations, and feedback loops that generate sustainability. It permits us not only to measure better sustainability, but also to think more clearly and practically about how to deliver it. We have not provided a definition of what a sustainable business or economy is, but a dynamic perspective of what any sustainable development strategy entails from an economic perspective.

True pricing also helps to illuminate the current discussion about the distributive aspect of sustainability, which is often framed in terms of egalitarian or non-egalitarian views. True pricing provides an approach to the social distribution of natural, human and capital resources that does not require to develop and enforce moral or legal concepts of equality of income or wealth.

Even if the causal model and these indicators are grounded in accounting, it does not mean that we need to have access to everyone's accounts to see any use in them. We live in a world where we can find plenty of external evidence of the existence of specific accounting behaviours. For instance, one can easily identify cost avoidance without looking at the accounts of a person, household or business. What we need to 
observe is precisely what is not currently being computed in the accounts. We will further true prices more swiftly if we transparently share accurate accounts, but we do not need to wait for that to take action.

A popular modern view on sustainability is embodied in the book The Great Leveler (SCHEIDEL, 2017), which argues that inequality - a key aspect of unsustainability - will keep prevailing until humankind has to deal with a drastic event of force majeure. One, or more, of the four horsemen of the Apocalypse will have to strike to balance our society: war, revolution, natural disasters such as climate change or pandemics, or the collapse of states. We disagree with the view that only massive catastrophe or violence have the power to make our economy more sustainable. Instead, true pricing might be another leveller to consider, which has the significant advantage of not riding out from the Apocalypse. We hope that this study demonstrated that true pricing and accounting can help us deliver sustainability, and that there is no need to wait for tragedy to do it for us.

\subsection{Policy implications}

This section discusses the policy implications of true price as a condition of sustainability for producers, consumers, investors, and public policymakers. Each of these actors have agency. ${ }^{34}$ One entity can indeed play the roles of different actors. For instance, a state is both a producer of public services, a consumer, an investor, and a public policymaker. We only discuss these roles separately for analytical purposes.

How much would producers need, and how far are actual prices above, or below, the true price threshold? This thesis was not about defining producers' needs in their full extent. But it is also clear that if certain necessities are not met, we cannot say that prices are true. Producers need access to goods, services, and finance both to operate their businesses and for personal consumption. They need minimum levels of financial security, that is, the guarantee that their life will not be majorly disturbed. For instance, farmers need to be protected from major market swings or climatic events, sudden

\footnotetext{
${ }^{34}$ Here, the term 'agency' is used in the sociological sense of having the ability to act autonomously and to make free choices.
} 
health issues or unemployment, with enough self-provision of cash reserves or appropriate insurance instruments. People also need to take care of their health, with adequate food, medicine, and leisure time. Arguably, every human being needs to be free of debt and to reach balanced (not necessarily positive) net worth at some point in their life. In accounting terms, their total assets need to equal their total liabilities, eventually. Prices must be high enough to cover the full costs of production, including financial obligations such as rent or interest on capital. Producers falsify prices when they generate and pass on liabilities and costs to other producers, current or future, or if they pay wages that do not cover even the basic needs of workers.

In some cases, when prices are so low that businesses cannot cover all their legitimate costs and make a profit, it may be that they simply need to move on to other business activities because their business is not functioning well or needed. Among other reasons, producers may fail to maintain a business because they do not attend to the needs of their customers, manage their business or finances inappropriately, ${ }^{35}$ or rely too much on the value of their assets as collateral. In all these cases, true pricing might involve closing the business and redirecting the producer to another branch of the economy.

If producers do not dispose of enough liquidity so that they have a negative cash flow during the production period, then prices are also untrue. To keep liquid, producers need to generate positive cash flows during the production cycle. Ideally, producers should be paid at the beginning of the production cycle for products to be delivered, and payment understood as credit received for future production. ${ }^{36}$ If producers run through periods of negative cash flow, they need enough credit and working capital to finance the gap, otherwise they will draw on their balance sheet, for example by reamortising loans, using up or selling their assets, reducing depreciation expenses, or increasing accounts payable. In such cases, the cash flow may look positive, but in reality, prices are untrue.

\footnotetext{
${ }^{35}$ For instance, poor practices in terms of production, time management, spending, investment, marketing, or accounting.

${ }^{36}$ On the futures markets, producers agree with buyers on the price for delivering a specific quantity and grade of a product at some future date. In effect, they hedge against the risk of price swings and finance the production cycle ex-ante. This is the main economic benefit of futures markets for producers, at least in theory. Indeed, futures markets are often distorted and can falsify prices, but these are implementation failures rather than motives to dismiss futures markets altogether.
} 
Furthermore, producers need to raise enough income to keep solvent. Businesses are solvent if their current assets are sufficient to cover current liabilities. Current liabilities are debt and interest that have reached maturity. Producers who receive untrue prices may not generate enough capital during the production cycle to cover all current liabilities. Over time, these producers need to devote more and more current assets to the financing of liabilities, which may crowd out revenue-generating investments. Alternatively, producers may finance their assets with more debt or fail to compensate for their depreciation. They thereby reduce their future income because they are endowed with less productive assets. When producers receive true prices, they can depreciate, amortise, and further invest in production. They increasingly finance production with self-generated capital rather than debt.

True pricing helps progress towards optimal allocation of human, environmental, and capital resources. We express optimal resource allocation as a situation where producers have access to enough resources and use them with minimal to no waste and pollution during production. To determine whether we allocate resources to producers optimally, we need to compare the productive assets they get to those they need to operate as sustainably as possible. Producers may hold assets that are below or surpass their productive capacity. If they receive more or less capital than they need, they are either under- or over-capitalised. In the first case, the producer's capacity stretches out available capital. The producer needs an inflow of capital. In the second case, it is capital that over-stretches the producer's capacity. Such producers need to outflow the capital they hold in excess. In either case, the allocation of resources is sub-optimal.

Producers can diversify or verticalize production to increase their income. Diversified income streams can help to spread financial risks, stabilize cash flow throughout the year and provide opportunities of synergies between activities (e.g. fertility transfers on a farm). That said, it is not always possible for producers to diversify and verticalize. They need time, skills, funds, technical support, and access to profitable markets in order to do so. Maybe more to the point, when producers compensate for untrue prices with diversification and verticalization, it may also be that they only circumvent the root of the problem. Subsidising unprofitable economic activities with profitable ones does not solve the profitability issue of the former in any way. Internal forms of subsidies or remittance do not truthen prices any more than 
external ones do. They simply make untrue prices more bearable and can even have counterproductive effects. They can give the false impression that prices are high enough because producers seem to be coping with them. It is not to say that producers should not diversify or verticalize, only that true price indicates that the chosen solutions need to have a sound economic basis such as synergies between activities, improved cash flows, or more optimal use of productive assets.

If producers both receive and pay true prices, accounting expects that they will always make a profit. If the ethos shifts from profit maximisation to true pricing, the question is not how much profit producers can make, but how many expenses and sales are enough and what to do as investors with the profit. We will discuss the second question later in this section. Producers who receive true prices and already satisfy the needs of their customers have no reason to push for more sales through marketing or other means. In these cases, producers need to check if inducing more consumption and producing more has any economic grounding, since overproduction results in price falsification. One proof of this is that several markets have attempted to reduce overproduction by adopting caps and quotas. ${ }^{37}$

Predatory pricers ${ }^{38}$ or undercutters drop prices below their cost to produce. Many companies routinely act as predatory pricers, for example, Amazon, Walmart, or airline companies. During the period of predatory prices, the profit of undercutters are negative and prices are untrue. They can sustain these prices because they have stronger balance sheets and are able to burn more cash for more time than their competitors. Once their competitors vanish, undercutters can raise prices and recoup their losses with more market power or higher prices. In essence, predatory pricing consists of falsifying prices for both the dominant and the other producers. Predatory pricing is, therefore, fundamentally unsustainable and can also lead to oligopolies or even monopolies.

Before we discuss the implications of the thesis for consumers, we must clarify our use of the term. We use 'consumers' to refer to buyers in general, that is, all the

\footnotetext{
37 For instance, see the quotas or planting rights established by the European Union's Common Agricultural Policy for products such as milk, sugar, or wine.

38 Predatory pricing is described as "a deliberate strategy, usually by a dominant firm, of driving competitors out of the market by setting very low prices or selling below the firm's incremental costs of producing the output. ... Once the predator has successfully driven out existing competitors and deterred entry of new firms, it can raise prices and earn higher profits." (OECD, 2002)
} 
economic agents who purchase goods or services. ${ }^{39}$ True pricing challenges most buyers' view that prices paid to producers are a cost that should be kept to a minimum. One may argue that true pricing would not be an affordable policy to consumers. Such reasoning does not consider that most if not all consumers are either a producer or a dependant of producers. Since true price emphasises the needs of producers and their dependants, if all consumers pay true prices, they guarantee indirectly that their own needs are being met. In theory, an economy that adopts both a true pricing policy and a universal social security system attends to the needs of all consumers, not just those of those who are also producers. The social security payments made by producers are enough to cover the expenses of all non-productive consumers, ranging from retired to sick, unemployed, or disabled people. In such an economy, all the expenses of nonproductive consumers can be paid by the contributions of current producers: true prices ensure that they can afford to. The whole population of consumers is encompassed in such a scope, since, in the aggregate, all non-productive consumers are directly or indirectly covered as dependants of all producers. The arrangement also does not require the non-productive consumers to live off their balance sheets, such as capital gains from speculation or rent, and possibly removes drivers of price falsification.

Consumers and producers may disagree on the appropriate price during an economic exchange. Consumers may say that they cannot afford the prices they pay, and producers that the prices they receive are untrue. How can consumers and producers settle the price in such a case? They could look at the issue neutrally and objectively, by observing the impacts of said price on each other's accounts, especially the permanent accounts on their balance sheets. Consumers, just like producers, have balance sheets. If they pay untrue prices, their balance sheets give the false impression that they have more liquidity than they really do. Consumers can accumulate capital by paying prices that are untrue. Since this portion of capital only exists on their balance sheets to the extent that the producers' needs were deprived, consumers should consider whether they really own it, and transfer it back to their suppliers, or at least pay true prices next time around or in the first place. If consumers can pay true prices and not leave their own legitimate needs unmet, then they have no

\footnotetext{
${ }^{39}$ Consumers may range from households to small or large businesses, governments, and non-profits, and may also simultaneously play the economic roles of producers or investors. The category embraces not only producing, but also non-producing, consumers.
} 
economic justification not to do so. ${ }^{40,41}$ The exact changes of conduct or amounts or forms of compensation could be decided objectively using accounting. Buyers should assess the occurrence and intensity of unmet needs among their suppliers and give to these unmet needs an overriding priority when deciding how much, when, and how to pay them.

If prices are too high that they become unaffordable to buyers, then it may be necessary to decrease them. (Again, we need to stress the caveat that 'too high' prices for consumers may also mean their own income is too low or untrue.) More products can be delivered at a lower price if production is expanded by involving more producers and making the related investments. Or we can increase the productivity of current producers. The correct way to intervene would depend on the cause of the lack of production. For example, is it demand or production costs that are in excess? Or is it productivity or access to productive assets that is lacking? If prices are too low or untrue for producers, then either prices or productivity have to increase or some producers have to leave the business because they upset the balance of prices by causing overproduction. We can deliberately reduce the number of producers to reduce production and raise and truthen prices for the remaining ones. A smaller number of producers can receive lower, yet true, prices if their productivity levels are raised to sufficient levels. Again, the correct interventions would depend on the context.

At the societal level, advocating for true prices does not mean that one defends ever-increasing prices. When prices are untrue, they are not necessarily too low; they can also be too high. For example, the costs of accessing assets or debt can be too excessive and raise the costs of production to inappropriate levels. In this case, moving towards true pricing can involve the deflation of asset or debt prices and have the effect of diminishing the prices needed to be true. Nor does true pricing go against the needs of consumers, or understand that competition is nocuous. The concept of true price does not emancipate producers from the obligation to bring actual value to consumers,

\footnotetext{
${ }^{40}$ For example, according to the Financial Times (2019), as of August 2019, Apple and Alphabet had respectively 117 and 102 billion USD in cash reserves, net of debt. If an analysis of the prices paid by these companies to their suppliers shows that such prices are untrue, they can clearly afford to use their cash reserves to pay true prices.

${ }^{41}$ In the case of the coffee sector, the downstream value chain (i.e. traders, roasters, consumer goods companies, and retailers) has grown significantly over the last decades. But Valiente-Riedl notes that that growth was based "not so much by increasing retail prices, but simply by reaping the rewards of lower [coffee] market prices" (2012, p. 43).
} 
but rather questions whether competition makes any economic sense when the competitors operate under untrue prices. We do not need to abolish competition at all, but reconceive its meaning. The verb 'to compete' comes from the Latin competere, which means to strive in common, to aim at together. In contrast, most people in the modern world see competition as entering in rivalry or enmity. One could rethink the concept of competition as producers, investors, consumers and policymakers seeking true prices together. It may be that prices are untrue as a result of excessive competition, or vice versa. It could be the case that too many producers are competing or that some of them are excessively competitive. In these cases, resolving competition issues becomes answering the questions of how to transfer the producers in excess to other branches of the economy, or how to reduce the excessive competitiveness of some producers and raise the insufficient competitiveness of others.

According to a popular view, under a capitalist system, prices conceal instead of reveal to consumers what happens during the production process. The argument goes that since capitalism is based on an opaque market pricing mechanism, consumers cannot know if their purchase is sustainable by looking at prices. Only technology can tell them if what they buy was produced sustainably or not; prices are sources of disinformation (SCHÖNBERGER; RAMGE, 2018). For instance, if we buy milk, it is not the price but, say, chips on cows or a blockchain system which will accurately inform us of their well-being. We argue that seeing in technology our main or only saviour is unjustified. Prices, when their effects on the accounts are properly understood and observed, generate a wealth of information on sustainability. Rejecting prices as a key spring of information for consumers is a critical mistake. True pricing is, above all, a matter of clear human thinking and will. Technology cannot be a shortcut, only an auxiliary support. What matters most is that consumers actually further thoughts and deeds that are conducive to true prices.

We continue our discussion of policy implications with the case of investors. The model and the results of the case studies provide technical grounding to Aristotle's claim that "we cannot . . . do fine actions if we lack the resources" (2009, p. 21). The implications for investors are twofold. Investors should stop investing in ways that falsify prices and make more investments that truthen prices. To understand the difference between these two types of intervention, we can consider two examples. 
Both these examples involve speculation, here in the specific sense of some asset bought, unaltered, and then sold at a higher price.

The first example is investors who buy shares in a company. They can buy equity in two different ways. If investors buy shares during an Initial Private Offering for privately-owned businesses or a Seasoned Offering for publicly traded companies, they inject capital into the producer's balance sheet. Producers can then use this capital to further productivity, incomes, and truthen prices. Investors can also buy shares which are traded on secondary stock markets. In this case, they do not inject cash into the company. They only trade the right to claim dividends and sell the share in the future, the effect of which can be to inflate the costs for producers in the event that they have to retain more earnings to pay the required dividends. We could say that the first type of investment can further true prices: investors inject capital that producers can then use to optimise production. In the case of buying shares on the secondary stock market, the investor has no positive impact on capitalising the business. No new capital is thereby made available and, if profit maximising is the operative policy, dividends can increase costs and falsify prices.

The other example is the case of landlords charging rent to let a producer use the productive assets that they own. Before renting these productive assets, these landlords may have done work that improved the quality of these assets. For example, they could have reformed and improved a building or improved the fertility of the land in some way. In this case, they have produced real work that increases the productivity of these assets. These landlords had needs and incurred costs when they improved the productivity of assets. Maybe they also incurred debt to buy these assets. It is therefore reasonable and necessary for landlords to charge rent to recoup these expenditures because when producers pay rent, they get access to these improvements. Provided it is not too excessive, such a rent furthers true prices. An economically different case is when landlords ask rent for granting access to land without making any improvement. Let us imagine a typical case of an investor cashing in when real estate values are high or rise quickly. One example could be buy-to-let investors, that is, investors who buy properties only to rent them out. ${ }^{42}$ They do not

\footnotetext{
42 As a sign of the times, the UK Daily Mail organised in 2015 a competition for a buy-to-let house worth 260,000 GBP. The retired woman who won the competition used the money to pay for her own mortgage (MARDSEN, 2015). In effect, she created a stream of revenues that falsified prices to others in order to
} 
contribute in any way to production or increases in productivity. Producers raise their production costs by paying rent or buying assets at speculated prices. They can respond in two ways. First, they can raise the prices they charge to their customers, in which case the only effect on producers and the economy is inflationary. Second, they can adopt the four strategies discussed in this study. In both cases, the outcome is a decrease in sustainability.

Investments falsify prices if, as a result, access to productive assets is made more expensive or worse. Such investments syphon off the income of producers, increase the break-even cost of doing business, and become unjustified overheads, which only weaken balance sheets. Investors provide capital to producers in the form of debts, mortgages and shares. To establish the returns they want, they often refer to the prices of these property rights and bonds on the markets, where prices vary depending on financial speculation. Investors can make capital gains by speculating on different markets, such as raw materials, real estate, currencies, shares, bonds, holdings, and derivatives, for instance. These capital gains falsify prices if financial returns are more related to market speculation rather than to the income that producers can generate. When the interests and dividends that producers need to pay become connected to these market fluctuations, producers need to service dividends or debt repayments that are unrelated to their productive reality. The coffee crisis showed that it is unrealistic for creditors to ask producers to service debt levels that their income levels cannot cover. In that sense, a price may be untrue, not only because it generates too little income, but because the burden of paying rent and dividends and servicing debt is too high, or because businesses have no or inadequate access to finance. True pricing would both require the reduction in price-falsifying rents and to diminish the reliance on these rents. In macro-terms, the 'right' relationship between income and capital, trade and finance, goods and money would be restored.

Conversely, investments truthen prices if, as a result, producers have better access to capital. To truthen prices, investors can lower the threshold for prices to be true by capitalising producers in ways that improve access to productive assets and incomes, for instance to expand their operations, save on costs or improve productivity. These investments increase productivity, lower the threshold at which prices become untrue prices both fuelling and being fuelled by price falsification. 
true and strengthen the balance sheets of producers. In doing so, investors need to be aware that producers currently operate in the context of a market economy. Market prices emerge regardless of the variability of productivity and profitability levels across producers. This can be problematic because the same price can be true for one producer and untrue for another. To illustrate the point being made, let us compare the productivity levels among producers of cereals. Appendix 3 (p. 167) draws from data from Mazoyer and Roudart (2006) and compares the productivity of the least and most capitalised grain farmers who compete on the same international market. On one side, the world's least productive grain producers are generally poorly endowed with land (e.g. size, location, topography, soil quality), under-equipped, and use manual tools. They cultivate without fertilisers or pesticides, often with unimproved plant varieties. On the other side, the best equipped and land-endowed producers are the most competitive and command market prices. The productivity ratio between these two groups is 2,000:1. This gap in productivity is far from trivial ${ }^{43}$ and urgently needs to be reduced. We use this example to illustrate an important point about the role of investors in (un)balancing productivity and therefore prices. Given the above productivity gap, it would make more economic sense to fund the least capitalised producers and to promote access to land and equipment (e.g. through land reforms or access to credit) than to fix higher prices for them. Chiefly, it may also be that the most efficient farmers are too productive and disturbing the price balance. If so, investors should redirect their investments from the most to the least efficient farmers, ${ }^{44}$ for the current logic is opposite and fuels untrue prices. Such a transition would need to be backed by appropriate public policies.

The main criteria that investors currently use to decide whether to invest their money in a venture is how much interest they will get and what risks they take. Capital moves towards prospects of higher profits and lower risks, and away from prospects of lower profits and higher risks. However, as the example of grain farmers shows,

\footnotetext{
${ }^{43}$ Census data from 2013 surveyed 460 million farmers across 111 countries. $72 \%$ of producers farmed less than one hectare of land, a further $20 \%$ farmed between 2 to 10 hectares, and only $2 \%$ more than 20 hectares (LOWDER; SKOET; RANEY, 2016, p. 23).

${ }^{44}$ By less efficient farmers, we mean here farmers who cannot compete at current prices but would if they had access to the appropriate means of production. We do not mean that any and all uncompetitive producers should be considered here. For some farmers, better access to the means of production may not solve the problem because of internal or structural reasons. In this case, it may be most appropriate to help them abandon the business and move to another one smoothly. In agriculture, history shows that disorderly exit means rural exodus, unemployment, shanty towns, or international migrations.
} 
market prices can be untrue because the pricing mechanism displays discrepant realities between under- and over-capitalized businesses. An economy based on true prices is therefore an impossibility if investors only stick to investments that provide the highest possible returns and lowermost risks. If society wants producers who receive untrue prices to stay in business, investors need to provide equal or better access to finance to these producers than the most efficient ones. If the latter are privileged by finance, a vicious cycle is generated that makes untrue prices prevail more and more. Low income businesses could present higher risks of default that need to be managed differently. Investors can, for example, provide post-disbursement technical assistance to borrowers to lower these risks. When default occurs, the losses can be mutualized, for instance, using risk pooling and group liability.

Pleading for true pricing instead of return maximisation does not mean denying investors any interest at all. The borrower is not obliged to lend back to the other when needed; he or she pays interest partly to compensate for the non-retributive nature of the loan. Lenders also need income to cover a range of costs to facilitate transactions, keep track of them, and manage the risk of default. We agree with Steiner, however, who rejected that compound interest (interest on interest) has any economic grounding. True pricing means that investors need to make sure that their returns are not so high that they overcrowd the producers' capacity to both meet needs and service debt. Compound interest is an exponential function, while the income of producers is not. Compound interest, therefore, defies the reality of production.

If investors ensure that the capital that they provide to producers does truthen prices, traditional performance measures may go down in some cases. In particular the levels of shareholder return and return on invested capital could reduce compared to the rates investors are used to in an economy based on untrue prices. These metrics are normally used to observe and explain if the business performs well, but they cannot tell whether value creation resulted in true prices. True prices may have the effect of lowering these metrics and bring the uncomfortable reality that what is nowadays considered as solid financial management has to be profoundly reviewed. To put it in another way, economic mindsets and policies that truthen prices have the effect of lessening what Karl Marx called the 'fetishism of capital'.

Lenders generally require producers to pledge security against the risk of default. Businesses who borrow money typically provide productive assets as security 
or collateral. Different tangible assets can serve as collateral - for example, real estate, plants, machinery, stocks of saleable products, or accounts receivable. For this reason, investors who lend against collateral call it real credit. Asking for collateral is problematic in situations where productivity varies a lot across producers. The producers who need capital most are the ones who lack assets (and collateral to pledge to get credit). Thinking that real credit can provide capital and restore the profitability of asset-constrained producers is an economic oxymoron. A solution is to capitalise such producers by switching from real to personal credit. Lenders issue personal credit when they base credit, not on collateral requirements, but on the sales of borrowers. ${ }^{45}$ In this case, the credit line does not have the requirement of an asset as collateral pledged to it. For this reason, personal credit is also called unsecured credit. However, personal credit involves security, though not in the form of assets. In this case, lenders calculate the amount of credit and interest based on the borrower's income. They are worthy of credit, not because they have assets, but because of the new, additional, income that the credit will allow them to generate. Many lenders already provide lines of personal credit, yet they paradoxically offer it to businesses who already have a lot of collateral available and least need personal credit. In contrast, they do not provide it to those with no available collateral, to whom most need it. Extending personal credit to businesses who are denied access to real credit would be key to make goods and services more sustainable and cheaper to produce. If an unexpected event, such as the coffee crisis, impedes borrowers' ability to make the profits, lenders would then pursue the same goal as the producer, instead of disposing of their assets as if it was a sound economic action. Lender and borrower would both have an interest in finding the most efficient way to return to profitability and generate enough disposable income for producers through access to credit, matched by capacity building and technical support.

Prices may be untrue not only when they are too low and unprofitable to producers, but also if irregular or uncertain events falsify them. If market prices are (even temporarily) untrue, producers need liquidity to bridge the gap in cash flow. Some of this needed liquidity could come from ensuring that producers make enough profits to accumulate enough cash when these events occur. Nonetheless, producers

\footnotetext{
${ }^{45}$ The verb credit comes from the Middle French crédit (belief, trust). Personal credit consists essentially in placing credence in someone's enterprise, in alignment with the etymology of the word.
} 
cannot hedge themselves against all risks through pre-emptive self-retention. In the case of unpredictable or less frequent events that falsify prices, transaction and administrative costs may be cost-effective enough for the financial industry to provide liquidity. Such financial instruments already exist. They include insurance, hedging contracts, futures markets, and contingent borrowing strategies, for instance. Although in principle such instruments truthen prices, investors sometimes distort them and they end up falsifying prices. Further research could assess to what extent current and new instruments could provide liquidity that furthers true prices. (It bears repeating that, to be viable, the price paid by producers for such financial services should be proportionate to their income.)

Public policymakers will achieve little if they treat sustainability as a legal issue and try to use economically arbitrary legislation and enforcement to impel producers who receive untrue prices to behave sustainably. Neither should public policymakers enforce true prices by fixing them, for that would be anti-economic. As we have seen, prices arise only after a complex economic process has come about, involving many relationships between producers, consumers, and investors, that contribute to either truthen or falsify the final price. So true pricing is not something that law-makers can or should impose. Their role, instead, is to ensure that the legal context does not nudge the economy towards untrue prices in the first place. It is also important to note that true prices would result in far fewer sustainability issues and therefore require less state intervention. For example, had prices been true during the coffee crisis, governments would not have dealt with drug production, illegal immigration, unemployment, foreclosures, and so forth. If the need for states to intervene is reduced, many public expenses would decrease. For instance, expenditures for social protection, health, public order and safety, debt interest, and subsidies to producers and households would diminish.

Governments often intervene by determining from which places and producers to import. Government authorities can increase or decrease how much producers get by imposing taxes on imports. These taxes vary with time and country. If it is more costly to import, importers and exporters ask producers to cut their prices. Authorities can also set quality standards at will on imports. Depending on these quality standards, importers will shift sourcing in ways that impact producers. Governments can even vet 
and sanction certain countries and producers. ${ }^{46}$ Governments can also protect producers from over-production and price falls. They can establish price controls, quota markets, accumulate and even destroy stocks, or raise taxes on traders and commodities, which affect prices in both national and international markets. To state the somewhat obvious, if governments in consuming and producing countries were to see that they would truthen prices if they changed their policies, they could do so at their discretion, at any time. ${ }^{47}$

Another critical question to ponder is that untrue prices may also be a key cause of what Keynes would call lack of 'effective demand' and too much 'latent demand', where consumers want to purchase goods or service but lack the income to do so. When producers respond to untrue prices, they spend less, the macroeconomic effect being a fall in effective demand and a rise in latent demand. True prices would remove the need for governments to intervene with activist Keynesian fiscal policies. Anticyclical policies in case of recessions do not remove overhanging debt (and its pricefalsifying effects), because they only transfer debt from private to public accounts rather than eliminate it. If prices were true, governments would not need to spend money to bail out companies, boost consumption and aggregate output, for producers and their dependants will already have enough income to consume and keep solvent. True pricing is the micro foundation to guarantee what Keynes would consider enough effective demand and the elimination of latent demand at the macro level.

Academics have extensively discussed the fact that the Gross Domestic Product (GDP) is a metric of economic growth, not of economic sustainability. ${ }^{48}$ This thesis suggests another way to look at the problem with GDP as a metric of sustainability: it indiscriminately aggregates activities that generate untrue prices and true ones. Public policymakers need to distinguish these two categories. The more transactions truthen prices and the less they falsify prices, the more sustainable the economy becomes. We should, therefore, separate the part of the GDP that comes

\footnotetext{
${ }^{46}$ For example, in 1962 the United States placed an embargo on all imports from Cuba, including coffee. Cuban coffee-growers planted 170,000 hectares in 1961 and 28,000 hectares in 2013 (FAOSTAT, 2019).

47 Steiner notes that "rather than think, people [prefer] to alter facts, by setting up customs barriers whenever there [is] a problem" (1993, p. 215).

${ }^{48}$ For instance, it mixes up destructive economic activities and defensive expenses (e.g. cleaning up pollution) with economic operations that are beneficial to society. Furthermore, GDP does not indicate anything in terms of economic distribution (e.g. unbalanced accumulation of income and wealth) or about avoided costs such as unpaid work, or unmet school or medical expenses.
} 
from economic activities that truthen prices from the other part. An economy is progressing towards sustainability if it reduces its Untrue Domestic Product and increases its True Domestic Product (TDP). The ratio 'TDP/GDP' is a better indicator of how sustainable an economy is, rather than the size of GDP or GDP per capita. The closer this ratio is to one, the more this economy can be deemed to be sustainable.

Macroeconomists could use the concept of true price to rethink the problems of inflation and deflation of the prices of goods, services, expenses, assets, and debt. Inflation commonly refers to the general rise in prices. Here, we understand that a rise in prices can have either positive or negative effects. It is positive when it furthers true prices (e.g. a rise in wages received by poor workers), and negative when it does not. We should use the term inflation, understood as an adverse economic phenomenon, to refer to the second case. Inflation falsifies prices if, for instance, a real value is exchanged for a fictional or apparent value, such as in the case of rent or capital gains derived from purely speculative activities. What kind of inflation and deflation should we combat, why and how? Is inflation or deflation detrimental if its effect is to truthen prices?

Public policymakers could also further true prices through changes in taxation. Taxation makes economic sense when taxes are lower for what society wants more of, and higher for what society wants less of. If true price is a condition of sustainability, then society will want more true prices and less untrue ones. Economists will thus have to rethink how taxes contribute to falsifying or truthening prices. Higher taxes should apply to financial transactions and relationships that falsify prices, and lower ones to those that truthen prices. ${ }^{49}$

True pricing contradicts the idea that using public resources to subsidise overproduction is sound economic policy. ${ }^{50}$ Historically, subsidies for overproduction have always led, in one way or another, to its dumping ${ }^{51}$ on international markets, with the effect of artificially furthering the purchase of production at untrue prices and

\footnotetext{
${ }^{49}$ For instance, policymakers could set higher taxes for capital gains from compound interest or real credit than for capital gains from personal credit.

${ }^{50}$ For example, the Common Agricultural Policy of the European Union (EU) consumes two-fifths of the EU budget. In the United States, the top $10 \%$ and $1 \%$ of recipients of commodity subsidies received $78 \%$ and $26 \%$ of payments between 1995 and 2019 (ENVIRONMENTAL WORKING GROUP, 2019).

${ }^{51}$ Dumping is the practice of exporting products at prices below the cost of production. It is widespread in agricultural commodity markets. For example, in 2017 , the United States dumped $38 \%$ of its exports for wheat, $12 \%$ for cotton and 9\% for corn (MURPHY et al., 2019, p. 1).
} 
disturbing the price balance. In recent history, governments have tried to decouple subsidies to reduce price distortions by not tying them to the producer's output. However, with the artificial income stream of decoupled subsidies, producers only appear to afford to produce. How to resolve the problem of lack of income differently than with subsidies is another matter and would be a sensitive and complex task. ${ }^{52}$ Our purpose here is not to detail how to proceed to phase out subsidies or to cover all the root issues that they intend to solve, but to highlight that they can divert our attention from structural economic problems we should tackle straight ahead. Worse, subsidies can distort economic incentives to produce by artificially raising profitability and the price of assets, encouraging rent-seeking and further price falsification.

True pricing would not come about in a free market economy as it is understood today (capitalism), but it is neither reminiscent of a planned economy (socialism) because the theory puts the spotlight on the collaborative agency of individuals and businesses in combatting untrue prices, not on some central planning entity. The state has nonetheless a role to play, since the behaviour of agents intending to further true prices should be supported rather than stifled by public policies. We mostly discussed fiscal policy, but monetary policy is equally important - for example, real independence of central banks from both governments and financial markets. However, we argue that true pricing is mostly a matter of us human beings (including public policymakers and central bankers) actively changing our own economic conceptions and behaviours rather than relying on some Hobbesian Leviathan to nudge and steer us in the right direction. We need first and foremost education, transparency, and collaboration, and only use laws and enforcement as a last resort.

\subsection{Suggestions for further research}

This research presents two chief limitations. The first is the choice of case studies and to which extent our findings are generalisable. The second is the risk of overdetermination. We discuss both these limitations and suggest how future research

\footnotetext{
${ }^{52}$ For example, it may be that some producers have achieved productivity levels that are too high and depress prices, that they do not get paid enough for their produce, or that the prices of productive assets have inflated unrealistically.
} 
could overcome them in this section. The coffee crisis and the Brazilian Amazon are cases where we were confident enough that prices were untrue and unsustainability occurred. We could thus see the causal mechanism at work. We also chose these cases because their study was manageable within the scope of a doctoral study. The coffee crisis was an event of a particular nature that affected coffee growers over a specific period, and deforestation fronts of the Amazon are limited by geography. One may argue that these two cases are not sufficient to draw conclusions about the effect of untrue prices on producers in general. We argue that these two cases were not trivial and provided for harder tests. Since many researchers have studied the coffee crisis and the Brazilian Amazon, the cases are well-known; researchers noticed and reported extensively on them. It is easier to contest our findings than it would have been for more complex or obscure cases.

Any theory or model is only useful in as much as it explains a vast diversity of situations. This thesis provided the empirical existence of the causal model in two cases. However, how widespread is it? If the model is generalisable, it should provide insights into other historical or current events. Researchers could investigate new cases to find out how general the model is. A list of all possible case studies would be too extensive to identify and provide here. Suffice to say that price falsification and untrue prices are recurrent economic phenomena. Businesses have repeatedly paid or received untrue prices across history and continue to do so nowadays. The economic system regularly triggers our causal mechanism, repeatedly producing unsustainable development. Price falsification can occur either in sharp, sudden ways or over long periods of time. Interventions or events that result in untrue prices can be either systemic (macro events which affect producers systematically) or idiosyncratic (micro events which affect producers individually). The 1999-2003 coffee crisis was a systemic shock. Other shocks of this type could include natural shocks, for example when production fails due to weather events such as droughts, floods, or diseases. Human beings can also generate systemic shocks. Human interventions could include the hoarding or sales of stocks, changes in exchange, interest, taxation rates, or trade policies, among many other types of interventions. Researchers could also study idiosyncratic shocks. Cases could include, for instance, situations where producers suffer from an internal issue, such as the sudden loss of productive assets, an illness, injury, or disability. External idiosyncratic events can also falsify prices, such as fires, 
thefts, pollution, or pests. Untrue prices can also be the result of more structural issues and complex combinations of drivers, as shown in the case of the Brazilian Amazon.

Further studies could also compare price falsification shocks of higher or lower magnitude to see if patterns change with their intensity, or cases where one group of producers is affected by a price-falsifying intervention $(1, Y$ ?) while another is not $(0, Y ?)$. We studied two $(1,1)$ cases; prices were untrue and unsustainability arose. Further research could also focus on finding and analysing $(1,0)$ cases, where prices are untrue, but sustainability arises nonetheless. If such cases exist, we would have either to reformulate the model to account for these cases, to reduce its scope of action, or to reject it altogether. These cases would be instrumental in refining the theory and finding its limits. It would be reasonable to expect that the causal mechanism does not work under certain conditions. For example, an array of economic, social, or environmental conditions or interventions could counteract it.

It bears repeating that claiming that true prices are a condition of unsustainability is not to say that they are its one and only foundation. Indeed, other micro, meso, and macro drivers can also cause unsustainability. These causes may or may not interact with untrue prices to create system qualities that are inherently unsustainable and 'beyond repair' through true pricing. After all, a society is a complex system where multiple economic, cultural, political, technological and environmental factors interact constantly. Although sustainability demands true pricing, it obviously does not only boil down to it. One could grant that untrue prices played an important role during the coffee crisis and in the Brazilian Amazon, but argue that they are rare cases of high magnitude and that, overall, untrue prices do not play a systemic role in bringing about unsustainable development. Other conditions and causal mechanisms may be necessary for sustainability to occur, giving rise to the problem of over-determination and spurious correlations. Additional robust tests could be performed to further assess this risk of over-determination. Further studies need to clarify to which extent untrue prices are a trivial or essential cause of unsustainability in comparison to other ones. The best cases for future empirical analysis would be ones where all the other conditions (such as cultural, environmental, social, or political conditions) are present and suggest that sustainability should occur, but prices are untrue. If these cases show that unsustainability still arises even when all the other conditions are present, the role that untrue prices play in impeding sustainability would be harder to refute. 
If there is no such thing as a sustainable economy until we reach true prices, we need to make changes to the status quo that some economic agents will find inconvenient. From the points of view of political economy and moral philosophy, the shift from untrue to true prices may bring about strong distributional conflicts. If true pricing is the guiding policy, some agents will have to spend more, relinquish some sources of financial income or make less profits so that other agents can receive true prices. The policy, if adopted, would obviously shake the current power structure, whether one benefits from it or not. Future research could answer questions that the thesis leaves open in this regard. If our current economic system is based on untrue prices, who actively or passively gains and who loses from it? How and why so? Is true pricing possible without the releasing of and relief from powerful, repressed, social conflicts? If truthening prices demands drastic changes in the power structure, how would such a change realistically happen? Which is the better and swiftest path to true pricing: outer changes such as incremental reforms or even an economic revolution at the societal level, or a more fundamental inner transformation in how each person or business cognizes or is aware of the economy?

When we navigate the idea that true prices are imperative to sustainability, we face ourselves and our contradictions because every price we pay or receive echoes in its economic environment. We need to refrain from furthering untrue prices because they make us, other human beings and nature suffer. For this cessation to happen, we need to start by reflecting on whether our economic behaviours or those of others repress our needs or theirs, and change our behaviours accordingly. The concept asks profound questions to every human being about how we relate economically to each other. Yet we should not shrink from the challenge of moving from untrue to true pricing, for we have no reason to reject for ourselves the capacity to think and act afresh.

In a famous Greek myth, Sisyphus is condemned by the gods to repeatedly push a boulder uphill and let it roll down when it reaches the top. In the same way, we will not reach sustainable development in an economic world predicated on untrue prices. Sustainability is the rock we push, and untrue prices make it roll downhill, rendering our efforts useless. A world based on true pricing will look very different from how we relate economically to each other today. We will be able to understand the difference between economic and anti-economic activities and manifest sustainability with more 
success. We will know that the economy cannot prosper at the expense of ourselves, other human beings or nature. By exchanging products and circulating capital in ways that generate true prices, we will help a sustainable society to blossom. True pricing could be a response to Khalil Gibran's plea:

Invoke then the master spirit of the earth, to come into your midst and sanctify the scales and the reckoning that weighs value against value....

And before you leave the market-place, see that no one has gone his way with empty hands.

For the master spirit of the earth shall not sleep peacefully upon the wind till the needs of the least of you are satisfied. (GIBRAN, 1997, p. 22) 


\section{Bibliography}

AGRAFNP. Anualpec. Relatório de Análise do Mercado de Terras. São Paulo, 2015.

AGUIAR GOMES, C.; PERZ, S.G.; VADJUNEC, J.M. Convergence and Contrasts in the Adoption of Cattle Ranching: Comparisons of Smallholder Agriculturalists and Forest Extractivists in the Amazon. Journal of Latin American Geography, January 2012.

ALENCAR, A.; PEREIRA, C.; CASTRO, I.; CARDOSO, A. Desmatamento nos assentamentos da Amazônia: histórico, tendências e oportunidades. Instituto de Pesquisa Ambiental da Amazônia, 2016.

AMARAL, A.; ALMEIDA, O.; MCGRATH, D. Sistema de crédito da pesca artesanal: impacto do FNO na renda do pescador do Baixo Amazonas e inadimplência. III Encontro da ANPPAS - Associação Nacional de Pós-graduação e Pesquisa em Meio Ambiente e Sociedade. May 23-26, 2006.

AMBINAKUDIGE, S. The Global Coffee Crisis and Indian Farmers: the Livelihood Vulnerability of Smallholders. Canadian Journal of Development Studies/Revue Canadienne D'études Du Développement, 28 (3-4), pp. 553-66, 2009.

AMBINAKUDIGE, S.; CHOI, J. Global Coffee Market Influence on Land-Use and LandCover Change in the Western Ghats of India. Land Degradation \& Development, v. 20 (3): pp. 327-335. 2009.

AMINI, M.; BIENSTOCK, C. Corporate sustainability: an integrative definition and framework to evaluate corporate practice and guide academic research. Journal of Cleaner Production, n. 76, pp. 12-19, 2014.

ANTOLÍN-LÓPEZ, R.; DELGADO-CEBALLOS, J.; MONTIEL, I. Deconstructing Corporate Sustainability: a Comparison of Different Stakeholder Metrics. Journal of Cleaner Production, 136, pp. 5-17, 2016.

AQUINAS, T. Summa Theologica (Vol. 1-2). New York, NY: Benziger Brothers. 1947.

ARISTOTLE. The Nichomachean Ethics. Oxford World's Classics. Editor: Lesley Brown. OUP Oxford, pp. 1-336, 2009.

ARROW, K. J. The organization of economic activity: Issues pertinent to the choice of market versus non market allocation, in: Congress of the United States, The Analysis and Evaluation of Public Expenditures: The PPB System, 47-64, 1969. 
ASSUNÇÃO, J.; GANDOUR, C.; ROCHA, R.; ROCHA, R. The effect of rural credit on deforestation: evidence from the Brazilian Amazon. PUC-Rio, núcleo de avaliação de políticas climáticas, pp. 1-40, 2016.

BABIN, N. The Coffee Crisis, Fair Trade, and Agroecological Transformation: Impacts on Land-Use Change in Costa Rica. Agroecology and Sustainable Food Systems. Vol. 39 (1) pp.99-129, 2014.

BACON, C. Confronting the Coffee Crisis: Can Fair Trade, Organic, and Specialty Coffees Reduce Small-Scale Farmer Vulnerability in Northern Nicaragua? World Development. Vol. 33, pp. 497-511, 2005.

BACON, C. M.; MÉNDEZ, E.; GLIESSMAN, S.; GOODMAN, D.; FOX, J. (ed.). Confronting the Coffee Crisis: Fair Trade, Sustainable Livelihoods and Ecosystems in Mexico and Central America. MIT Press Books, The MIT Press, edition 1, volume 1, pp. 1-405, 2008.

BACON, C. M.; SUNDSTROM, W. A.; FLORES GÓMEZ, M. E.; MÉNDEZ, V. E.; SANTOS, R.; GOLDOFTAS, B.; DOUGHERTY, I. Explaining the "Hungry Farmer Paradox": Smallholders and Fair Trade Cooperatives Navigate Seasonality and Change in Nicaragua's Corn and Coffee Markets. Global Environmental Change, 25, pp. 133-149, 2014.

BATHFIELD, B., P.; GASSELIN, P.; VANDAME, R.; LÓPEZ-RIDAYRA, S.; BARRIOS, L. G. Adaptation de la gestion technique des producteurs de café et de miel face aux variations de prix au Guatemala: concepts et méthodes. Colloque " Agir en situation d'incertitude", Montpellier, France, November 2010.

BAUMOL, W. J.; OATES, W. E. The Theory of Environmental Policy. $2^{\text {nd }}$ ed., 1988, Cambridge: Cambridge University Press, 1975.

BEACH, D.; PEDERSEN, R. B. Case Selection Techniques in Process-Tracing and the Implications of Taking the Study of Causal Mechanisms Seriously. APSA Annual Meeting Paper, 2012.

BEACH, D.; PEDERSEN, R. B. Process-Tracing Methods: Foundations and Guidelines. Ann Arbor: University of Michigan Press, 2013.

BEACH, D.; PEDERSEN, R. B. Causal Case Study Methods. University of Michigan Press, 2016.

BECKER, B. K. Amazônia. Parcerias Estratégicas, v. 18, n. 36, pp. 107-128, 2013.

BIKIÉ, H.; NDOYE, O.; SUNDERLIN, W. D. L'impact de la crise économique sur les systèmes agricoles et le changement du couvert forestier dans la zone forestière humide du Cameroun. Center for International Research on Forestry. Occasional Paper $n^{\circ} 27,16$ p., 2000.

BLACKMAN, A.; ÁVALOS-SARTORIO, B.; CHOW, J.; AGUILAR, F. X. Tree Cover Loss in El Salvador's Shade Coffee Areas. Resources for the Future, 77 p., 2006. 
BOUVARD, A.; DEGROOTE, A. ; DEVIENNE, S. Stratégies Paysannes De Lutte Contre La Pauvreté Et Recherche De Sources De Revenus Complémentaires, Vers La Pluriactivité. Field Actions Science Reports (FACTS Reports), Veolia Institute, 2013.

BRADY, M. E.; GORGA, C. From Aristotle, Augustine, Aquinas, and Adam (Smith) to Concordian Monetary Policy - How to Use Public Policy to Guide Accumulation Toward Virtuous Ends. SSRN Electronic Journal, 14 p., 2017.

BROOKS, H. Sustainability and Technology. Science and Sustainability: Selected Papers on IIASA's 25th Anniversary, pp. 29-60, Vienna, IIASA, 1992.

BROWN, D. R.; STEPHENS, E. C.; OUMA, J. O.; MURITHI, F. M.; BARRET, C. B. Livelihood Strategies in the Rural Kenyan Highlands. African Association of Agricultural Economists, vol. 1(1), pp. 1-16, December, 2006.

CALANDINO, D.; WEHRMANN, M.; KOBLITZ, R. Contribuição dos assentamentos rurais no desmatamento da Amazônia: um olhar sobre o Estado do Pará. Desenvolvimento e Meio ambiente, v. 26, 2012.

CARTER, M. R.; LYBBERT, T. J. Consumption Versus Asset Smoothing: Testing the Implications of Poverty Trap Theory in Burkina Faso. Journal of Development Economics, 99 (2), Elsevier B.V, pp. 255-64, 2012.

COASE, R. H. The problem of social cost. Journal of Law Economics, 3, 1-44, 1960. COSTANZA, R. What is ecological economics? Ecological Economics, 1, p. 1-7, 1989.

COSTANZA, R.; SEGURA, O.; MARTÍNEZ-ALIER, J. 1996. Getting down to earth: practical applications of ecological economics. International Society for Ecological Economics series. Washington, D.C.: Island Press, 472 p., 1996.

DALY, H. Beyond Growth. The Economics of Sustainable Development. Boston: Beacon Press, 265 p., 1996.

DAVIRON, B.; PONTE, S. The Coffee Paradox: Global Markets, Commodity Trade and the Elusive Promise of Development. London: Zed Books Ltd, 288 p., 2013.

DUBE, O.; VARGAS, J. F. Commodity Price Shocks and Civil Conflict: Evidence From Colombia. The Review of Economic Studies, 80 (4), pp. 1384-1421, 2013.

EAKIN, H.; TUCKER, C. M.; CASTELLANOS, E. 2005. Market Shocks and Climate Variability: the Coffee Crisis in Mexico, Guatemala, and Honduras. Mountain Research and Development, 25 (4), International Mountain Society and United Nations University, pp. 304-09, 2005.

EAKIN, H.; TUCKER, C.; CASTELLANOS, E. Responding to the Coffee Crisis: a Pilot Study of Farmers' Adaptations in Mexico, Guatemala and Honduras. The Geographical Journal, 172 (2), pp. 156-71, 2006. 
EAKIN, H.; TUCKER, C.; CASTELLANOS, E.; DIAZ-PORRAS, R.; BARRERA, J.; MORALES, $\mathrm{H}$. Adaptation in a multi-stressor environment: perceptions and responses to climatic and economic risks by coffee growers in Mesoamerica. Environment, Development and Sustainability: A Multidisciplinary Approach to the Theory and Practice of Sustainable Development, Springer, vol. 16(1), pp. 123-139, February. 2013.

EELS, R. The Corporation and the Arts: Studies of the modern corporation. New York: The Macmillan Company, 365 p., 1967.

ELKINGTON, J. Cannibals with Forks: the Triple Bottom Line of 21st Century Business. Stony Creek: New Society Publishers, 407 p., 1998.

ENVIRONMENTAL WORKING GROUP. Farm Subsidy Database. Commodity subsidies in the United States from 1995-2019, 2019.

https://farm.ewg.org/progdetail.php?fips $=00000 \&$ progcode=totalfarm\&page=conc\&re gionname=theUnitedStates. Accessed 25 August 2019.

DEL GIGLIO, A. Os desafios do microcrédito no Amazonas. GVExecutivo. Vol. 17. No. 2, March/April 2018.

FEARNSIDE, P. M. Desmatamento na Amazônia. Acta amazônica, v. 36, n. 3, pp. 395-400, 2005.

FERREIRA, M. D. P.; COELHO, A. B. Desmatamento Recente nos Estados da Amazônia Legal. Revista de Economia e Sociologia Rural, v. 53, n. 1, pp. 91-108, 2015.

FAOSTAT. Food and Agriculture Organization of The United Nations Statistics Division, http://www.fao.org/faostat/en/\#home, 2019. Accessed 25 August 2019.

FINANCIAL TIMES. Google parent Alphabet overtakes Apple to become new king of cash. August 31 2019. https://www.ft.com/content/332dd974-b349-11e9-8cb2$\underline{799 a 3 a 8 c f 37 b}$

FORERO ÁLVAREZ, J. Colombian Family Farmers Adaptations to New Conditions in the World Coffee Market. Latin American Perspectives,37 (2), pp. 93-110, 2010.

GARRETT, R.D; GARDNER, T.; FONSECA MORELLO, T.. MARCHAND, S.; BARLOW, J.; EZZINE DE BLAS, D.; FERREIRA, J.; LEES, A.C.; PARRY, L. Explaining the Persistence of Low Income and Environmentally Degrading Land Uses in the Brazilian Amazon. Ecology and Society 22, no. 3 (2017): art. 27-24, 2017.

GELETA, D.; AKMEL, A.; REDDY, R. U. Households Food Insecurity and Livelihood Strategies in the Central High Lands: the Case of Abichu and Gnea Woreda, Oromia. Environment \& We An International Journal of Science \& Technology, 13, pp. 149-65, 2018.

GIBRAN, Kahlil. 1997. The Prophet. New York: Wordsworth Editions, 80 p., 1997. 
GLENNAN, S. The New Mechanical Philosophy. Oxford: Oxford University Press, 256 p., 2017.

GODAR, J.; TIZADO, E.J.; POKORNY, B. Who is responsible for deforestation in the Amazon? A spatially explicit analysis along the Transamazon Highway in Brazil. Forest Ecology and Management 267, pp. 58-73, 2011.

GOERTZ, G. Multimethod Research, Causal Mechanisms, and Case Studies. An Integrated Approach. Oxford: Princeton University Press, collection «Political science », 298 p., 2017.

GOODLAND, R. 'The world in over-shoot': a celebration of Herman Daly's contributions to ecological economics - the science of sustainability, in: Beyond Uneconomic Growth, chapter 2, Cheltenham: Edward Elgar Publishing, pp. 22-47, 2016.

HA, D. T.; SHIVELY, G. Coffee Boom, Coffee Bust and Smallholder Response in Vietnam's Central Highlands. Review of Development Economics, 12 (2), pp. 31226, 2008.

HART, S. L.; MILSTEIN, M. B. Creating sustainable value. The Academy of Management Executive, 17 (2), pp. 56-67, 2003.

HAUSERMANN, H.; EAKIN, H. Producing "Viable" Landscapes and Livelihoods in Central Veracruz, Mexico: Institutional and Producer Responses to the Coffee Commodity Crisis. Journal of Latin American Geography, 7(1), pp. 109-131, 2008.

HIGGINS, J. P. T.; GREEN, S. Cochrane Handbook for Systematic Reviews of Interventions: Cochrane Book Series, Hoboken: John Wiley and Sons, September, pp. 1-673, 2008.

HOUGHTON BUDD, C. The emergence of 'auditorial central banking' : an inquiry into the relation between central banking and the financial markets since the end of Bretton Woods, with particular reference to the Bank of England. Thesis (PhD). City, University of London, 2002.

HOUGHTON BUDD, C. Finance at the Threshold: Rethinking the Real and Financial Economies. Farnham: Gower, 258 p., 2011.

INSTITUTO BRASILEIRO DE GEOGRAFIA E ESTATÍSTICA. Censo Agropecuário 2017, 2019. Available at: https://sidra.ibge.gov.br/pesquisa/censoagropecuario/censo-agropecuario-2017. Accessed in February 2017.

INSTITUTO CENTRO VIDA. Características do desmatamento mato-grossense na Amazônia em 2018. Cuiabá, MT, 2018.

INSTITUTO NACIONAL DE PESQUISAS ESPACIAS. Plataforma de dados geográficos Terrabrasilis, 2020. Available at: http://terrabrasilis.dpi.inpe.br. Accessed in February 2020. 
INTERNATIONAL COFFEE ORGANIZATION. Historical data on the global coffee trade. Annual average prices to growers, 2019. Available at:

http://www.ico.org/historical/1990\%20onwards/Excel/3a\%20-

\%20Prices\%20paid\%20to\%20growers.xlsx. Accessed in January 2019.

JACKS, D. S. From Boom to Bust: A Typology of Real Commodity Prices in the Long Run, CEH Discussion Papers 013, Centre for Economic History, Research School of Economics, Australian National University, 2013. Available at: http://www.sfu.ca/ djacks/data/boombust/index.html. Accessed 15 September 2019.

JACOBS, M. Sustainable development as a contested concept, in Dobson, A.P. (ed.) Fairness and Futurity, Oxford: Oxford University Press, pp. 21-45, 1999.

JAFFEE, D. Brewing Justice: Fair Trade Coffee, Sustainability, and Survival. February, Los Angeles : University of California Press, pp. 1-351, 2007.

KAPLAN, D. M. Explanation and Description in Computational Neuroscience. Synthese, 183 (3), pp. 339-73, 2011.

KEYNES, J. M. A tract on monetary reform. London: Macmillan and co., 209 p., 1923.

KEYS, M. M. Aquinas, Aristotle, and the Promise of the Common Good. Cambridge: Cambridge University Press, pp. 1-271, 2006.

LÉLÉ, S. M. Sustainable development: a critical review. World Development, v. 19, n. 6, pp. 607-621, 1991.

LE TOURNEAU, F. M.; BURSZTYN, M. Assentamentos rurais na Amazônia: contradições entre a política agrária e a política ambiental. Ambiente \& Sociedade, v. 13, n. 1, 2010.

LÉVY, A.; BOUHENI, F. B.; AMMI, C. Financial Management. USGAAP and IFRS standards. Volume 6. London: John Wiley and Sons, 408 p., 2018.

LEWIN, B.; GIOVANNUCCI, D.; VARANGIS, P. Coffee Markets: New Paradigms in Global Supply and Demand. World Bank Agriculture and Rural Development, Discussion Paper No. 3, 150 p., 2004.

LOWDER, S. K.; SKOET, J.; RANEY, T. The Number, Size, and Distribution of Farms, Smallholder Farms, and Family Farms Worldwide. World Development Vol. 87, pp. 16-29, 2016.

LOZANO, R.; CARPENTER, A.; HULSINGH, D. A review of 'theories of the firm' and their contributions to Corporate Sustainability. Journal of Cleaner production. Vol. 106, pp. 430-442, 2015.

MALUCCIO, J. A. Coping with the "coffee crisis" in Central America: The Role of the Nicaraguan Red de Protección Social. FCND discussion papers, 188, International Food Policy Research Institute (IFPRI), 44 p., 2005. 
MARTÍNEZ-ALIER, J. The Environmentalism of the Poor. Cheltenham: Edward Elgar Publishing, 328 p., 2003.

MARX, K. Value, Price and Profit. New York: International Co., Inc. 1969. [1898].

MARX, K. Capital, Volume I. Fowkes, Ben (trans.). London: Penguin Classics, 1152 p., 1990. [1867].

MAZOYER, M.; ROUDART, L. A history of world agriculture: from the Neolithic age to the current crisis. New York: Monthly Review Press, 496 p., 2006.

McAFEE, K. The Contradictory Logic of Global Ecosystem Services Markets. Development and Change, 43 (1), pp. 105-31, 2012.

MHANDO, D. G. Farmers' Coping Strategies with the Changes of Coffee Marketing after Economic Liberalization: The Case of Mbinga District, Tanzania. Ph.D. Thesis, Graduate School of Anan and African Area Studies, Kyoto: Kyoto University, 2005.

MHANDO, D. G.; HALLER, T.; MBEYALE, G.; LUDI, E. Adaptation to changes in the coffee value chain and the price of coffee among coffee producers in two villages in Kilimanjaro, Tanzania. African Study Monographs, 34 (1), pp. 27-56, 2013.

MHANDO, D G.; ITANI, J. Farmers' Compensating Strategies to a Changed Coffee Market After Economic Liberalization: The Case of Mninga District in Tanzania. The Center for African Area Studies, African study monographs. Supplementary issue (2007), 36, pp. 39-58, 2007.

MINSKY, H. P. Stabilizing an Unstable Economy. McGraw-Hill Education, 432 p., 2008.

MURADIAN, R.; ARSEL, M. ; PELLEGRINI, L. ; ADAMAN, F. ; AGUILAR, B. ; AGARWAL, E. ; CORBERA, E. et al. 2013. Payments for Ecosystem Services and the Fatal Attraction of Win-Win Solutions. Conservation Letters, 6 (4): pp. 274-79, 2013.

MURPHY, S.; HANSEN-KUHN, K. The true cost of US agricultural dumping, Renewable Agriculture and Food Systems. Cambridge: Cambridge University press, 15 p., 2019.

NEVINS, J. Dying for a Cup of Coffee? Migrant Deaths in the US-Mexico Border Region in a Neoliberal Age. Geopolitics 12 (2): pp. 228-47, 2007.

NIKOLOSKI, Z.; CHRISTIAENSEN, L.; HILL, R. 2018. Household Shocks and Coping Mechanism: Evidence from Sub-Saharan Africa. Cambridge, MA: National Bureau of Economic Research, pp. 123-134, 2018.

ORGANISATION FOR ECONOMIC COOPERATION AND DEVELOPMENT (OECD). Glossary of Industrial Organisation Economics and Competition Law, compiled 
by R. S. Khemani and D. M. Shapiro, commissioned by the Directorate for Financial, Fiscal and Enterprise Affairs, 90 p., 2002.

OSORIO, N. Lessons from the World Coffee Crisis: a Serious Problem for Sustainable Development. London: International Coffee Organization, 6p., 2004.

PADOCH, C.E.; BRONDIZIO, E.; COSTA, S.; PINEDO-VASQUEZ, M.; SEAR, R.R.; SIQUEIRA, A. Urban Forest and Rural Cities: Multi-sited Households, Consumption Patterns, and Forest Resources in Amazonia. Ecology and Society 13(2):2, 2008.

PEDINI, S.; SANTUCCI, F.; SILVESTRE, A. L. Fair Trade Minimum Price: A Comparative Analysis for the Arabica Coffee Market. British Journal of Economics, Management \& Trade. 17, 2017.

PISSOURIOS, I. A. An Interdisciplinary Study on Indicators: a Comparative Review of Quality-of-Life, Macroeconomic, Environmental, Welfare and Sustainability Indicators. Ecological Indicators, 34 (November 2013), pp. 420-27, 2013.

PONETTE-GONZÁleZ, A. G. 2001: A Household Analysis of Huastec Maya Agriculture and Land Use at the Height of the Coffee Crisis. Human Ecology, 35 (3), pp. 289-301, 2007.

PREMAND, P.; VAKIS, R. Do shocks affect poverty persistence? Evidence using welfare trajectories from Nicaragua. Well-Being and Social Policy, 6.1, pp. 95-129, 2010.

RANGANATHAN, J. Sustainability Rulers: Measuring Corporate Environmental and Social Performance. Sustainable Enterprise Perspectives, World Resource Institute: Washington, DC, 1998.

RENARD, M. C. The Mexican coffee crisis. Latin American Perspectives, 37 (2), pp. 21-33, 2010.

RETTBERG, A. Global Markets, Local Conflict. Latin American Perspectives, 37 (2), pp. 111-32, 2010.

REYDON, B.P., 2011. O desmatamento da floresta amazônica: causas e soluções. Política Ambiental, vol. 8, 143-155, 2011

REYDON, B.P.; FERNANDES, V.T. Land tenure in Brazil: The question of regulation and governance. Land Use Policy. 42. 509-516, 2015.

REYDON, B; FENANDES, V.B. Financialization, land prices and land grab: a study based on the Brazilian reality. Economia e Sociedade, Campinas, v. 26, Número Especial, pp. 1149-1179, 2017.

RICE, R. 2003. Coffee Production in a Time of Crisis: Social and Environmental Connections. SAIS Review, 23 (1), pp. 221-45, 2003. 
MAYER-SCHÖNBERGER, V; RAMGE, T. Reinventing Capitalism in the Age of Big Data. (English Edition) eBook Kindle. 2018.

SABLAYROLLES, P. Politiques agraires et stabilisation de l'agriculture sur les fronts pionniers. Le cas de la région Transamazonienne (Altamira-PA, Brésil). INA-PG (AgroParisTech), 2004.

SCHEIDEL, W. The Great Leveler: Violence and the History of Inequality from the Stone Age to the Twenty-First Century. Princeton/Oxford: Princeton University Press, 503 pp., 2017.

SCREPANTI, E.; ZAMAGNI, S. An Outline of the History of Economic Thought. Oxford: Oxford University Press, 2005.

SEN, A. The idea of justice. London: Penguin. 2010.

SMITH, A. An Inquiry into the Nature and Causes of the Wealth of Nations. 1 (1 ed.). London: W. Strahan, 517 p., 1776.

SOARES-FILHO, B. S.; NEPSTAD, D. C.; CURRAN, L.; CERQUEIRA, G. C.; GARCIA, R. A.; RAMOS, C. A.; VOLL, L.; MCDONALD, A.; LEFEBVRE, P.; SCHLESINGER, P.; MCGRATH, D. Cenários de desmatamento para a Amazônia. Estudos Avançados, v. 19, n. 54, 2005.

SKIDELSKY, R. Keynes. The Return of the Master. London: Penguin Books, 256 p., 2010.

SPASH, C. L. The Brave New World of Carbon Trading. New Political Economy, 15 (2): pp. 169-95, 2010.

STEINER, R. The Inner Nature of Man and Life Between Death and Rebirth Lecture 6 - GA 153. Vienna, April 14, 1914.

https://wn.rsarchive.org/Lectures/GA153/English/APC1928/19140414p01.html.

Accessed December 2, 2019.

STEINER, R. The Central Question of Economic life. Rudolf Steiner Archive, 1921. https://wn.rsarchive.org/Lectures/GA/GA0079/19211130p01.html. Accessed 16 June 2019.

STEINER, R. The Renewal of the Social Organism. Rudolf Steiner Archive, 1985. https://wn.rsarchive.org/Books/GA024/English/AP1985/GA024 c10.html.

Accessed 16 June 2019.

STEINER, Rudolf. Economics. The world as one economy. Canterbury: New Economics Publications. [Translation of: Nationalökonomischer Kurs (GA 340: Fourteen lectures, July 24 to August 6,1922 ) and Nationalökonomisches Seminar (GA 341: Six seminars, July 31 to August 5, 1922), Dornach: Rudolf Steiner Verlag.] 249 p. 1993 [1922]. 
STEINER, R. The Christian Mystery. Steiner Books. GA 97. Cologne, 30 November, 1906, 1998.

STEINER, Rudolf. Towards Social Renewal: rethinking the basis of society. London: Rudolf Steiner Press. [Translation of Die Kernpunkte der sozialen Frage in den Lebensnotwendigkeiten der Gegenwart und Zukunft, (GA 23) Dornach: Rudolf Steiner Verlag.] 134 p. 1999 [1919].

STEWARD, W. C.; KUSKA, S. Sustainometrics: Measuring Sustainability Design, Planning, and Public Administration for Sustainable Living. Greenway Communications, Norcross, GA, 144 p., 2011.

SOUZA, E. S.; RAMOS, D. P.; HEINECK, D. T.; GOMES, R. M. Impacto das estruturas urbanas em relação à biodiversidade Amazônica. Revista de Arquitetura IMED, v. 3, n. 2, 2015.

SUDGEN, R. Credible worlds, capacities and mechanisms. Erkenntnis, 70, pp. 3-27, 2009.

TALBOT, J. M. Coffee Crisis: The Case for a Regulated Market. Georgetown Journal of International Affairs, 3, no. 1, pp. 45-52, 2002.

TITUS, M. J.; BURGERS, P. Rural Livelihoods, Resources, and Coping with Crisis in Indonesia: A Comparative Study. Amsterdam University Press. 2008.

TOWNSEND, C.R.; DE LUCENA COSTA, N.; GOMES DE ARAÚJO PEREIRA, R. Aspectos econômicos da recuperação de pastagens na Amazônia legal. Amazônia: Ci. \& Desenv., Belém, v. 5, n. 10, jan./jun. 2010.

TUCKER, C. Honduras's Smallholder Coffee Farmers, the Coffee Crisis, and Neoliberal Policy. In Central America in the New Millennium: Living Transition and Reimagining Democracy, v. 102, pp. 163, 2013.

TUCKER, C. M.; EAKIN, H.; CASTELLANOS, E. J. Perceptions of Risk and Adaptation: Coffee Producers, Market Shocks, and Extreme Weather in Central America and Mexico. Global Environmental Change, 20 (1), pp. 23-32, 2010.

UDOMKIT, N.; WINNET, A. Fair Trade in Organic Rice: A Case Study from Thailand. Small Enterprise Development, 13, 3, pp. 45-53, 2002.

UNITED NATIONS. Our Common Future, Report of the World Commission on Environment and Development. World Commission on Environment and Development, 1987.

UNITED NATIONS. Report of the World Summit on Sustainable Development, Johannesburg, South Africa. 26 August-4 September 2002, A/CONF.199/20, New York: United Nations, 2002.

UNITED NATIONS. World Population Prospects. Washington, DC, 2015. 
VAKIS, R. N.; KRUGER, D.; MASON, A. D. Shocks and Coffee: Lessons From Nicaragua. Social Protection, Labor Markets, Pensions, Social Assistance, World Bank, 2004.

VALIENTE-RIEDL, E. Is fairtrade fair? Basingstoke: Palgrave Macmillan, 2013.

VANWEY L.K.; HULL, J.R.; GUEDES, G.R. Capitals and context: bridging health and lievelihoods in smallholder frontiers. Crews K, King B, editors. Ecologies and Politics of Health. Routledge Press, 2011.

VARANGIS, P.; SIEGEL, D; GIOVANNUCCI, F.; LEWIN, B. Dealing with the Coffee Crisis in Central America: Impacts and Strategies. The World Bank, 2003.

VERÍSSIMO, A.; PEREIRA, D. Produção na Amazônia Florestal: características, desafios e oportunidades. Parcerias Estratégicas, v. 19, n. 38, pp. 13-44, 2014.

WAGNER, G. Implementing and managing economic, social and environmental efforts of business sustainability", Management of Environmental Quality: An International Journal, Vol. 26 Issue 2 pp. 195 - 213, 2015.

WATSON, K.; ACHINELLI, M. L. Context and Contingency: The Coffee Crisis for Conventional Small-Scale Coffee Farmers in Brazil. Geographical Journal, 174 (3), pp. 223-34, 2008.

WILSON, B. R. Indebted to Fair Trade? Coffee and Crisis in Nicaragua. Geoforum, 41 (1), pp. 84-92, 2010.

WILSON, B. R. Breaking the Chains: Coffee, Crisis, and Farmworker Struggle in Nicaragua. Environment and Planning A: Economy and Space, 45 (11), pp. 25922609, 2013.

WINKELS, A. Rural in-Migration and Global Trade: Managing the Risks of Coffee Farming in the Central Highlands of Vietnam. Mountain Research and Development, 28 (1), pp. 32-40, 2008. 


\section{Glossary of terms used}

Falsification of prices: any human intervention that brings prices to a position that is below the true price threshold falsifies prices.

Sustainable development: "economic and social development that meets the needs of the current generation without undermining the ability of future generations to meet their own needs." (UNITED NATIONS, 1987)

True price: true prices are forthcoming when producers receive, as counter-value for the product they have made, sufficient to enable them to satisfy all their needs, including those of their dependants, until they will again have completed a like product.

Truthening of prices: any human intervention that brings prices to a position that is closer or above the true price threshold does truthen prices.

Unsustainable development: economic and social development that does not meets the needs of the current or future generations.

Untrue price: An untrue price is a price that is below the true price threshold, meaning the producer's needs are not fully covered. 


\section{Index of subjects}

Aquinas, 28

Thomas Aquinas, 26, 151, 154

Aristotle, 26, 27, 151, 154

asset, 35, 44, 45, 57, 82, 84, 87, 112,

$116,119,121,136,140$

assets, 34, 35, 42, 43, 44, 45, 46, 48, $50,51,52,55,56,57,58,59,62$, $71,78,82,83,84,86,87,90,91$, $100,103,112,113,115,116,117$, $119,120,124,126,127,130,131$, $132,134,136,139,143,144,145$, 167

productive assets; fixed assets, 41 , $44,46,52,57,58,82$

capital, 24, 25, 28, 34, 35, 44, 45, 46, $47,52,54,55,56,57,58,59,79$, $91,103,116,117,126,130,131$, $133,136,137,139,140,143,147$. 148

cash flow, 47, 48, 68, 131, 140

causal mechanism, $17,41,42,52,64$, $75,94,103,122,145,146$

causal model, 18, 95, 100, 112, 122, 123, 128

coffee crisis, $3,8,18,64,68,69,70$, $71,73,75,76,79,81,84,86,87$, $88,90,91,92,101,112,137,140$, $141,145,146,154,156$

consumers, $8,15,23,30,33,45,48$, $52,57,132,133,134,141$

cost avoidance, 55, 62, 79, 100

debt, 35, 42, 44, 45, 46, 47, 48, 50, 52, $59,60,62,77,79,84,85,86,90$, $91,121,124,126,127,130,131$, $134,136,139,141,142,143$

deforestation fronts, $8,18,68,93,94$, $95,96,101,107,122,145$

expenses, 42, 44, 45, 46, 48, 50, 51, $52,55,56,57,59,71,79,81,87$, $101,109,110,112,120,126,127$, $130,132,133,141,142,143,147$

externalities, 24, 25, 36, 48, 55, 67, 90, 127 falsification

price falsification, falsification of prices, falsifying, 39

income, 15, 25, 27, 28, 41, 44, 45, 54, 77

indicator, 16, 34, 61, 127, 143

indicators, 100, 101, 114, 128

investment

investments, invest, investing, 24, 46

investments

investment, 46, 54, 59, 78, 82, 83, $86,91,103,109,120,128,131$, $134,135,137,138,139$

investors, 8, 35, 46, 48, 52, 91, 124, $133,135,136,137,139,140,141$ labour, 6, 23, 27, 28, 35, 45, 52, 54, $55,56,60,77,79,80,82,83,86$, $87,90,91,109,141$

land, 6, 34, 35, 41, 46, 52, 54, 55, 56, $58,78,79,80,83,84,85,86,87$, $91,94,95,96,99,100,104,106$, $109,114,116,117,118,119,120$, $121,122,136,138,156,167$ liabilities, 47

liability, 27, 43, 44, 45, 46, 48, 50, $51,52,57,59,71,84,87,100$, $114,120,121,130,131$

liquidity

liquid, 47, 82, 130, 133, 140, 141

means of production, $35,45,50,52$,

$55,57,58,137,138$

needs, $6,15,16,20,23,26,28,29$, $30,31,32,34,36,37,41,50,55$, $56,59,62,78,81,86,87,90,91$, $102,103,126,129,130,131,132$, $133,134,136,139,147,148,160$ policymakers, $8,20,124,129,141$, 142,143

price falsification, $40,65,75,86,87$, $91,132,144,145,146$

pricing, $8,18,26,36,37,61,67,93$, $94,122,124,127,131,132,133$, $137,139,141,142,143,144,147$ 
producers, $5,8,15,16,26,27,28,29$, $30,31,33,35,37,44,45,48,50$, $52,54,55,56,57,58,59,60,65$, $68,69,70,71,75,76,77,78,79$, $80,81,82,83,84,85,86,90,91$, $124,129,130,131,132,133,134$, $136,137,138,139,140,141,142$, $144,145,160$

Steiner, 5, 7, 15, 27, 29, 30, 31, 32, 33, $34,35,36,67,139,142,157$

Steiner, Rudolf, 3, 8, 15, 18, 26, 27 , $28,29,31,32,34,35,158$

strategies

financial strategies, 51, 60, 62, 76

sustainability

sustainable development, 8, 14, 15 , $16,17,18,19,20,21,22,23,24$, $25,26,36,37,40,41,49,52,53$, $54,55,60,61,62,66,67,68,76$, $90,95,114,121,124,125,126$, $127,128,129,135,137,141,142$, $143,146,147,149,153,159$

systematic review, 75

test

testing, 16, 17, 75

tests, $52,75,85,87,88,100,122$, 145 true price, $8,15,18,26,27,28,29,34$, $35,39,160$

true prices, $16,17,18,19,29,30$, $31,32,36,39,58,67,95,102$, $103,113,126,129,132,133,134$. 143

true prices, $8,16,18,19,31,33,36$, $58,67,90,129,131,132,133,134$, $136,138,139,140,141,143,146$

Truthening of prices

price truthening, truthen, 160

unsustainability, 16, 41

unsustainable development, 8,15 , $16,18,28,37,38,40,50,52,66$, $67,86,88,90,93,94,95,125$, $127,128,129,145,146$

untrue price, $39,57,160$

untrue prices, 5, 16, 18, 27, 36, 37, 39, $50,52,54,55,57,59,60,67,68$, $77,79,85,88,90,125,126,131$, $133,135,139,140,141,142,144$. 146

untrue price, $8,16,18,38,50,51$, $52,58,60,66,71,93,94,95,102$, $115,121,122,125,126,135,138$, $144,145,146,147$

Working Capital, 57, 84 


\section{Appendixes}

Appendix 1: Top 100 municipalities in terms of deforestation between 2016 and 2017, based on INPE (2019)

\begin{tabular}{|c|c|c|c|c|}
\hline Municipality & State & $\begin{array}{r}\begin{array}{r}\text { Deforestation } \\
\text { rank }\end{array} \\
\end{array}$ & $\begin{array}{r}\text { Deforestation } \\
2006-7\left(\mathrm{~km}^{2}\right) \\
\end{array}$ & $\begin{array}{r}\text { Running sum of } \\
\text { deforestation }\left(\mathrm{km}^{2}\right)\end{array}$ \\
\hline Porto Velho & RO & 1 & 354 & 354 \\
\hline Lábrea & AM & 2 & 284 & 637 \\
\hline São Félix do Xingu & PA & 3 & 240 & 877 \\
\hline Altamira & PA & 4 & 225 & 1,102 \\
\hline Nova Nazaré & MT & 5 & 212 & 1,314 \\
\hline Nova Mamoré & RO & 6 & 180 & 1,494 \\
\hline Pacajá & PA & 7 & 180 & 1,674 \\
\hline Colniza & MT & 8 & 176 & 1,850 \\
\hline Apuí & AM & 9 & 170 & 2,020 \\
\hline Portel & $\mathrm{PA}$ & 10 & 168 & 2,188 \\
\hline Novo Aripuanã & AM & 11 & 127 & 2,315 \\
\hline Novo Repartimento & PA & 12 & 122 & 2,437 \\
\hline Medicilândia & PA & 13 & 116 & 2,553 \\
\hline Candeias do Jamari & RO & 14 & 107 & 2,660 \\
\hline Manicoré & AM & 15 & 100 & 2,760 \\
\hline Machadinho D'Oeste & $\mathrm{RO}$ & 16 & 99 & 2,860 \\
\hline Anapu & PA & 17 & 99 & 2,959 \\
\hline Senador José Porfírio & PA & 18 & 99 & 3,057 \\
\hline Aripuanã & $\mathrm{MT}$ & 19 & 93 & 3,150 \\
\hline Boca do Acre & AM & 20 & 91 & 3,241 \\
\hline Uruará & PA & 21 & 89 & 3,330 \\
\hline Placas & PA & 22 & 88 & 3,419 \\
\hline Cujubim & RO & 23 & 87 & 3,506 \\
\hline Trairão & PA & 24 & 82 & 3,587 \\
\hline Itaituba & PA & 25 & 80 & 3,667 \\
\hline Buritis & RO & 26 & 68 & 3,735 \\
\hline Monte Alegre & PA & 27 & 64 & 3,800 \\
\hline Novo Progresso & PA & 28 & 61 & 3,861 \\
\hline Alto Paraíso & RO & 29 & 54 & 3,914 \\
\hline Nova Bandeirantes & MT & 30 & 49 & 3,963 \\
\hline Nova Maringá & MT & 31 & 49 & 4,012 \\
\hline Gaúcha do Norte & MT & 32 & 48 & 4,061 \\
\hline Marcelândia & $\mathrm{MT}$ & 33 & 48 & 4,109 \\
\hline União do Sul & $\mathrm{MT}$ & 34 & 46 & 4,155 \\
\hline Moju & PA & 35 & 46 & 4,201 \\
\hline
\end{tabular}




\begin{tabular}{|c|c|c|c|c|}
\hline Nova Ubiratã & MT & 36 & 44 & 4,244 \\
\hline Cotriguaçu & MT & 36 & 44 & 4,288 \\
\hline Rurópolis & $\mathrm{PA}$ & 38 & 43 & 4,331 \\
\hline Marabá & $\mathrm{PA}$ & 39 & 42 & 4,373 \\
\hline Cumaru do Norte & $\mathrm{PA}$ & 40 & 42 & 4,415 \\
\hline Paranaíta & MT & 41 & 41 & 4,456 \\
\hline Feliz Natal & MT & 42 & 41 & 4,497 \\
\hline Santarém & $\mathrm{PA}$ & 43 & 41 & 4,537 \\
\hline Peixoto de Azevedo & MT & 44 & 40 & 4,577 \\
\hline Prainha & $\mathrm{PA}$ & 45 & 38 & 4,615 \\
\hline Sena Madureira & $A C$ & 46 & 38 & 4,653 \\
\hline Jacareacanga & PA & 47 & 35 & 4,688 \\
\hline Humaitá & AM & 48 & 35 & 4,724 \\
\hline Rorainópolis & $\mathrm{RR}$ & 49 & 35 & 4,759 \\
\hline Ouro Preto do Oeste & RO & 50 & 34 & 4,793 \\
\hline Juína & MT & 51 & 33 & 4,826 \\
\hline Costa Marques & RO & 52 & 31 & 4,857 \\
\hline Cláudia & MT & 53 & 31 & 4,888 \\
\hline Aveiro & PA & 54 & 31 & 4,919 \\
\hline Itupiranga & PA & 55 & 30 & 4,949 \\
\hline Canutama & AM & 56 & 28 & 4,977 \\
\hline Brasil Novo & $\mathrm{PA}$ & 57 & 28 & 5,005 \\
\hline Rio Branco & $\mathrm{AC}$ & 58 & 28 & 5,033 \\
\hline Apiacás & MT & 59 & 28 & 5,060 \\
\hline Tabaporã & MT & 59 & 28 & 5,088 \\
\hline Campo Novo de Rondônia & RO & 61 & 27 & 5,115 \\
\hline Santa Carmem & MT & 62 & 27 & 5,143 \\
\hline Brasiléia & $A C$ & 63 & 27 & 5,170 \\
\hline Confresa & MT & 64 & 27 & 5,196 \\
\hline Feijó & $A C$ & 65 & 26 & 5,222 \\
\hline Comodoro & MT & 66 & 26 & 5,248 \\
\hline Brasnorte & MT & 67 & 25 & 5,273 \\
\hline Alenquer & PA & 68 & 24 & 5,297 \\
\hline Goianésia do Pará & $\mathrm{PA}$ & 69 & 24 & 5,321 \\
\hline Arame & MA & 70 & 24 & 5,345 \\
\hline Barra do Corda & MA & 71 & 23 & 5,368 \\
\hline Caracaraí & $\mathrm{RR}$ & 72 & 23 & 5,391 \\
\hline São José do Rio Claro & MT & 73 & 23 & 5,414 \\
\hline Pimenta Bueno & RO & 74 & 23 & 5,437 \\
\hline Almeirim & PA & 75 & 21 & 5,458 \\
\hline Santa Terezinha & MT & 76 & 21 & 5,479 \\
\hline Ariquemes & RO & 76 & 21 & 5,500 \\
\hline Nova Monte Verde & MT & 78 & 21 & 5,521 \\
\hline Cachoeira do Piriá & PA & 78 & 21 & 5,542 \\
\hline
\end{tabular}




$\begin{array}{lllll}\text { Maués } & \text { AM } & 80 & 21 & 5,563 \\ \text { Autazes } & \text { AM } & 81 & 20 & 5,583 \\ \text { Acará } & \text { PA } & 82 & 20 & 5,603 \\ \text { Paragominas } & \text { PA } & 83 & 20 & 5,623 \\ \text { Alta Floresta D'Oeste } & \text { RO } & 83 & 20 & 5,643 \\ \text { Tapurah } & \text { MT } & 83 & 20 & 5,663 \\ \text { Novo Mundo } & \text { MT } & 86 & 20 & 5,682 \\ \text { Porto dos Gaúchos } & \text { MT } & 87 & 20 & 5,702 \\ \text { Rondon do Pará } & \text { PA } & 88 & 19 & 5,721 \\ \text { Xapuri } & \text { AC } & 89 & 19 & 5,740 \\ \text { Monte Negro } & \text { RO } & 90 & 19 & 5,759 \\ \text { Óbidos } & \text { PA } & 91 & 18 & 5,777 \\ \text { Itaúba } & \text { MT } & 91 & 18 & 5,795 \\ \text { Juruena } & \text { MT } & 91 & 18 & 5,814 \\ \text { Juara } & \text { MT } & 94 & 18 & 5,832 \\ \text { Santa Maria das Barreiras } & \text { PA } & 95 & 18 & 5,850 \\ \text { Querência } & \text { MT } & 96 & 17 & 5,867 \\ \text { Vila Bela da Santíssima } & & & & \\ \text { Trindade } & \text { MT } & 97 & 17 & 5,884 \\ \text { Santa Cruz do Xingu } & \text { MT } & \text { RR } & 17 & 5,901 \\ \text { Caroebe } & \text { MA } & 100 & 16 & 5,918 \\ \text { Bom Jesus das Selvas } & & 16 & 5,934\end{array}$

Source: elaborated by the author with data from INPE (2017). 
Appendix 2: Relative and absolute contribution to deforestation in function of the size of the farm, from GODAR et al. (2011)

Note: Graphs (b) and (c) show that relative deforestation (percentage of deforested property, in percentages) decreases with the size of farms, while absolute deforestation (total deforestation of the property, in hectares) increases with their size.
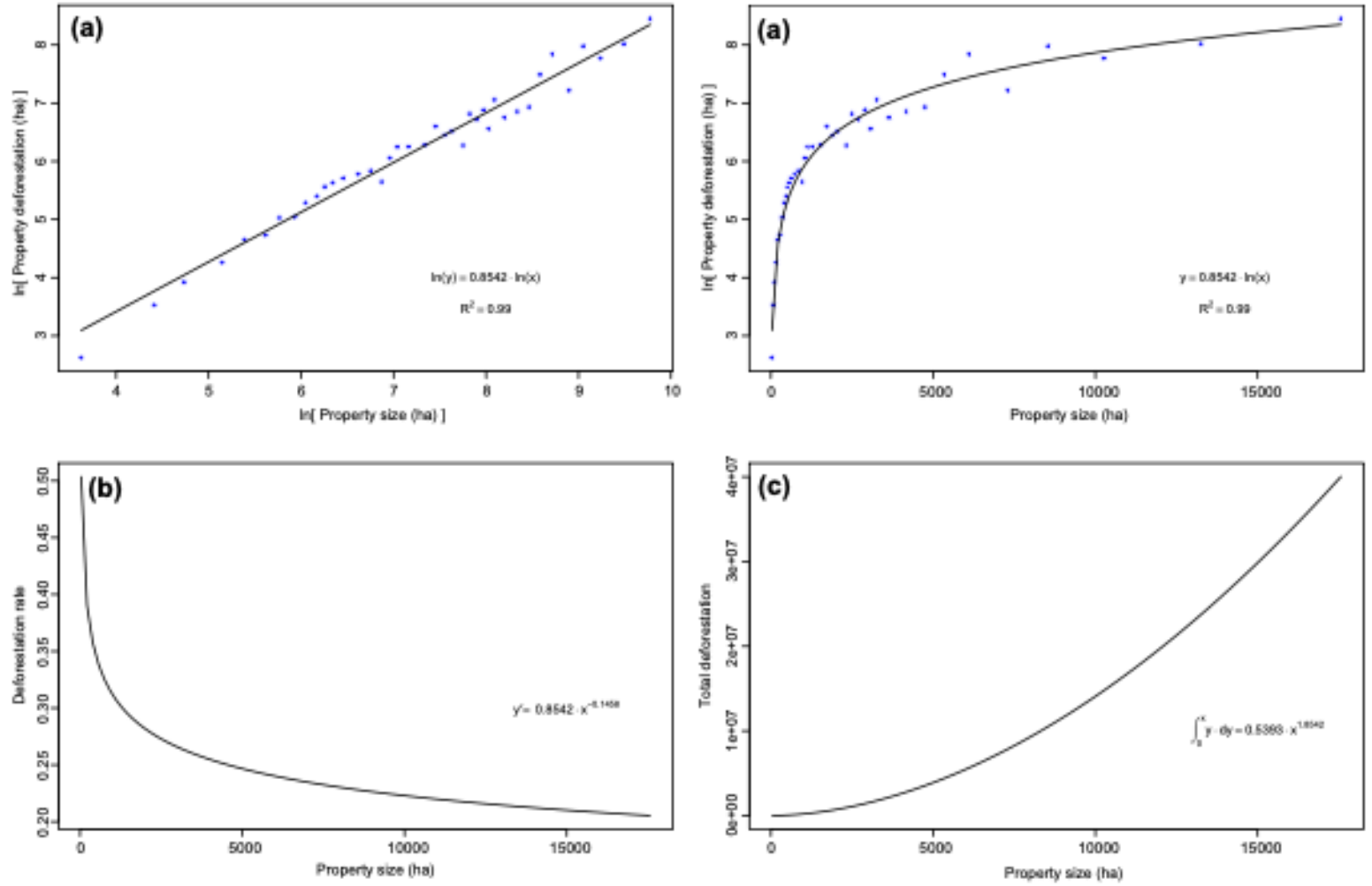

Fig. 5. Regression curve between property area and total property deforestation. Only the properties with deforestation higher than $5 \%$ of the property area were considered, thereby eliminating properties without obvious management. The properties were aggregated into 39 size classes. (a) The regression curves represent the relationship between property size and property deforestation based on data of 8281 properties classified in 39 size groups. (b) The curve represents the derivate of the obtained regression curve (instant percentage rate of deforestation for a given property size). (c) The curve represents the integral of the obtained regression curve. The area below the integral curve represents the total accumulated deforestation in the sample properties vs. property size.

Source: reproduced from GODAR et al. (2011, p. 67) 
Appendix 3: Productivity and income of highly and poorly capitalized grain farmers, from Mazoyer and Roudart (2006)

\begin{tabular}{lccc} 
& Latifundium & $\begin{array}{c}\text { Smallholder with } \\
\text { animal traction }\end{array}$ & $\begin{array}{c}\text { Manual smaller } \\
\text { holder }\end{array}$ \\
$\begin{array}{l}\text { Productive assets } \\
\text { Motorisation, } \\
\text { mechanisation, 200 ha }\end{array}$ & Animal power, 5 ha & $\begin{array}{c}\text { Manual tools, 1 } \\
\text { ha }\end{array}$ \\
$\begin{array}{l}\text { Market price (USD/ton) } \\
\text { Land productivity } \\
\text { (tons/ha) }\end{array}$ & 200 & 200 & 200 \\
$\begin{array}{l}\text { Labour productivity } \\
\text { (ton/worker) }\end{array}$ & 10 & 10 & 10 \\
$\begin{array}{l}\text { Farmer's gross } \\
\text { revenues (USD/year) }\end{array}$ & 2,000 & 50 & 10 \\
Productivity ratio & 400,000 & 1,000 & 200 \\
\hline
\end{tabular}

Source: elaborated by the author based on data from Mazoyer and Roudart (2006). 